\title{
Synthesis and antiviral activity of novel spirocyclic nucleosides
}

Article

Accepted Version

Cobb, A. J. A., Dell'Isola, A., Abdulsattar, B. O., McLachlan, M. M. W., Neuman, B. W., Müller, C., Shankland, K., Al-Mulla, H. M. N., Binks, A. W. D. and Elvidge, W. (2018) Synthesis and antiviral activity of novel spirocyclic nucleosides. New Journal of Chemistry, 42 (22). pp. 18363-18380. ISSN 1144-0546 doi: https://doi.org/10.1039/c8nj02777c Available at https://centaur.reading.ac.uk/80622/

It is advisable to refer to the publisher's version if you intend to cite from the work. See Guidance on citing.

To link to this article DOI: http://dx.doi.org/10.1039/c8nj02777c

Publisher: Royal Society of Chemistry

All outputs in CentAUR are protected by Intellectual Property Rights law, including copyright law. Copyright and IPR is retained by the creators or other copyright holders. Terms and conditions for use of this material are defined in the End User Agreement.

www.reading.ac.uk/centaur

\section{CentAUR}


Central Archive at the University of Reading

Reading's research outputs online 


\section{Synthesis and Antiviral Activity of Novel Spirocyclic Nucleosides}

Received 00th January 20xx Accepted 00th January 20xx DOI: $10.1039 / \times 0 \times x 00000 x$ www.rsc.org/

\author{
Alexander J A. Cobb, ${ }^{\mathrm{a}, \mathrm{b} *}$ Antonio Dell'Isola, ${ }^{\mathrm{b}}$ Ban O. Abdulsattar, ${ }^{\mathrm{c}, \mathrm{d}}$ Matthew M. W. McLachlan, ${ }^{\mathrm{e}}$ \\ Benjamin W. Neuman, ${ }^{c, f}$ Christin Müller, ${ }^{\text {g }}$ Kenneth Shankland, ${ }^{\text {b }}$ Hawaa M. N. Al-Mulla, ${ }^{c}$ Alexander \\ W. D. Binks, ${ }^{c}$ Warren Elvidge. ${ }^{c}$
}

The synthesis of a number of spirocyclic ribonucleosides containing either a triazolic or azetidinic system is described, along with two analogous phosphonate derivatives of the former. These systems were constructed from the same $\beta$-Dpsicofuranose starting material. The triazole spirocyclic nucleosides were constructed using the 1-azido-1-hydroxymethyl derived sugars, where the primary alcohol was alkylated with a range of propargyl bromides, whereas the azetidine systems orginated from the corresponding 1-cyano-1-hydroxymethyl sugars. Owing to their close simlarity with ribavirin, the library of compounds were investigated for their antiviral properties using MHV (Mouse Hepatitis Virus) as a model.

\section{Introduction}

Ribavirin 1 (also known as rebatol $^{\oplus}$ and virazole ${ }^{\oplus}$ ), a 1,2,4triazole nucleoside, discovered by Witkowski and co-workers in $1972,{ }^{1}$ exhibits a broad spectrum of antiviral activity against both DNA and RNA viruses and has been used for the treatment of a variety of viral infections, such as severe respiratory syncytial virus (RSV) infection, lassa fever, influenza A and B, measles and mumps. ${ }^{2}$ Today ribavirin is the standard care for the treatment of chronic hepatitis $\mathrm{C}$ in combination with PEGylated interferon- $\alpha .^{3}$

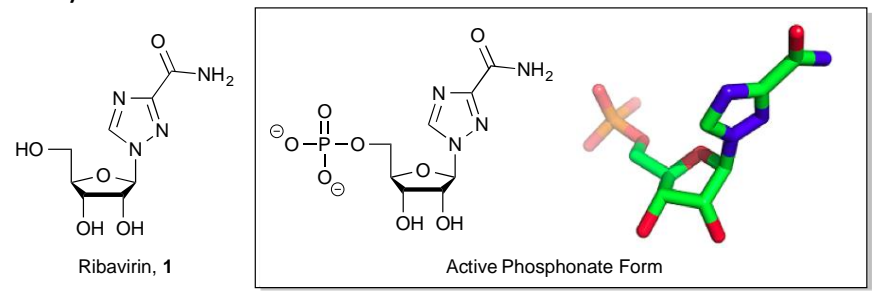

Figure 1 : Ribavirin 1, and its phosphorylated active form.

Despite its potent antiviral activity, the use of ribavirin is limited by adverse effects - mainly associated with haemolytic anaemia. ${ }^{4}$ In plasma, the nucleoside is transported into erythrocytes by suitable transporters and converted into its phosphate forms (RMP, RDP and RTP). These then accumulate owing to the lack the phosphatases needed to hydrolyse them, leading to a relative deficiency of adenosine triphosphate and subsequent extravascular haemolysis. ${ }^{5}$

Therefore, driven by the need to find safer and more specific IMP mimics, we set out to develop a range of spirocyclic nucleosides, the first class containing a [1,2,3]-triazolyl moiety (accessed via an intramolecular [1,3]-dipolar cycloaddition) and the second an azetidine functionality (accessed via intramolecular $\mathrm{S}_{\mathrm{N}} 2$ reaction) around the spirocyclic anomeric centre (Figure 2) and which show remarkable structural similarity to ribavirin. Nucleosides where the conformational restriction involves the nucleobase are known as cyclonucleosides, and have garnered interest on a number of fronts, including agrochemical (e.g. hydantocidin), ${ }^{6}$ as well as being of synthetic interest. ${ }^{7,8}$

Nucleosides restricted in this way can often show a greater specificity towards their enzymatic target, and this can result in enhanced biological activity. ${ }^{9}$

\footnotetext{
a. Current Address : Department of Chemistry, King's College London, Britannia House, 7 Trinity Street, London SE1 1DB, UK. E-mail: andre.cobb@kcl.ac.uk

b. School of Chemistry, Food and Pharmacy (SCFP), University of Reading,

Whiteknights, Reading, Berks RG6 6AD, UK

c. School of Biological Sciences, University of Reading, Whiteknights, Reading, Berks RG6 6AJ, UK

d. Current Address : College of Science, Department of Biology, Al-Mustansiriyah University, Baghdad, Iraq

e. Syngenta, Jealott's Hill International Research Centre, Bracknell, Berks RG42 6EY, UK

f. Current Address : Texas A\&M University-Texarkana, Department of Biology, 7101 University Ave, Texarkana, TX 75503, USA

g.AG Ziebuhr, Medizinische Virologie, Schubertstr.81, 35392 Gießen, Germany

+ Footnotes relating to the title and/or authors should appear here.

Electronic Supplementary Information (ESI) available: [details of any supplementary

information available should be included here]. See DOI: 10.1039/x0xx00000x
} 
Spirocyclic Triazolooxazine<smiles>[R]C[C@@]12O[C@@H]3[C@H](O)[C@]3(COCc3c([R2])nnn31)O2</smiles>

$\mathrm{R}_{1}=\mathrm{OH},=\mathrm{CHP}(\mathrm{O})(\mathrm{OH})_{2}$, $\mathrm{CH}_{2} \mathrm{P}(\mathrm{O})(\mathrm{OH})_{2}$ $\mathrm{R}_{2}=\mathrm{H}, \mathrm{Me}, \mathrm{Et}, \mathrm{Ar}$

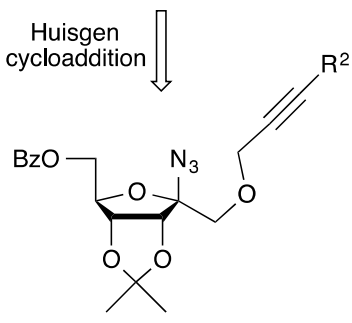

2
Spirocyclic Azetidinic Nucleoside<smiles>[R]N1CC2(C1)OC(CO)C(O)C2O</smiles>

$\mathrm{R}=\mathrm{H}, \mathrm{SO}_{2} \mathrm{Me}, \mathrm{SO}_{2} \mathrm{Ar}$

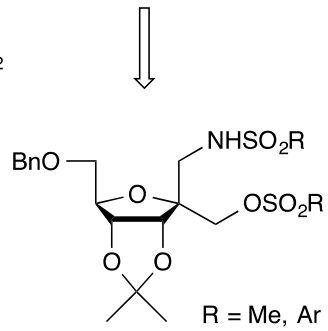

Figure 2: Spirocyclic nucleosides targeted

\section{Results and Discussion}

The starting point for the synthesis of both spirocyclic systems was $\beta$-D-fructopyranose $\mathbf{4}$, which was converted to D- psicopyranose $\mathbf{5}$ in a straightforward and previously reported three step procedure. ${ }^{10}$ This intermediate was then converted to the corresponding furanose 6 using amberlyst A15 resin in acetone (Scheme 1 ). The subsequent protecting group used on the 6'OH-position was found to be hugely influential on the next glycosidation step. In the case of azide insertion, the benzoate ester 7 sufficed, but for the nitrile insertion, the benzylated intermediate $\mathbf{8}$ was required for efficient reaction (Scheme 1). These glycosidations were achieved through the use of trimethylsilyl triflate and either TMS azide for compound 9, or TMS nitrile for compound $\mathbf{1 1 .}{ }^{11}$

The former resulted in the trimethylsilyl ether which required acidic methanolysis to give the primary alcohol 10, but fortunately this was very high yielding. Also satisfyingly, only the desired anomer was produced and this is assumed to be a result of the intermediate oxonium ion being very hindered on the $\alpha$ face owing to the presence of the acetonide, in addition to the product being the more stable isomer owing to a positive anomeric effect.

\section{$2.1[1,2,3]$-Triazolooxazines}

With building block 10 in hand, the alkylation of the primary alcohol to form the alkynyl-azido compound $\mathbf{2}$ was undertaken. A variety of bases were used to achieve this, initially with propargyl bromide as the electrophile (Table 1). Using sodium hydride in THF (Entry 1), two products were isolated 
<smiles>OC[C@]1(O)OC[C@@H](O)[C@@H](O)[C@@H]1O</smiles>

-D-Fructopyranose 4<smiles>CC1(C)OC2C(COC(=O)OCc3ccccc3)OC3(COC(C)(C)O3)C2O1</smiles>

7

$$
\text { 89\% } \mid \begin{gathered}
\mathrm{TMSN}_{3} \\
\mathrm{TMSOTf} \\
4 \AA \mathrm{MS} \\
\mathrm{MeCN} 0^{\circ} \mathrm{C}, 5 \mathrm{~min}
\end{gathered}
$$<smiles>CC1(C)O[C@H]2CO[C@@]3(COC(C)(C)O3)[C@H](O)[C@@H]2O1</smiles>

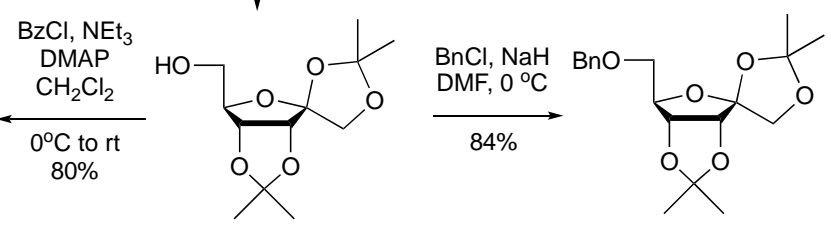

6

8

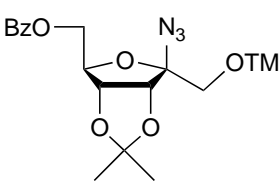

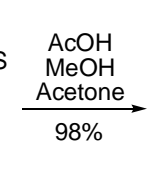

$\underset{98 \%}{\stackrel{\substack{\mathrm{AcOH} \\ \mathrm{MeOH} \\ \text { Acetone }}}{\longrightarrow}}$

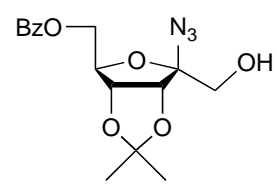

10 TMSCN
TMSOTf
$\mathrm{CH}_{2} \mathrm{Cl}_{2},-20^{\circ} \mathrm{C}$

Key Spirocyclic Building Blocks

Scheme 1 : Access to psicofuranosyl derivatives building blocks $\mathbf{1 0}$ and $\mathbf{1 1}$.

The first was identified as the required product $\mathbf{2 a}$, which was obtained in a disappointing $11 \%$ yield, and the second obtained in $6 \%$ yield - was the hydrolysed diol 12. None of the other metal bases screened gave the desired compound in any useful yield, and interestingly KHMDS in THF gave predominantly the diol $\mathbf{1 2}$. We then tested the non-metallic phosphazene base BEMP in acetonitrile (Entry 6), and pleasingly this gave exclusively the azido-alkynyl product $2 a$ in $54 \%$ yield.

Table 1 : Alkylation study for the synthesis of azido-alkyne $\mathbf{2 a}$

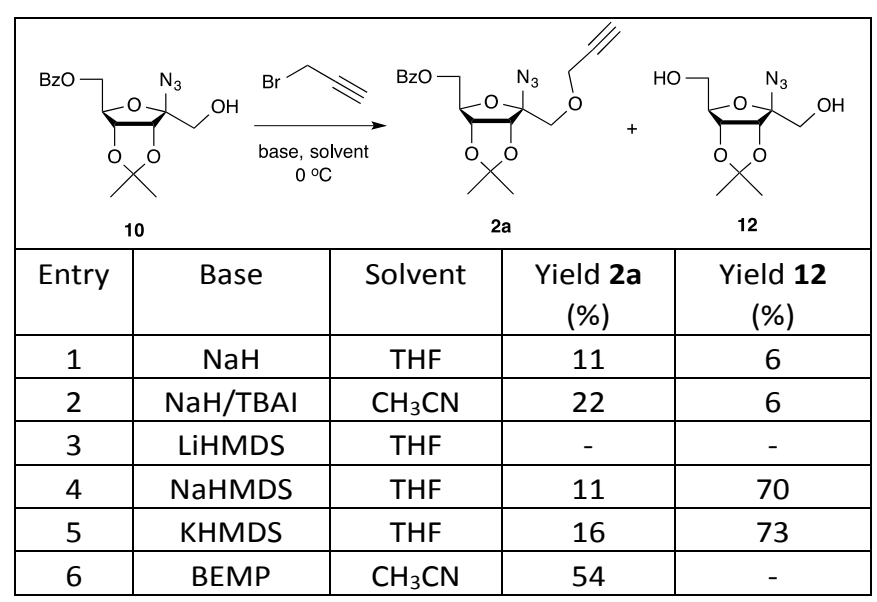

[a] Reactions were performed at $0{ }^{\circ} \mathrm{C}$ for $2 \mathrm{~h}$

With the optimised alkylation conditions in place, a range of propargyl bromides 15a-f were used to obtain the corresponding propargylic ethers $\mathbf{2}$. These were prepared from commercially available aryl iodides and propargyl alcohol using a two-step process involving Sonogashira coupling ${ }^{12}$ followed by conversion of the resulting 3-arylprop-2-ynyl alcohols 14a-f to their corresponding bromides under Appel conditions (Table 2).

Table 2 : Preparation of 3-arylprop-2-ynyl bromides 15a-f.

\begin{tabular}{|c|c|c|c|c|c|}
\hline 13 & 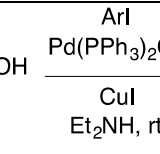 & $\mathrm{Ar}$ & 14 & $\begin{array}{c}\underset{\mathrm{CH}_{2} \mathrm{Cl}_{2}}{\mathrm{CPh}_{4}} \\
\mathrm{OP}^{\circ} \mathrm{C} \text { to rt }\end{array}$ & 15 \\
\hline Entry & $\mathrm{Ar}$ & Product & $\begin{array}{c}\text { Yield, } \\
\%\end{array}$ & Product & $\begin{array}{c}\text { Yield, } \\
\%\end{array}$ \\
\hline 1 & $\mathrm{Ph}$ & $14 a$ & nd & $15 a$ & 83 \\
\hline 2 & $\begin{array}{l}\text { 4-Cl- } \\
\mathrm{C}_{6} \mathrm{H}_{4}\end{array}$ & $14 b$ & 68 & $15 b$ & 76 \\
\hline 3 & $\begin{array}{c}\text { 4-MeO- } \\
\mathrm{C}_{6} \mathrm{H}_{4}\end{array}$ & $14 c$ & 84 & $15 c$ & 56 \\
\hline 4 & $4-\mathrm{F}-\mathrm{C}_{6} \mathrm{H}_{4}$ & 14d & 86 & $15 d$ & 85 \\
\hline 5 & $3-\mathrm{F}-\mathrm{C}_{6} \mathrm{H}_{4}$ & $14 e$ & 81 & $15 e$ & 70 \\
\hline 6 & $2-\mathrm{F}-\mathrm{C}_{6} \mathrm{H}_{4}$ & $14 f$ & 55 & $15 f$ & 49 \\
\hline
\end{tabular}

The $O$-alkylation reaction was then performed using the optimized conditions described (Table 3 ). The crude alkynylazido intermediates 2a-k underwent efficient intramolecular 1,3-dipolar cycloaddition upon heating in toluene for $24 \mathrm{~h}, 13$ 
resulting in the novel protected anomeric spironucleoside library 16a-k.

Table 3 : Alkylation and 1,3-dipolar cycloaddition to access the spirocyclic nucleoside system

\begin{tabular}{|c|c|c|c|}
\hline Product & Overall yield,\% \\
\hline 1 & $\mathrm{H}$ & $\mathbf{1 6 a}$ & 51 \\
\hline 2 & $\mathrm{Me}$ & $\mathbf{1 6 b}$ & 53 \\
\hline 3 & $\mathrm{Et}$ & $\mathbf{1 6 c}$ & 43 \\
\hline 4 & $2-\mathrm{Napthyl}$ & $\mathbf{1 6 d}$ & 59 \\
\hline 5 & $\mathrm{Ph}$ & $\mathbf{1 6 e}$ & 44 \\
\hline 6 & $4-\mathrm{Cl}-\mathrm{C}_{6} \mathrm{H}_{4}$ & $\mathbf{1 6 f}$ & 45 \\
\hline 7 & $4-\mathrm{MeO}-\mathrm{C}_{6} \mathrm{H}_{4}$ & $\mathbf{1 6 g}$ & 43 \\
\hline 8 & $4-\mathrm{F}-\mathrm{C}_{6} \mathrm{H}_{4}$ & $\mathbf{1 6 h}$ & 43 \\
\hline 9 & $3-\mathrm{F}-\mathrm{C}_{6} \mathrm{H}_{4}$ & $\mathbf{1 6 i}$ & 39 \\
\hline 10 & $2-\mathrm{F}-\mathrm{C}_{6} \mathrm{H}_{4}$ & $\mathbf{1 6 j}$ & 45 \\
\hline 11 & $n-\mathrm{Pentyl}_{2}$ & $\mathbf{1 6 k}$ & 36 \\
\hline
\end{tabular}

[a] Overall isolated yield for alkylation and cycloaddition

Debenzoylation of these compounds, using a $7 \mathrm{M}$ solution of ammonia in methanol gave intermediates 17a-k. X-ray diffraction on a single crystal of 17a was our first glimpse of the spirocyclic nature of these novel systems (Figure 3). Finally, these acetonide systems were deprotected with acidic resin (Dowex ${ }^{\circledR} 50 \mathrm{~W}$ ) to give straightforward access to anomeric spironucleosides 18a-k in satisfactory yield (Table 4). ${ }^{14}$

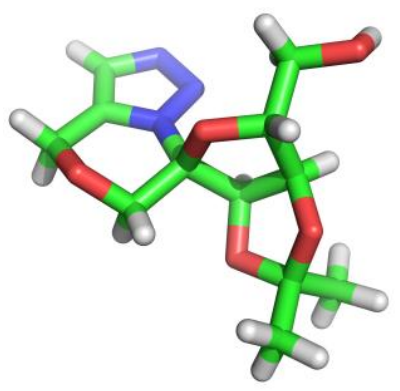

Figure 3 : X-ray crystal structure of 17 a (CCDC 1840501)

\begin{tabular}{|c|c|c|c|}
\hline \multicolumn{3}{|c|}{ Table 4 : Final deprotection steps to obtain anomeric spirocyclic nucleosides $\mathrm{Xa-k}$} \\
\hline Entry & $\mathrm{R}$ & Product & Overall yield,\% \\
\hline 1 & $\mathrm{H}$ & $\mathbf{1 8 a}$ & 56 \\
\hline 2 & $\mathrm{Me}$ & $\mathbf{1 8 b}$ & 47 \\
\hline 3 & $\mathrm{Et}$ & $\mathbf{1 8 c}$ & 51 \\
\hline 4 & $2-\mathrm{Napthyl}$ & $\mathbf{1 8 d}$ & 50 \\
\hline 5 & $\mathrm{Ph}$ & $\mathbf{1 8 e}$ & 67 \\
\hline 6 & $4-\mathrm{Cl}_{-} \mathrm{C}_{6} \mathrm{H}_{4}$ & $\mathbf{1 8 f}$ & 63 \\
\hline 7 & $4-\mathrm{MeO}-\mathrm{C}_{6} \mathrm{H}_{4}$ & $\mathbf{1 8 g}$ & 52 \\
\hline 8 & $4-\mathrm{F}-\mathrm{C}_{6} \mathrm{H}_{4}$ & $\mathbf{1 8 h}$ & 80 \\
\hline 9 & $3-\mathrm{F}-\mathrm{C}_{6} \mathrm{H}_{4}$ & $\mathbf{1 8 i}$ & 74 \\
\hline 10 & $2-\mathrm{F}-\mathrm{C}_{6} \mathrm{H}_{4}$ & $\mathbf{1 8 j}$ & 73 \\
\hline 11 & $n-\mathrm{Pentyl}$ & $\mathbf{1 8 k}$ & 69 \\
\hline
\end{tabular}

[a] Overall isolated yield for benzoate and acetonide deprotection

\subsection{Spiro-[1,2,3]-triazolooxazine Nucleoside Phosphonates}

As has been mentioned, the active form of ribavirin is the $5^{\prime}$ phosphate, and as such nucleoside analogues containing the phosphonate moiety as a bioisostere of this have achieved reasonable success. ${ }^{15}$ As such we sought to also make the phosphonate $\mathbf{2 2}$ as a part of our library (Scheme 2). This was achieved through Dess-Martin oxidation of the $5^{\prime}-\mathrm{OH}$ in 17 a to the corresponding aldehyde 19 in $80 \%$ yield, followed by Horner-Wadsworth-Emmons reaction using tetraethyl methylenediphosphonate to give the corresponding vinyl phosphonate 20 in a 5:2 E/Z ratio. High pressure (4 bar) reduction in methanol gave the corresponding alkyl phosphonate $\mathbf{2 1}$ in $61 \%$ yield. This underwent deprotection, first of the acetonide using Dowex resin as described previously, followed by deprotection of the phosphonate ester to the corresponding phosphonic acid $\mathbf{2 3}$ using trimethylsilyl bromide and 2,6 -lutidine in dichloromethane in a $12 \%$ overall yield for the two final steps. 


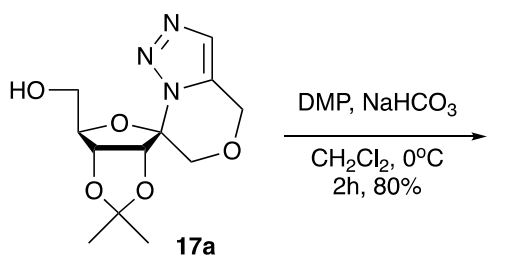

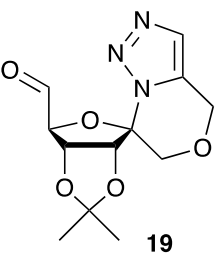

19<smiles>CCOP(=O)(O)CP(=O)(O)OC</smiles>

$\mathrm{NaH}, \mathrm{THF}, \mathrm{r}$ $2 \mathrm{~h}, 57 \%$

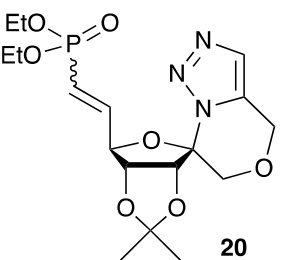

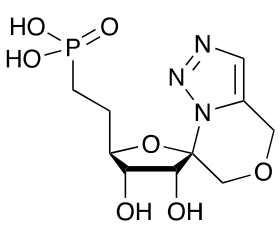

23

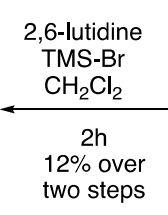

two steps

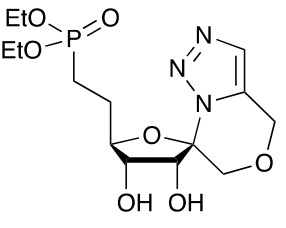

22

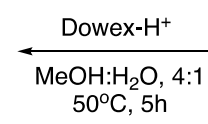
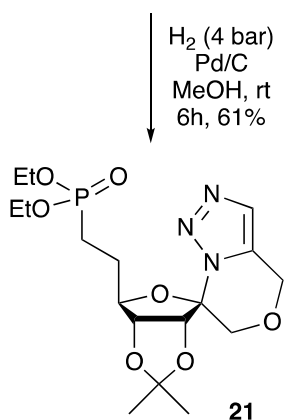

Scheme 2 : Synthesis of phosphonate $\mathbf{2 3}$<smiles>CC1(C)OC2OC1C(CO)(CO)OC2CO</smiles>

11

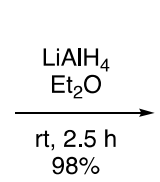

$98 \%$<smiles>CC1(C)OC2C(CO)OC1(CN)OC2(CO)CO</smiles>

24

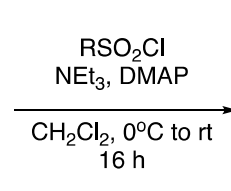

$6 \mathrm{~h}$

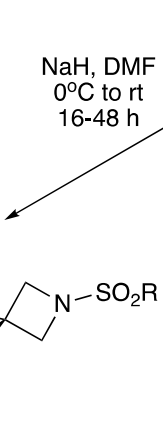

26a : $\mathrm{R}=\mathrm{CH}_{3}, 63 \%$

26b : $\mathrm{R}=4-\mathrm{CH}_{3}-\mathrm{C}_{6} \mathrm{H}_{4}, 54 \%$ 26c : $R=4-\mathrm{NO}_{2}-\mathrm{C}_{6} \mathrm{H}_{4}, 12 \%$

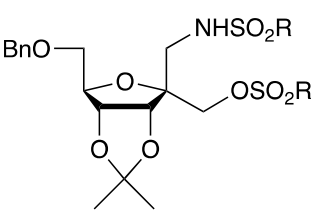

25a $: \mathrm{R}=\mathrm{CH}_{3}, 66 \%$

25b : $\mathrm{R}=4-\mathrm{CH}_{3}-\mathrm{C}_{6} \mathrm{H}_{4}, 62 \%$ 25c : $\mathrm{R}=4-\mathrm{NO}_{2}-\mathrm{C}_{6} \mathrm{H}_{4}, 97 \%$

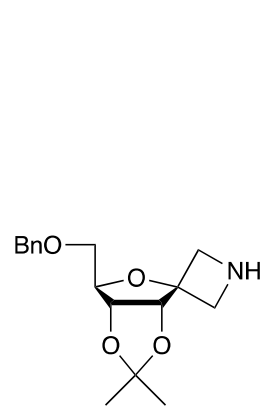

28

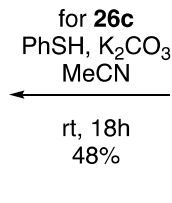

$18 \mathrm{~h}$

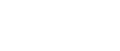

Scheme 3 : Synthesis of azetidinic systems.

\subsection{Spirocyclic Azetidines}

Another class of spirocyclic nucleoside we were interested in was based on the azetidinic system as described previously by Fuentes and co-workers. ${ }^{16}$ In this work, they took the $\mathrm{N}-, \mathrm{O}$ methyl sulfonate 25a and subjected it to sodium hydride in DMF, whereupon intramolecular cyclisation of the sulfonamide anion onto the $O$-mesylate resulting in the azetidinic system 26a. We conducted the same reaction for tosyl and nosyl compounds $\mathbf{2 5 b}$ and $\mathbf{2 5 c}$. Subsequently, for the mesyl, and tosyl systems (26a and $\mathbf{2 6 b}$ respectively), we achieved deprotection of the acetonide in the usual way, followed by removal of the benzyl protecting group at high pressure to give spirocylic azetidines $\mathbf{2 7}$ a and $\mathbf{2 7} \mathbf{b}$. The configuration of the tosyl derivative 27b was determined by X-ray crystallography (Figure 4). The nosyl derivative $\mathbf{2 6 c}$ was synthesized due to the ease with which it can be removed from the nitrogen atom on which it resides compared to the mesyl and tosyl compounds to expose the secondary amine. However, we were unable to deprotect this compound fully to the corresponding triol but did managed to convert it to the secondary amine intermediate $\mathbf{2 8}$. This possibly represents a useful scaffold to generate a library with structurally diverse spironucleosides. 


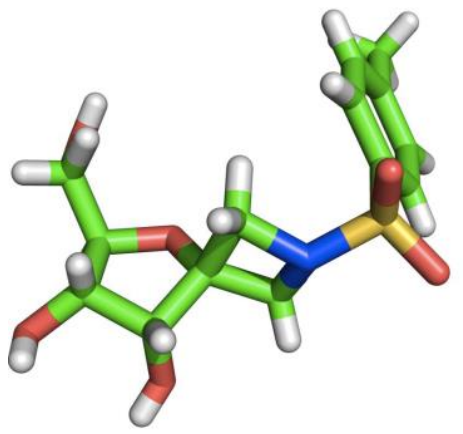

Figure 4 : X-ray crystal structure of novel tosyl azetidinic system 27b. (CCDC 1840502)

\section{Biological Evaluation}

Coronaviruses are an important family of human and veterinary pathogens that can cause enteric and respiratory infections, including severe acute respiratory syndrome coronavirus (SARS) and middle east respiratory syndrome coronavirus (MERS), which are amongst the most lethal viral infections currently known. Infection with the model coronavirus Murine hepatitis virus (MHV) can also lead to gastroenteritis, nephritis, hepatitis, encephalitis, and progressive demyelinating disease, depending on the animal model, virus strain and inoculation route used. ${ }^{17}$ Coronaviruses are considered the largest and most complex RNA viruses known, encoding an unusually wide array of proteins that interact with or modify viral RNA. ${ }^{18}$ Since coronaviruses are enveloped viruses with a positive-sense RNA genome, they are predicted to be sensitive to RNA-like drugs, ${ }^{19}$ and some nucleosides, such as ribavirin 1 , have anti-coronaviral activity.

As a result, Mouse Hepatitis Virus (MHV) has been chosen as a proving ground for the novel nucleoside analogues described in this study for antiviral activity. In order to test for antiviral effects, MHV was grown on mouse $17 \mathrm{Cl}-1$ cells that had been pre-treated with the experimental compounds at a concentration of $1 \mathrm{mM} 3 \mathrm{~h}$ before inoculation to allow time for drug uptake and potential phosphorylation, inoculated with 10 infectious units of virus per cell for $1 \mathrm{~h}$ to ensure as many cells as possible were infected, rinsed with saline to remove any virus that had not entered a cell yet, and incubated again with the same amount of experimental compound for $14 \mathrm{~h}$. The amount of MHV released from infected cells usually peaks at about $14 \mathrm{~h}$ after infection (Figure 5a). The amount of virus released from infected cells was then measured by plaque assay. Two of the treatments, $\mathbf{1 8 b}$ and $\mathbf{1 8 f}$ reduced the amount of $\mathrm{MHV}$ that was released by about tenfold (Figure 5b). Unfortunately, no significant activity was seen for compound $\mathbf{2 7 b}$ or the phosphonate analogue, compound 22.

$\mathrm{MHV}$ infection in $17 \mathrm{Cl}-1$ cells normally results in formation of large multinucleate syncytia starting about $6 \mathrm{~h}$ after infection, followed by detachment of cells from the culture flask and widespread cell death by $14 \mathrm{~h}$ after infection.

Compounds were tested for side effects on cell growth (Figure 6a) and then for the ability to protect cells from overt signs of infection (Figure 6b). Selected compounds were tested for side effects on cell viability and growth over three days of treatment by MTT assay. The most effective experimental compound $\mathbf{1 8 f}$ did not show any significant toxicity at concentrations of $1 \mathrm{mM}$ and below (Figure $6 \mathrm{c}$ ). The concentration that produced a $50 \%$ reduction in cell viability in these assays was greater than $1 \mathrm{mM}$ for each of the experimental compounds tested, demonstrating that the compounds are relatively non-toxic.

Compound $\mathbf{1 8 f}$ was then screened for the ability to protect cells from MHV-induced cytopathology, including cell fusion and detachment from the culture flask. The $17 \mathrm{Cl}-1$ cells were pretreated with $18 \mathrm{f} 3 \mathrm{~h}$ before infection, rinsed after $24 \mathrm{~h}$ to remove any dead or detached cells, and surviving adherent cells were photographed $24 \mathrm{~h}$ after infection. Treatment with $1 \mathrm{mM}$ compound $\mathbf{1 8 f}$ resulted in a dose-dependent reduction in both syncytium formation and detachment of infected cells (Figure $6 d$ and $6 e)$.

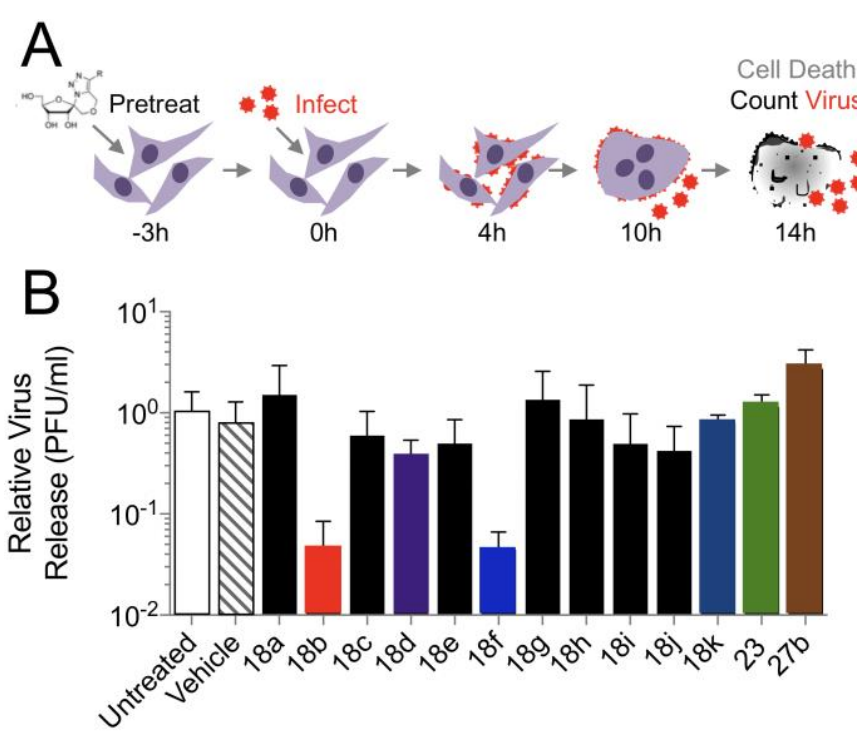

Figure 5. Effects of spirocyclic nucleosides on release of infectious virus. (A) Experimental procedure used to test antiviral efficacy. Mouse $17 \mathrm{Cl}-1$ cells were pre-treated with compounds $3 \mathrm{~h}$ before inoculation with the virus $\mathrm{MHV}$. After $14 \mathrm{~h}$ virus growth was measured by plaque assay. (B) Effects of $1 \mathrm{mM}$ treatment on virus release, normalized to virus release from infected untreated cells.

From these data it was concluded that $\mathbf{1 8 f}$ exerted a limited protective effect on treated cells at concentrations of $250 \mu \mathrm{M}$, and appeared to completely protect treated cells from overt cytopathic effects of virus infection at $2 \mathrm{mM}$. This also demonstrated that the apparent antiviral activity of $\mathbf{1 8 f}$ was not simply an artefact of cytotoxicity. More detailed dose-response experiments were performed for four of the experimental compounds in order to better gauge their antiviral potential. The two treatments that were previously identified as most effective, compound $\mathbf{1 8 b}$ and $\mathbf{1 8 f}$, strongly reduced virus growth at $1 \mathrm{mM}$ and $2 \mathrm{mM}$ concentrations, but did not significantly inhibit virus growth at $0.1 \mathrm{mM}$ or lower concentrations (Figure 7) similar to the dose-effectieness profile of the antiviral nucleoside ribavirin (Fig. 8). Indeed, the low activity of ribavirin against MHV has been well documented. ${ }^{20-}$ 
22 Two groups using different cell culture methods demonstrated an approximately ten-fold reduction of $\mathrm{MHV}$ growth in the presence of 41 micromolar ribavirin, ${ }^{22}$ and a greater than ten-fold reduction in MHV growth in the presence of a 40 micromolar conjugate of human hemoglobin and ribavirin bound to haptoglobin. ${ }^{20}$ However, ribavirin treatment has also been shown to reduce the severity of MHV-induced disease in mice and alter the cytokine profile in infected mice. ${ }^{20-}$ 22 In the investigation of our spirocyclic systems, pre-treatment with $2 \mathrm{mM}$ of $\mathbf{1 8 f}$ produced the strongest antiviral effects, resulting in approximately one million-fold reduction of $\mathrm{MHV}$ growth. Unfortunately, no significant activity was seen for compounds $\mathbf{2 3}$ or $\mathbf{2 7} \mathbf{b}$ at any of the concentrations tested.

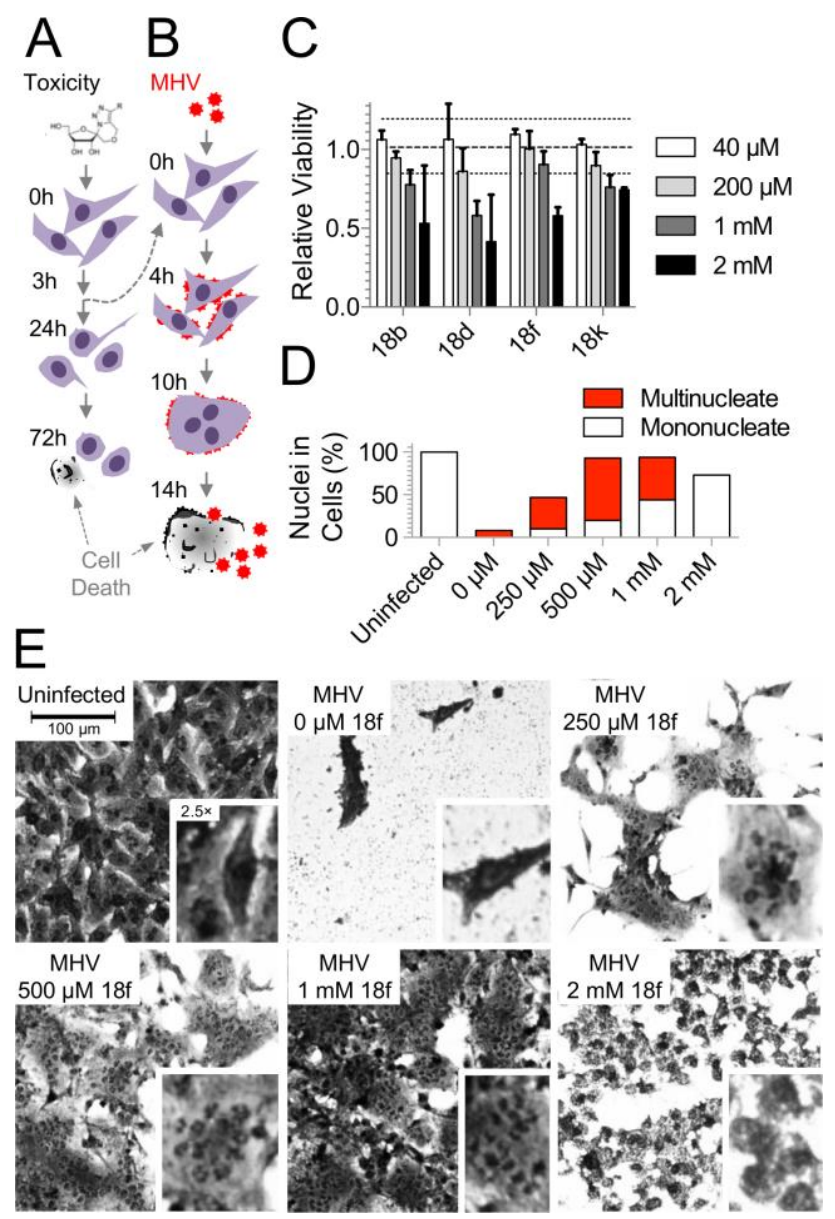

Figure 6. Effects of spirocyclic nucleoside treatment on cells. The experimental procedures used to test for effects on cell viability (A) and the appearance of virus-induced cytopathic effects in mouse $17 \mathrm{Cl}-1$ cells (B) are shown. The effects of experimental compounds on cell viability were assessed by MTT assay 24 hours after treatment (C). Cytopathic effects due to MHV infection were assessed by counting visible nuclei in cells and syncytia after infection in the presence of absence of experimental compounds (D). Representative examples of cells from each treatment group are shown (E) to illustrate the appearance of typical MHV cytopathic effects including formation of multinucleate syncytia (most apparent in $2.5 \times$ magnified insets from infected $250 \mu \mathrm{M}$, $500 \mu \mathrm{M}$ and $1 \mathrm{mM}$ treatment groups) and loss of cells due to cell destruction (apparent in the infected $0 \mu \mathrm{M}$ and $150 \mu \mathrm{M}$ treatment groups).
A further experiment was performed in order to learn more about the mechanism of $\mathbf{1 8 f}$ antiviral activity by evolving drug resistance. MHV was serially passaged eight times on $17 \mathrm{Cl}-1$ cells, which had been pre-treated with $1 \mathrm{mM}$ 18f, a concentration that reproducibly reduced viral growth by about $90 \%$. Previous work on antiviral compounds suggested that these conditions were appropriate for the selection of drugresistant coronavirus within about five passages. ${ }^{23} \mathrm{MHV}$ growth in the presence of $\mathbf{1 8 f}$ was consistently reduced by about $90 \%$ compared to the virus produced in untreated control cells, and did not develop resistance (data not shown). These results suggest that the mechanism of action of $\mathbf{1 8 f}$ is unclear, and that effects of $18 \mathrm{f}$ on the cell cannot be ruled out as a potential explanation of the antiviral effects.
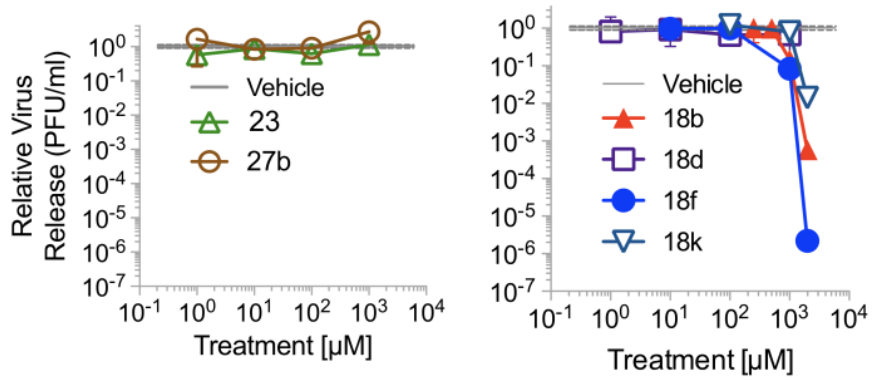

Figure 7. Dose-dependent inhibition of virus growth. The experimental protocol was performed as described in Fig. 6a.

\section{Ribavirin}

cell line: 17C1-1

time point p.i.: $14 \mathrm{~h}$

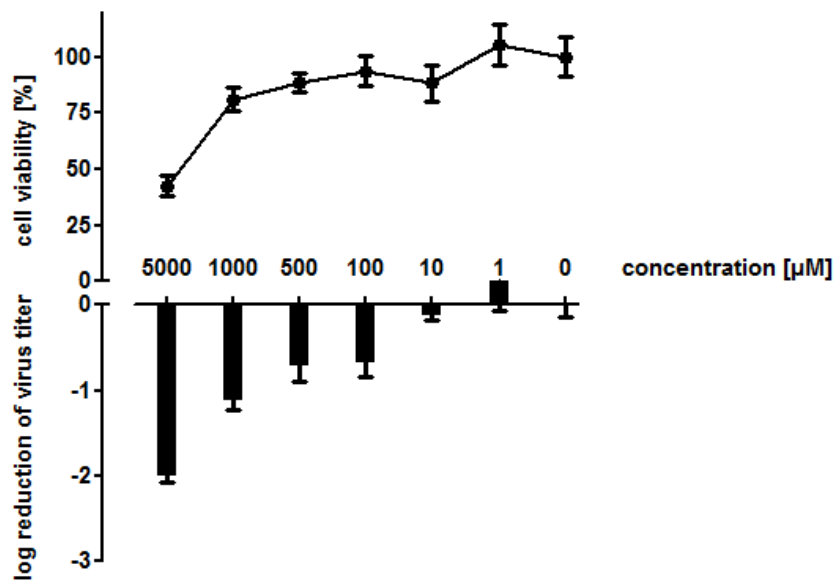

Figure 8. Ribavirin has the similarly low $\mathrm{mM}$ cytotoxicity as for our compounds and reduced virus titre in a dose-dependent manner.

\section{Conclusions}

In conclusion, we have synthesized an array of spirocyclic ribonucleosides from a common precursor, the protected psicose derivative 6 . Both triazolic and azetidinic systems were accessed, as well as phosphate derivatives. Some of these agents showed 
promising activity towards MHV (Mouse Hepatitis Virus), with the most promising being the triazolic system $\mathbf{1 8 f}$.

\section{Experimental}

\section{Materials and methods}

All moisture-sensitive reactions were carried out under an atmosphere of nitrogen. All solvents were analytical grade purity, dried over standard drying agents and stored over $3 \AA$ molecular sieves. All commercially available chemicals were purchased from Sigma Aldrich and used as supplied unless otherwise stated. Reactions were monitored by thin layer chromatography (TLC), which was performed on Merck aluminium backed plates coated with $0.2 \mathrm{~mm}$ silica gel $60 \mathrm{~F} 254$. The spots were visualised using UV light $(254 \mathrm{~nm})$ and then by charring with $10 \%$ sulfuric acid in methanol. Column chromatography was carried out using silica gel $60 \AA(35-70 \mu \mathrm{m})$. ${ }^{1} \mathrm{H}-\mathrm{NMR}$ spectra were recorded in suitable deuterated solvents $\left(\mathrm{CDCl}_{3}, \mathrm{CD}_{3} \mathrm{OD}\right)$ using a Bruker DPX $400(400$ $\mathrm{MHz}$ ) or a Bruker Avance III 400 (400 MHz) or a Bruker Avance II+ 500 (500 MHz) spectrometer. In all cases, tetramethylsilane (TMS) was used as internal standard for calibrating chemical shifts $(\delta)$, which were quoted in parts per million. Abbreviations were used for the following multiplicities: $s$, singlet; $d$, doublet; $d d$, doublet of doublets; $\mathrm{ddd}$, double double doublet; $\mathrm{dt}$, doublet of triplets; $\mathrm{t}$, triplet; $\mathrm{td}$, triplet of doublets, tt, triplet of triplets; q, quartet; m, multiplet and the coupling constants J were quoted in $\mathrm{Hz} .{ }^{13} \mathrm{C}-\mathrm{NMR}$ spectra were recorded at $100 \mathrm{MHz}$ on a DPX 400 or Avance III 400 or $125 \mathrm{MHz}$ on a Avance II+ 500 in suitable deuterated solvents (CDCl3, CD3OD). Assignments were confirmed by homonuclear 2D COSY and heteronuclear 2D correlated experiments $\left({ }^{1} \mathrm{H},{ }^{13} \mathrm{CHSQC},{ }^{1} \mathrm{H},{ }^{13} \mathrm{C}\right.$ $\mathrm{HMBC}$ ). Infrared spectra were recorded on a Perkin-Elmer FT-IR spectrometer as a thin film. The absorptions are quoted in wavenumbers $(\mathrm{cm}-1)$. Mass spectrometry data was recorded on a Thermo Scientific LTQ Orbitrap XL using electrospray ionisation (ESI) conditions. Optical rotations were recorded with a Perkin-Elmer 341 polarimeter using a sodium lamp (D line, $589 \mathrm{~nm}$ ) and mercury lamp (yellow line, $578 \mathrm{~nm}$ ) as the source of polarized light. They were measured at $20 \pm 2{ }^{\circ} \mathrm{C}$ in the stated solvent and are quoted in units of $10^{-1} \mathrm{deg} \mathrm{cm}^{2} \mathrm{~g}^{-1}$. Solution concentrations (c) are given in the units of $10^{-2} \mathrm{~g} \mathrm{~cm}^{-3}$. Melting points are uncorrected and were determined on a Stuart SMP3 melting point apparatus. HPLC analysis was determined on an Agilent Technologies 1200 Series HPLC, using a ratio of HPLC grade hexanes and propan-2-ol as the eluent, using either a Chiralpak AD-H column $(0.46 \mathrm{~cm} \varnothing \times 25 \mathrm{~cm})$ or a Chiralcel OD column $(0.46 \mathrm{~cm} \varnothing \times 25 \mathrm{~cm})$, and detection by UV at $210 \mathrm{~nm}$ or 254 $\mathrm{nm}$.

\section{Synthetic Procedures}

\section{1,2:3,4-di-O-isopropylidine- $\beta$-D-psicofuranose $6^{\mathbf{1 0}}$}

I,2:3,4-di-O-isopropylidine- $\beta$-D-psicopiranose 5 (5.0 g, $19.2 \mathrm{mmol}$ ) was dissolved in acetone $(50 \mathrm{~mL})$. A15 amberlyst resin $(250 \mathrm{mg}$ ) was added in one portion and the resulting suspension was stirred vigorously for $13 \mathrm{~h}$, then the resin was filtered off, basified with triethylamine and washed with acetone. The filtrate was evaporated under reduced pressure to afford the crude residue as orange oil, which is pure enough to be used immediately for the next step. Purification of the crude product by column chromatography (silica gel, hexane/ethyl acetate $85 / 15)$ gave the pure protected $\beta$-Dpsicofuranose 6 ( $4.4 \mathrm{~g}, 88 \%$ yield) as white solid. Data for 6: White solid, $\mathrm{mp}=56-57^{\circ} \mathrm{C} .[\alpha]_{\mathrm{D}}{ }^{20}=-92.1\left(\mathrm{c}=0.01, \mathrm{CHCl}_{3}\right) .{ }^{1} \mathrm{H}-\mathrm{NMR}(400$ $\mathrm{MHz}, \mathrm{CDCl} 3): \delta 1.33\left(3 \mathrm{H}, \mathrm{s}, \mathrm{CH}_{3}\right), 1.41\left(3 \mathrm{H}, \mathrm{s}, \mathrm{CH}_{3}\right), 1.45\left(3 \mathrm{H}, \mathrm{s}, \mathrm{CH}_{3}\right)$, $1.53\left(3 \mathrm{H}, \mathrm{s}, \mathrm{CH}_{3}\right), 3.18(1 \mathrm{H}, \mathrm{dd}, J=10.4,2.8, \mathrm{OH}), 3.65(1 \mathrm{H}, \mathrm{td}, J=12.4$, 3.6, H-6a), $3.77\left(1 \mathrm{H}, \mathrm{dt}, J=12.4,2.4, \mathrm{H}-6_{\mathrm{b}}\right), 4.07\left(1 \mathrm{H}, \mathrm{d}, J=10.0, \mathrm{H}-\mathrm{1}_{\mathrm{a}}\right)$, $4.30(1 \mathrm{H}, \mathrm{t}, J=2.8, \mathrm{H}-5), 4.34(1 \mathrm{H}, \mathrm{d}, J=9.8, \mathrm{H}-1 \mathrm{~b}), 4.65(1 \mathrm{H}, \mathrm{d}, J=6.0$, $\mathrm{H}-3), 4.92(1 \mathrm{H}, \mathrm{dd}, J=6.0,1.2, \mathrm{H}-4) .{ }^{13} \mathrm{C}-\mathrm{NMR}\left(100 \mathrm{MHz}, \mathrm{CDCl}_{3}\right): 24.8$ $\left(\mathrm{CH}_{3}\right), 26.2\left(\mathrm{CH}_{3}\right), 26.3\left(\mathrm{CH}_{3}\right), 26.5\left(\mathrm{CH}_{3}\right), 64.0(\mathrm{C}-6), 69.9(\mathrm{C}-1), 81.7$ (C-4), 85.8 (C-3), 86.8 (C-5), 111.7 (C-2), $112.3\left(\mathrm{C}\left(\mathrm{CH}_{3}\right)_{2}\right), 113.4$

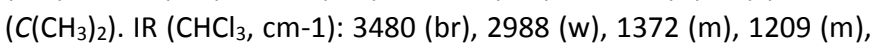
$1062(\mathrm{~s}), 1029$ (s), 851 (s).

\section{1,2:3,4-di-O-isopropylidene-6-O-benzoyl- $\beta$-D-psicofuranose $7^{10}$}

To a stirring solution of I,2:3,4-di-O-isopropylidine- $\beta$-D-psicofuranose $6(5.0 \mathrm{~g}, 19.2 \mathrm{mmol})$, triethylamine $(13 \mathrm{~mL}, 96.0 \mathrm{mmol})$ and dimethylaminopyridine $(230 \mathrm{mg}, 1.92 \mathrm{mmol}$ ) in dichloromethane $(60$ $\mathrm{mL}$ ) was added benzoyl chloride $(2.45 \mathrm{~mL}, 21.1 \mathrm{mmol})$ dropwise at 0 ${ }^{\circ} \mathrm{C}$. The resulting light yellow solution was allowed to warm to room temperature and stirred for $14 \mathrm{~h}$. The mixture was partitioned between saturated aq. $\mathrm{NaHCO}_{3}$ and dichloromethane. The combined organic layers were washed with brine, dried over $\mathrm{MgSO}_{4}$, filtered and concentrated to dryness under reduced pressure. Purification of the crude product by column chromatography (silica gel, hexane/ ethyl acetate $9 / 1$ ) gave the title compound 7 ( $5.6 \mathrm{~g}, 80 \%$ yield) as a white solid. Data for 7: White solid, $\mathrm{mp}=72-73^{\circ} \mathrm{C}$. $[\alpha]_{\mathrm{D}}^{20}=-64.4(\mathrm{c}=$ $\left.0.01, \mathrm{CHCl}_{3}\right) .{ }^{1} \mathrm{H}-\mathrm{NMR}\left(400 \mathrm{MHz}, \mathrm{CDCl}_{3}\right): \delta 1.34\left(3 \mathrm{H}, \mathrm{s}, \mathrm{CH}_{3}\right), 1.35(3 \mathrm{H}$, $\left.\mathrm{s}, \mathrm{CH}_{3}\right), 1.43\left(3 \mathrm{H}, \mathrm{s}, \mathrm{CH}_{3}\right), 1.47\left(3 \mathrm{H}, \mathrm{s}, \mathrm{CH}_{3}\right), 4.08\left(1 \mathrm{H}, \mathrm{d}, J=9.6, \mathrm{H}-1_{\mathrm{a}}\right)$, $4.31\left(1 \mathrm{H}, \mathrm{d}, \mathrm{J}=9.6, \mathrm{H}-\mathrm{1}_{\mathrm{b}}\right), 4.36-4.48(3 \mathrm{H}, \mathrm{m}, \mathrm{H}-3, \mathrm{H}-4$ and $\mathrm{H}-5), 4.68$ $\left(1 \mathrm{H}, \mathrm{d}, \mathrm{J}=5.6, \mathrm{H}-6_{\mathrm{a}}\right), 4.83\left(1 \mathrm{H}, \mathrm{d}, J=6.0, \mathrm{H}-6_{\mathrm{b}}\right), 7.44(2 \mathrm{H}, \mathrm{t}, J=8.0$, $\left.2 \times \mathrm{H}_{m}\right), 7.57\left(1 \mathrm{H}, \mathrm{tt}, J=7.6,1.2, \mathrm{H}_{p}\right), 8.08\left(2 \mathrm{H}, \mathrm{dd}, J=8.4,1.2,2 \times \mathrm{H}_{0}\right)$. ${ }^{13} \mathrm{C}-\mathrm{NMR}\left(100 \mathrm{MHz}, \mathrm{CDCl}_{3}\right): 25.1\left(\mathrm{CH}_{3}\right), 26.2\left(\mathrm{CH}_{3}\right), 26.3\left(\mathrm{CH}_{3}\right), 26.4$ $\left(\mathrm{CH}_{3}\right), 64.8$ (C-1), 66.1 (C-6), 82.2 (C-4), 83.0 (C-3), 85.2 (C-5), 111.7

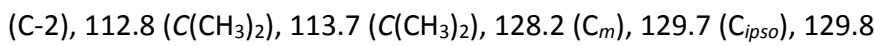
$\left(\mathrm{C}_{0}\right), 133.1\left(\mathrm{C}_{p}\right), 166.1$ (COPh). IR $\left(\mathrm{CHCl}_{3}, \mathrm{~cm}^{-1}\right): 2989(\mathrm{w}), 1720(\mathrm{~s})$, $1373(\mathrm{~m}), 1268$ (s), 1065 (s), 1024 (s), 854 (s), 709 (s).

\section{1,2:3,4-di- $O$-isopropylidene-6- $O$-benzyl- $\beta$-D-psicofuranose $\mathbf{8}^{11}$}

Sodium hydride ( $60 \%$ dispersion in mineral oil, $5.2 \mathrm{~g}, 0.13 \mathrm{~mol}$ ) was placed in a $1 \mathrm{~L} 3$ neck round bottom flask equipped with a thermometer and pressure equalising dropping funnel and cooled to $0{ }^{\circ} \mathrm{C}$. Anhydrous DMF $(50 \mathrm{~mL})$ was slowly added under inert atmosphere $\left(\mathrm{N}_{2}\right)$, ensuring that the internal temperature remained less than $10{ }^{\circ} \mathrm{C}$. A solution of protected D-psicofuranose 6 (28.66 g, $0.11 \mathrm{~mol})$ in anhydrous DMF $(200 \mathrm{~mL})$ was then added dropwise over $30 \mathrm{~min}$ - again with control of the exotherm and stirred for a further $30 \mathrm{~min}$ at $0{ }^{\circ} \mathrm{C}$. A solution of benzyl bromide $(19.4 \mathrm{~mL}, 0.16 \mathrm{~mol})$ in anhydrous DMF (100 mL) was then added dropwise at $0{ }^{\circ} \mathrm{C}$ and the resulting solution allowed to warm to room temperature. After this had been achieved, the mixture was stirred for a further $4 \mathrm{~h}$. It was then treated with methanol, diluted with water and extracted with diethylether. The combined organic layers were washed with brine, dried over $\mathrm{MgSO}_{4}$, filtered and concentrated to dryness under reduced pressure to afford the crude residue as orange oil. Purification of the crude product by column chromatography (silica gel, isohexane/ ethyl acetate 9/1) gave the title compound 8 (32.26 $\mathrm{g}, 84 \%$ yield) as colourless syrup. Data for 8: pale yellow syrup. $[\alpha]_{D}{ }^{20}=-65.6\left(\mathrm{c}=0.01, \mathrm{CHCl}_{3}\right) .{ }^{1} \mathrm{H}-\mathrm{NMR}(400 \mathrm{MHz}, \mathrm{CDCl} 3): \delta 1.29(3 \mathrm{H}$, 
$\left.\mathrm{s}, \mathrm{CH}_{3}\right), 1.35\left(3 \mathrm{H}, \mathrm{s}, \mathrm{CH}_{3}\right), 1.41\left(3 \mathrm{H}, \mathrm{s}, 2 \times \mathrm{CH}_{3}\right), 1.48-1.59(2 \mathrm{H}, \mathrm{m}, 2 \times \mathrm{H}$ 6), $4.03\left(1 \mathrm{H}, \mathrm{d}, J=9.6, \mathrm{H}-1_{\mathrm{a}}\right), 4.26-4.31(1 \mathrm{H}, \mathrm{m}, \mathrm{H}-5), 4.28(1 \mathrm{H}, \mathrm{d}, J=$ 9.6, $\left.\mathrm{H}-1_{\mathrm{b}}\right), 4.52\left(2 \mathrm{H}, \mathrm{AB} \mathrm{q}, J=12.4, \mathrm{CH}_{2} \mathrm{Ph}\right), 4.36-4.57(1 \mathrm{H}, \mathrm{d}, J=5.8$, $\mathrm{H}-3), 4.72(1 \mathrm{H}, \mathrm{d}, J=5.8, \mathrm{H}-4), 7.24-7.32\left(5 \mathrm{H}, \mathrm{m}, 5 \times \mathrm{H}_{\text {arom }}\right) .{ }^{13} \mathrm{C}-\mathrm{NMR}$ $\left(100 \mathrm{MHz}, \mathrm{CDCl}_{3}\right): 25.2\left(\mathrm{CH}_{3}\right), 26.3\left(\mathrm{CH}_{3}\right), 26.4\left(\mathrm{CH}_{3}\right), 26.5\left(\mathrm{CH}_{3}\right), 69.8$ (C-1), 70.9 (C-6), 73.3 (C-1'), 82.6 (C-4), 83.8 (C-5), 85.2 (C-3), 111.4 (C-2), $112.5(\mathrm{C}(\mathrm{CH} 3) 2), 113.6\left(\mathrm{C}\left(\mathrm{CH}_{3}\right)_{2}\right), 127.6\left(\mathrm{C}_{m}\right), 129.6\left(\mathrm{Ci}_{\text {pso }}\right), 129.3$ $\left(\mathrm{C}_{o}\right), 138.2\left(\mathrm{C}_{p}\right) . \mathrm{IR}\left(\mathrm{CHCl}_{3}, \mathrm{Cm}^{-1}\right): 2941$ (w), $1450(\mathrm{~s}), 1370(\mathrm{~s})$.

\section{1-O-Trimethylsilyl-2-azido-2-deoxy-3,4-O-isopropylidene-6-O- benzoyl - $\beta$-D-psicofuranose $9^{14}$}

To a solution of spiroketal $7(1.0 \mathrm{~g}, 2.74 \mathrm{mmol})$ and freshly distilled acetonitrile $(30 \mathrm{~mL})$ was added azidotrimethylsilane $(750 \mu \mathrm{L}, 5.48$ $\mathrm{mmol})$ at $0{ }^{\circ} \mathrm{C}$ under a nitrogen atmosphere in the presence of activated $4 \AA$ molecular sieves. The solution was stirred for $5 \mathrm{~min}$ and trimethylsilyltriflate $(146 \mu \mathrm{L}, 0.82 \mathrm{mmol})$ added dropwise, and the stirring was continued at $0{ }^{\circ} \mathrm{C}$ for a further $5 \mathrm{~min}$. The mixture was neutralized with triethylamine $(228 \mu \mathrm{L}, 1.64 \mathrm{mmol})$, diluted with ethyl acetate and warmed to room temperature. The resulting solution was partitioned between saturated aq. $\mathrm{NaHCO}_{3}$ and ethyl acetate. The organic layers were washed with brine, dried over $\mathrm{MgSO}_{4}$, filtered and concentrated to dryness under reduced pressure. Purification of the crude product by column chromatography (silica gel, hexane/ ethyl acetate 95/5) gave the pure $9(1.03 \mathrm{~g}, 89 \%$ yield $)$ as colourless syrup. Data for $9:[\alpha]_{\mathrm{D}^{20}}=$ $89.6\left(\mathrm{c}=0.01, \mathrm{CHCl}_{3}\right) .{ }^{1} \mathrm{H}$ NMR $(400 \mathrm{MHz}, \mathrm{CDCl} 3): \delta 0.01(9 \mathrm{H}, \mathrm{s}$, $\left.\mathrm{Si}\left(\mathrm{CH}_{3}\right)_{3}\right), 1.13\left(3 \mathrm{H}, \mathrm{s}, \mathrm{CH}_{3}\right), 1.47\left(3 \mathrm{H}, \mathrm{s}, \mathrm{CH}_{3}\right), 3.81(1 \mathrm{H}, \mathrm{d}, J=11.6, \mathrm{H}-$ 1a), $3.84(1 \mathrm{H}, \mathrm{d}, J=11.2, \mathrm{H}-1 \mathrm{~b}), 4.24-4.28\left(2 \mathrm{H}, \mathrm{m}, \mathrm{H}-4, \mathrm{H}-6_{\mathrm{a}}\right), 4.33$ $4.37\left(1 \mathrm{H}, \mathrm{m}, \mathrm{H}-6_{\mathrm{b}}\right), 4.42(1 \mathrm{H}, \mathrm{td}, J=6.4,1.6, \mathrm{H}-5), 4.67(1 \mathrm{H}, \mathrm{dd}, J=2.0$, 6.0, $\mathrm{H}-3), 7.25\left(2 \mathrm{H}, \mathrm{dd}, J=7.6,7.2,2 \times \mathrm{H}_{m}\right), 7.37(1 \mathrm{H}, \mathrm{tt}, J=7.6,1.2$, $\left.\mathrm{H}_{p}\right), 7.91\left(2 \mathrm{H}, \mathrm{d}, J=7.2,2 \times \mathrm{H}_{o}\right) .{ }^{13} \mathrm{C}$ NMR $\left(100 \mathrm{MHz}, \mathrm{CDCl}_{3}\right): 0.0$ ( $\mathrm{Si}(\mathrm{CH} 3) 3), 25.7$ (CH3), 27.1(CH3), 65.0 (C-6), 65.9 (C-1), 83.1 (C-3),

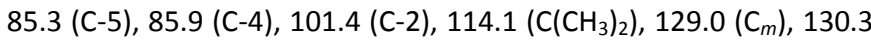
$\left(\mathrm{Ci}_{\text {pso }}\right), 130.4\left(\mathrm{C}_{0}\right), 133.8\left(\mathrm{C}_{p}\right), 166.7(\mathrm{COPh}) . \mathrm{IR}\left(\mathrm{CHCl}_{3}, \mathrm{~cm}^{-1}\right): 2956(\mathrm{w})$, $2114\left(\mathrm{~m}, \mathrm{~N}_{3}\right), 1723$ (s), 1247 (s), 1108 (m, Si-O), 839 (s), 709 (s). HRMS required for $\mathrm{C}_{19} \mathrm{H}_{27} \mathrm{~N}_{3} \mathrm{O}_{6} \mathrm{SiNa}^{+}$is 444.1561 , found 444.1561 .

\section{2-Azido-2-deoxy-3,4-O-isopropylidene-6-O-benzoyl- $\beta$-D- psicofuranose $10^{14}$}

To a solution of silyl ether derivative $9(1.10 \mathrm{~g}, 2.61 \mathrm{mmol})$ in acetone $(8 \mathrm{~mL})$ were added methanol $(10 \mathrm{~mL})$ and glacial acetic acid $(553 \mu \mathrm{L})$. The solution was stirred for $8 \mathrm{~h}$ at room temperature. Then, the reaction mixture was neutralized by triethylamine concentrated under reduced pressure. The resulting residue was partitioned between saturated aq. $\mathrm{NaHCO}_{3}$ and ethyl acetate. The organic layers were washed with brine, dried over $\mathrm{MgSO}_{4}$, filtered and concentrated to dryness under reduced pressure. Purification of the crude product by column chromatography (silica gel, hexane/ ethyl acetate 8/2) gave the pure alcohol 10 (893 mg, 98\% yield) as colourless syrup. Data for 10: $[\alpha]_{\mathrm{D}}{ }^{20}=-97.2\left(\mathrm{c}=0.01, \mathrm{CHCl}_{3}\right) .{ }^{1} \mathrm{H}-\mathrm{NMR}$ $\left(400 \mathrm{MHz}, \mathrm{CDCl}_{3}\right): \delta 1.32(3 \mathrm{H}, \mathrm{s}, \mathrm{CH} 3), 1.51(3 \mathrm{H}, \mathrm{s}, \mathrm{CH} 3), 3.08(1 \mathrm{H}, \mathrm{t}, J$ $=6.4, \mathrm{OH}), 4.00\left(2 \mathrm{H}, \mathrm{d}, J=6.0, \mathrm{H}-\mathrm{1}_{\mathrm{a}, \mathrm{b}}\right), 4.42-4.52\left(1 \mathrm{H}, \mathrm{m}, \mathrm{H}-6_{\mathrm{a}}\right), 4.53-$ $4.56\left(2 \mathrm{H}, \mathrm{m}, \mathrm{H}-3\right.$ and $\left.\mathrm{H}-6_{\mathrm{b}}\right), 4.63(1 \mathrm{H}, \mathrm{td}, J=6.0,1.2, \mathrm{H}-5), 4.87(1 \mathrm{H}$, $\mathrm{dd}, \mathrm{J}=6.0,1.6, \mathrm{H}-4), 7.43\left(2 \mathrm{H}, \mathrm{t}, \mathrm{J}=7.6,2 \times \mathrm{H}_{m}\right), 7.56(1 \mathrm{H}, \mathrm{tt}, \mathrm{J}=7.6$, $\left.1.2, \mathrm{H}_{p}\right), 8.08\left(2 \mathrm{H}, \mathrm{d}, \mathrm{J}=7.2,2 \times \mathrm{H}_{o}\right) .{ }^{13} \mathrm{C}-\mathrm{NMR}\left(100 \mathrm{MHz}, \mathrm{CDCl}_{3}\right): 24.8$ $\left(\mathrm{CH}_{3}\right), 26.1\left(\mathrm{CH}_{3}\right), 64.1(\mathrm{C}-1), 64.3(\mathrm{C}-6), 82.5$ (C-4), 84.6 (C-5), 85.4 (C3), $101.4(\mathrm{C}-2), 113.7\left(\mathrm{C}\left(\mathrm{CH}_{3}\right)_{2}\right), 128.5\left(\mathrm{C}_{m}\right), 129.6\left(\mathrm{C}_{\text {ipso }}\right), 129.7\left(\mathrm{C}_{o}\right)$, 133.3( $\left.\mathrm{C}_{p}\right), 166.2$ (COPh). IR ( $\left.\mathrm{CHCl} 3, \mathrm{~cm}^{-1}\right)$ : 3489 (br), $2956(\mathrm{w}), 2114$ $\left(\mathrm{m}, \mathrm{N}_{3}\right), 1720$ (s), 1270 (s), 709 (s). HRMS required for $\mathrm{C}_{16} \mathrm{H}_{19} \mathrm{~N}_{3} \mathrm{O}_{6} \mathrm{Na}^{+}$ is 372.1166 , found 372.1166 .

\section{6-O-benzyl-3,4-0-isopropylidene-ß-D-psicofuranosyl cyanide $11^{11}$}

Spiroketal 8 (38.0 g, $0.11 \mathrm{~mol})$ was placed in a $1 \mathrm{~L} 3$ neck round bottom flask equipped with a thermometer and pressure equalising dropping funnel and then cooled to $-20^{\circ} \mathrm{C}$ under an inert atmosphere of nitrogen. Trimethylsilyl cyanide $(40.7 \mathrm{~mL}, 0.32 \mathrm{~mol})$ was then added dropwise, followed by trimethylsilyl trifluoromethanesulfonate $(22.9 \mathrm{~mL}, 0.16 \mathrm{~mol})$. The reaction mixture was then stirred for $2 \mathrm{~h}$ at the same temperature $\left(-20^{\circ} \mathrm{C}\right)$. After this time, it was quenched with saturated sodium bicarbonate solution. The mixture was partitioned between saturated aq. $\mathrm{NaHCO}_{3}$ and dichloromethane and the aqueous layer treated with sodium hypochlorite. The combined organic layers were washed with brine, dried over $\mathrm{MgSO}_{4}$, filtered and concentrated to dryness under reduced pressure. Purification of the crude product by column chromatography (silica gel, isohexane/ ethyl acetate 75/25) gave the title compound 11 (20.4 g, 58\% yield) as colourless syrup. Data for 11: Oil. $[\alpha]_{\mathrm{D}}{ }^{20}=-29.0\left(\mathrm{c}=0.01, \mathrm{CHCl}_{3}\right) .{ }^{1} \mathrm{H}-\mathrm{NMR}\left(400 \mathrm{MHz}, \mathrm{CDCl}_{3}\right)$ : $\delta 1.34\left(3 \mathrm{H}, \mathrm{s}, \mathrm{CH}_{3}\right), 1.52\left(3 \mathrm{H}, \mathrm{s}, \mathrm{CH}_{3}\right), 2.61(1 \mathrm{H}, \mathrm{br}, \mathrm{OH}), 3.54-3.65(2 \mathrm{H}$, $\mathrm{m}, 2 \times \mathrm{H}-6), 3.89(2 \mathrm{H}, \mathrm{s}, 2 \times \mathrm{H}-1), 4.42(1 \mathrm{H}, \mathrm{m}, \mathrm{H}-5), 4.50(1 \mathrm{H}, \mathrm{d}, J=12.1$, $\mathrm{H}-7 \mathrm{a}), 4.69(1 \mathrm{H}, \mathrm{d}, J=12.1, \mathrm{H}-7 \mathrm{~b}), 4.90(1 \mathrm{H}, \mathrm{d}, J=5.9, \mathrm{H}-3), 5.09(1 \mathrm{H}$, $\mathrm{d}, J=5.8, \mathrm{H}-4), 7.30-7.36\left(5 \mathrm{H}, \mathrm{m}, 5 \times \mathrm{H}_{\text {arom }}\right) .{ }^{13} \mathrm{C}-\mathrm{NMR}\left(100 \mathrm{MHz}, \mathrm{CDCl}_{3}\right)$ : $24.5\left(\mathrm{CH}_{3}\right), 25.7\left(\mathrm{CH}_{3}\right), 64.9$ (C-1), 70.1 (C-6), 73.5 (C-7), 82.9 (C-2),

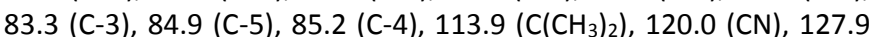
$\left(C_{p}\right), 128.1\left(C_{o}\right), 128.5\left(C_{m}\right), 137.3\left(C_{\text {ipso }}\right) . I R\left(\mathrm{CHCl}_{3}, \mathrm{~cm}^{-1}\right)$ : $3298(\mathrm{br})$, $2940(w), 1714(m), 1453(m), 1360(m)$

\section{((3aR,4R,6R,6aR)-6-azido-2,2-dimethyl-6-((prop-2-yn-1- yloxy)methyl)tetrahydrofuro[3,4-d][1,3]dioxol-4-yl)methyl benzoate $2 a$}

Azido alcohol 10 (500 mg, $1.43 \mathrm{mmol}$ ) was dried by evaporation of freshly distilled acetonitrile and dissolved in the same solvent (8.4 $\mathrm{mL})$. To the resulting solution were added BEMP ( $497 \mu \mathrm{L}, 1.72 \mathrm{mmol}$ ) followed by the suitable propargyl bromide $(2.15 \mathrm{mmol})$ dropwise at $0^{\circ} \mathrm{C}$ under a nitrogen atmosphere. The reaction mixture was stirred at the same conditions until TLC indicated completion of the reaction (2-4h). The resulting solution was partitioned between phosphate buffer solution $\mathrm{pH} 7.00$ and ethyl acetate. The organic layers were washed with $10 \% \mathrm{NaCl}$ aq. solution, dried over $\mathrm{MgSO}_{4}$, filtered and concentrated to dryness under reduced pressure to afford the crude residue as brown oil which in the majority of cases was used crude in the following cycloaddition step owing to spontaneous reactivity and in an effort to maximise overall yield. The characterisation for the purified intermediates is described below.

Chromatography of the crude residue over silica gel (hexane/ethyl acetate $8 / 2$ ) gave the pure $2 \mathrm{a}(299 \mathrm{mg}, 54 \%$ yield). Data for $2 \mathrm{a}$ : Colourless oil, $[\alpha]_{\mathrm{D}}{ }^{20}=-86.5\left(\mathrm{c}=0.02, \mathrm{CHCl}_{3}\right)$. ${ }^{1} \mathrm{H}-\mathrm{NMR}(400 \mathrm{MHz}$, $\left.\mathrm{CDCl}_{3}\right): \delta 1.21\left(3 \mathrm{H}, \mathrm{s}, \mathrm{CH}_{3}\right), 1.49\left(3 \mathrm{H}, \mathrm{s}, \mathrm{CH}_{3}\right), 2.42\left(1 \mathrm{H}, \mathrm{t}, J=2.4, \mathrm{H}-3^{\prime}\right)$, $3.89\left(2 \mathrm{H}, \mathrm{s}, \mathrm{H}-\mathrm{1}_{\mathrm{a}, \mathrm{b}}\right), 4.25\left(2 \mathrm{H}, \mathrm{d}, J=2.0, \mathrm{H}-\mathrm{1}_{\mathrm{a}, \mathrm{b}}{ }^{\prime}\right), 4.33-4.49(3 \mathrm{H}, \mathrm{m}, \mathrm{H}-$ $\left.3, \mathrm{H}-6_{\mathrm{a}, \mathrm{b}}\right), 4.54(1 \mathrm{H}, \mathrm{td}, J=6.4,1.6, \mathrm{H}-5), 4.80(1 \mathrm{H}, \mathrm{dd}, J=6.4,1.6, \mathrm{H}-$ 4), $7.39\left(2 \mathrm{H}, \mathrm{t}, J=8.0,2 \times \mathrm{H}_{m}\right), 7.51\left(1 \mathrm{H}, \mathrm{t}, J=7.2, \mathrm{H}_{p}\right), 8.02(2 \mathrm{H}, \mathrm{d}, J=$ 7.6, $\left.2 \times \mathrm{H}_{0}\right) .{ }^{13} \mathrm{C}-\mathrm{NMR}(100 \mathrm{MHz}, \mathrm{CDCl}): 25.1\left(\mathrm{CH}_{3}\right), 26.5\left(\mathrm{CH}_{3}\right), 59.1$ (C1'), 64.2 (C-6), 70.4 (C-1), 75.2 (C-3'), 79.3 (C-2'), 82.5 (C-4), 85.0 (C5), $85.5(\mathrm{C}-3), 100.7(\mathrm{C}-2), 114.0\left(\mathrm{C}\left(\mathrm{CH}_{3}\right)_{2}\right), 128.5\left(\mathrm{C}_{m}\right), 129.7\left(\mathrm{C}_{\text {ipso }}\right)$, $129.8\left(\mathrm{C}_{o}\right), 133.4\left(\mathrm{C}_{p}\right), 166.3$ (COPh). IR $\left(\mathrm{CHCl}_{3}, \mathrm{~cm}^{-1}\right)$ : $3292(\mathrm{w}), 2927$ $(\mathrm{w}), 2116\left(\mathrm{~m}, \mathrm{~N}_{3}\right), 1721(\mathrm{~s}), 1270(\mathrm{~s}), 1270(\mathrm{~s}), 1068(\mathrm{~m}), 711$ (s). HRMS required for $\mathrm{C}_{19} \mathrm{H}_{22} \mathrm{~N}_{3} \mathrm{O}_{6}{ }^{+}$is 388.1503 , found 388.1505 . 


\section{2-Azido-2-deoxy-3,4-O-isopropylidene- $\beta$-D-psicofuranose 12}

To a solution of compound $\mathbf{1 0}(75 \mathrm{mg}, 0.21 \mathrm{mmol})$ in freshly distilled THF (1.5 mL), a solution of NaHDMS (47 mg, $0.26 \mathrm{mmol}$ ) was added dropwise at $0{ }^{\circ} \mathrm{C}$ under nitrogen atmosphere. After $5 \mathrm{~min}$, propargyl bromide ( $36 \mu \mathrm{L}, 0.32 \mathrm{mmol}$ ) was added and the reaction mixture was stirred for $4 \mathrm{~h}$. Afterwards, saturated aq. $\mathrm{NH}_{4} \mathrm{Cl}$ was added and the resulting emulsion was extracted with ethyl acetate and washed with brine. The organic layers were dried over $\mathrm{MgSO}_{4}$, filtered and the solvent evaporated under reduced pressure. Chromatography of the crude residue over silica gel gave azidoalkyne $\mathbf{2 a}$ (hexane/ethyl acetate $8 / 2$ ) as the minor product $(9 \mathrm{mg}, 11 \%$ yield) and debenzoylated psicofuranose $\mathbf{1 2}$ (hexane/ethyl acetate 6/4) as major product (36 mg, 70\% yield). Data for 12 : Colourless syrup, ${ }^{1} \mathrm{H}-\mathrm{NMR}$ $\left(400 \mathrm{MHz}, \mathrm{CDCl}_{3}\right): \delta 1.27\left(3 \mathrm{H}, \mathrm{s}, \mathrm{CH}_{3}\right), 1.46\left(3 \mathrm{H}, \mathrm{s}, \mathrm{CH}_{3}\right), 2.27(2 \mathrm{H}, \mathrm{br}$, $2 \times \mathrm{OH}), 3.65-3.74\left(2 \mathrm{H}, \mathrm{m}, \mathrm{H}-6_{\mathrm{a}, \mathrm{b}}\right), 3.91\left(2 \mathrm{H}, \mathrm{s}, \mathrm{H}-\mathrm{1}_{\mathrm{a}, \mathrm{b}}\right), 4.33(1 \mathrm{H}, \mathrm{td}, J=$ $6.0,1.6, \mathrm{H}-5), 4.46(1 \mathrm{H}, \mathrm{d}, J=6.0, \mathrm{H}-3), 4.75(1 \mathrm{H}, \mathrm{dd}, J=6.0,1.6, \mathrm{H}-$ 4). ${ }^{13} \mathrm{C}-\mathrm{NMR}\left(100 \mathrm{MHz}, \mathrm{CDCl}_{3}\right): 23.4\left(\mathrm{CH}_{3}\right), 25.2\left(\mathrm{CH}_{3}\right), 62.4(\mathrm{C}-6), 63.4$ (C-1), 81.1 (C-4), 84.7 (C-3), 86.6 (C-5), 100.3 (C-2), $112.6\left(\mathrm{C}\left(\mathrm{CH}_{3}\right)_{2}\right)$.

\section{General Procedure for Sonogashira Coupling}

To a stirring suspension of aryl iodide $(4.2 \mathrm{mmol})$, dichlorobis(triphenylphosphine)palladium(II) (30 mg, $0.042 \mathrm{mmol}$ ), copper(I) iodide $(4 \mathrm{mg}, 0.021 \mathrm{mmol})$ and freshly distilled diethylamine $(50 \mathrm{~mL})$ was added propargyl alcohol $(4.2 \mathrm{mmol})$ dropwise under a $\mathrm{N}_{2}$ atmosphere.

The resulting reaction mixture was stirred for $5 \mathrm{~h}$ at room temperature. After this time, diethylamine was removed under reduced pressure and the crude product was partitioned between water and diethyl ether. The combined organic layers were washed with brine, dried $\left(\mathrm{MgSO}_{4}\right)$, filtered and concentrated under reduced pressure.

\section{General procedure for 0 -alkylation and intramolecular 1,3-dipolar cycloaddition $^{14}$}

Azido alcohol 10 ( $500 \mathrm{mg}, 1.43 \mathrm{mmol}$ ) was dried by evaporation of freshly distilled acetonitrile and dissolved in the same solvent (8.4 $\mathrm{mL})$. To the resulting solution BEMP $(497 \mu \mathrm{L}, 1.72 \mathrm{mmol})$ and the suitable propargyl bromide $(2.15 \mathrm{mmol})$ were added drop-wise at 0 ${ }^{\circ} \mathrm{C}$ under a nitrogen atmosphere. The reaction mixture was stirred under these conditions until TLC indicated completion of the reaction (2-4 h). The resulting solution was partitioned between phosphate buffer solution $\mathrm{pH} 7$ and ethyl acetate. The organic layers were washed with $10 \% \mathrm{NaCl}$ aq. solution, dried over $\mathrm{MgSO}_{4}$, filtered, and concentrated under reduced pressure to afford the crude residue as brown oil which in the majority of cases was used as telescoped material in the following cycloaddition step owing to spontaneous reactivity and in an effort to maximise overall yield. Thus, the crude azido alkyne 2a-k was dissolved in toluene $(28.6 \mathrm{~mL})$ and refluxed until TLC analysis showed full conversion to corresponding triazolooxazine 16a-k (16-24 h). The solvent was removed under reduced pressure and the residue was purified on silica gel.

((3aR,4R,6R,6aR)-2,2-dimethyl-3a,6a-dihydro-4' $H, 6 H, 6^{\prime} H$ spiro[furo[3,4-d][1,3]dioxole-4,7'-[1,2,3]triazolo[5,1-c][1,4]oxazin]6 -yl)methyl benzoate $16 a$
Chromatography of the crude residue over silica gel (hexane/ethyl acetate $6 / 4$ ) gave the pure triazolooxazine $16 \mathrm{a}$ ( $282 \mathrm{mg}, 95 \%$ yield). Data for 16a: Colourless oil, $[\alpha]_{\mathrm{D}}{ }^{20}=-11.87\left(\mathrm{c}=0.0016, \mathrm{CHCl}_{3}\right) .{ }^{1} \mathrm{H}-$ $\operatorname{NMR}\left(400 \mathrm{MHz}, \mathrm{CDCl}_{3}\right): \delta 1.37\left(3 \mathrm{H}, \mathrm{s}, \mathrm{CH}_{3}\right), 1.60\left(3 \mathrm{H}, \mathrm{s}, \mathrm{CH}_{3}\right), 4.19(1 \mathrm{H}$, $\left.\mathrm{d}, J=8.0, \mathrm{H}-\mathrm{1}_{\mathrm{a}}\right), 4.23\left(1 \mathrm{H}, \mathrm{d}, J=8.2, \mathrm{H}-\mathrm{1}_{\mathrm{b}}\right), 4.55-4.69(3 \mathrm{H}, \mathrm{m}, \mathrm{H}-5, \mathrm{H}-$ $\left.6_{a, b}\right), 4.83\left(1 \mathrm{H}, \mathrm{d}, J=15.2, \mathrm{H}-1^{\prime}{ }_{\mathrm{a}}\right), 5.04\left(1 \mathrm{H}, \mathrm{d}, J=15.2, \mathrm{H}-1^{\prime}{ }_{\mathrm{b}}\right), 5.16(1 \mathrm{H}$, $\mathrm{d}, J=6.0, \mathrm{H}-3), 5.30-5.31(1 \mathrm{H}, \mathrm{m}, \mathrm{H}-4), 7.43\left(2 \mathrm{H}, \mathrm{td}, J=7.8,1.6,2 \times \mathrm{H}_{m}\right)$, $7.52\left(1 \mathrm{H}, \mathrm{s}, \mathrm{H}-3^{\prime}\right), 7.55\left(1 \mathrm{H}, \mathrm{tt}, J=7.3,1.2, \mathrm{H}_{p}\right), 8.06(2 \mathrm{H}, \mathrm{dd}, J=8.0$, 1.6, $\left.2 \times \mathrm{H}_{0}\right) .{ }^{13} \mathrm{C}-\mathrm{NMR}\left(100 \mathrm{MHz}, \mathrm{CDCl}_{3}\right): 25.3\left(\mathrm{CH}_{3}\right), 26.8\left(\mathrm{CH}_{3}\right), 62.5(\mathrm{C}-$ 1'), 64.5 (C-6), 69.1 (C-1), 83.2 (C-4), 85.2 (C-3), 86.3 (C-5), 93.1 (C-2),

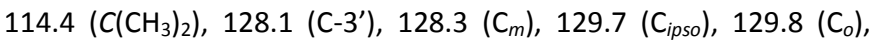
131.4 (C-2'), $133.1\left(\mathrm{C}_{p}\right), 166.1$ (COPh). IR $\left(\mathrm{CHCl}_{3}, \mathrm{Cm}^{-1}\right): 2923$ (w), 1721 $(\mathrm{s}), 1269(\mathrm{~s}), 1094(\mathrm{~s}), 1068(\mathrm{~m}), 713$ (s). HRMS required for $\mathrm{C}_{19} \mathrm{H}_{22} \mathrm{~N}_{3} \mathrm{O}_{6}{ }^{+}$is 388.1503 , found 388.1506 .

( (3aR,4R,6R,6aR)-2,2,3'-trimethyl-3a,6a-dihydro-4' $H, 6 H, 6^{\prime} H$ spiro[furo[3,4-d][1,3]dioxole-4,7'-[1,2,3]triazolo[5,1-c][1,4]oxazin]6-yl)methyl benzoate 16b

Chromatography of the crude residue over silica gel (hexane/ethyl acetate 6/4) gave the pure triazolooxazine $\mathbf{1 6 b}$ (304 mg, 96\% yield). Data for 16b: Colourless oil, $[\alpha]_{\mathrm{D}}{ }^{20}=-24.82\left(\mathrm{c}=0.01, \mathrm{CHCl}_{3}\right) .{ }^{1} \mathrm{H}-\mathrm{NMR}$ (400 MHz, $\left.\mathrm{CDCl}_{3}\right): \delta 1.38\left(3 \mathrm{H}, \mathrm{s}, \mathrm{CH}_{3}\right), 1.59\left(3 \mathrm{H}, \mathrm{s}, \mathrm{CH}_{3}\right), 2.27(3 \mathrm{H}, \mathrm{s}$, $\left.3 \times \mathrm{H}-4^{\prime}\right), 4.15\left(1 \mathrm{H}, \mathrm{d}, J=12.8, \mathrm{H}-1_{\mathrm{a}}\right), 4.22\left(1 \mathrm{H}, \mathrm{d}, J=12.4, \mathrm{H}-1_{\mathrm{b}}\right), 4.53-$ $4.67\left(3 \mathrm{H}, \mathrm{m}, \mathrm{H}-5, \mathrm{H}-6_{\mathrm{a}, \mathrm{b}}\right), 4.73\left(1 \mathrm{H}, \mathrm{d}, J=14.8, \mathrm{H}-1^{\prime}{ }_{\mathrm{a}}\right), 4.95(1 \mathrm{H}, \mathrm{d}, J=$ 14.8, H-1 ${ }^{\prime}$ b), $5.15(1 \mathrm{H}, \mathrm{d}, J=6.0, \mathrm{H}-3), 5.28(1 \mathrm{H}, \mathrm{dd}, J=6.0,2.8, \mathrm{H}-4)$, $7.43\left(2 \mathrm{H}, \mathrm{t}, J=7.2,2 \times \mathrm{H}_{m}\right), 7.55\left(1 \mathrm{H}, \mathrm{t}, J=7.6, \mathrm{H}_{p}\right), 8.06(2 \mathrm{H}, \mathrm{d}, J=7.8$, $\left.2 \times \mathrm{H}_{0}\right) \cdot{ }^{13} \mathrm{C}-\mathrm{NMR}\left(100 \mathrm{MHz}, \mathrm{CDCl}_{3}\right): 10.0\left(\mathrm{C}-4^{\prime}\right), 25.3\left(\mathrm{CH}_{3}\right), 26.8\left(\mathrm{CH}_{3}\right)$, 62.3 (C-1'), 64.6 (C-6), 68.9 (C-1), 83.2 (C-4), 85.1 (C-5), 86.1 (C-6), $93.0(\mathrm{C}-2), 114.4\left(\mathrm{C}\left(\mathrm{CH}_{3}\right)_{2}\right), 127.8\left(\mathrm{C}-3^{\prime}\right), 128.7\left(\mathrm{C}_{m}\right), 129.8\left(\mathrm{C}_{\text {ipso }}\right)$, $129.9\left(\mathrm{C}_{o}\right), 133.0\left(\mathrm{C}_{p}\right), 137.0\left(\mathrm{C}-2^{\prime}\right), 166.1(\mathrm{COPh}) . \mathrm{IR}\left(\mathrm{CHCl}_{3}, \mathrm{~cm}^{-1}\right)$ : 2989 (w), 1719 (s), 1269 (s), 1096 (s), 1068 (m), 709 (s). HRMS required for $\mathrm{C}_{20} \mathrm{H}_{24} \mathrm{~N}_{3} \mathrm{O}_{6}{ }^{+}$is 402.1660 , found 402.1658 .

((3aR,4R,6R,6aR)-3'-ethyl-2,2-dimethyl-3a,6a-dihydro-4' $H, 6 H, 6^{\prime} H$ spiro[furo[3,4-d][1,3]dioxole-4,7'-[1,2,3]triazolo[5,1-c][1,4]oxazin]6-yl)methyl benzoate 16c

Chromatography of the crude residue over silica gel (hexane/ethyl acetate $6 / 4)$ gave the pure triazolooxazine $79 \mathrm{c}(255 \mathrm{mg}, 82 \%$ yield). Data for 79c: Colourless oil, $[\alpha]_{\mathrm{Y}}{ }^{20}=-27.26\left(\mathrm{c}=0.015, \mathrm{CHCl}_{3}\right) .{ }^{1} \mathrm{H}-\mathrm{NMR}$ $\left(400 \mathrm{MHz}, \mathrm{CDCl}_{3}\right): \delta 1.26\left(3 \mathrm{H}, \mathrm{t}, J=7.6,3 \times \mathrm{H}-5^{\prime}\right), 1.38\left(3 \mathrm{H}, \mathrm{s}, \mathrm{CH}_{3}\right), 1.59$ $\left(3 \mathrm{H}, \mathrm{s}, \mathrm{CH}_{3}\right), 2.67\left(2 \mathrm{H}, \mathrm{q}, J=7.6,2 \times \mathrm{H}-4^{\prime}\right), 4.17\left(1 \mathrm{H}, \mathrm{d}, J=12.8, \mathrm{H}-1_{\mathrm{a}}\right)$, $4.22\left(1 \mathrm{H}, \mathrm{d}, \mathrm{J}=12.8, \mathrm{H}-\mathrm{1}_{\mathrm{b}}\right)$, 4.54-4.67 (3H, m, H-5, H-6, $\left.\mathrm{a}_{\mathrm{b}}\right), 4.76(1 \mathrm{H}, \mathrm{d}$, $\left.J=14.8, \mathrm{H}-1^{\prime}{ }_{\mathrm{a}}\right), 4.97\left(1 \mathrm{H}, \mathrm{d}, J=14.8, \mathrm{H}-1^{\prime}{ }_{\mathrm{b}}\right), 5.15(1 \mathrm{H}, \mathrm{d}, J=6.0, \mathrm{H}-3)$, $5.29(1 \mathrm{H}, \mathrm{dd}, J=5.6,2.8, \mathrm{H}-4), 7.43\left(2 \mathrm{H}, \mathrm{t}, J=7.6,2 \times \mathrm{H}_{m}\right), 7.55(1 \mathrm{H}, \mathrm{t}, J$ $\left.=7.2, \mathrm{H}_{p}\right), 8.05\left(2 \mathrm{H}, \mathrm{d}, J=7.8,2 \times \mathrm{H}_{o}\right) .{ }^{13} \mathrm{C}-\mathrm{NMR}\left(100 \mathrm{MHz}, \mathrm{CDCl}_{3}\right): 13.2$ (C-5'), $18.5\left(\mathrm{C}-4^{\prime}\right), 25.3\left(\mathrm{CH}_{3}\right), 26.8\left(\mathrm{CH}_{3}\right), 62.4\left(\mathrm{C}-1^{\prime}\right), 64.6$ (C-6), 68.9 (C-1), 83.3 (C-4), 85.1 (C-5), 86.1 (C-6), 93.1 (C-2), $\left.114.3\left(\mathrm{C}_{(\mathrm{CH}}\right)_{2}\right)$, $127.3\left(\mathrm{C}-3^{\prime}\right), 128.3\left(\mathrm{C}_{m}\right), 129.8\left(\mathrm{C}_{\text {ipso }}\right), 129.8\left(\mathrm{C}_{0}\right), 133.1\left(\mathrm{C}_{p}\right), 142.8(\mathrm{C}-$ $\left.2^{\prime}\right), 166.1$ (COPh). IR ( $\left.\mathrm{CHCl}_{3}, \mathrm{~cm}^{-1}\right): 2978$ (w), 1720 (s), 1271 (s), 1098 (s), $1069(\mathrm{~m}), 712$ (s). HRMS required for $\mathrm{C}_{21} \mathrm{H}_{26} \mathrm{~N}_{3} \mathrm{O}_{6}{ }^{+}$is 416.1803, found 416.1809 .

((3aR,4R,6R,6aR)-2,2-dimethyl-3'-(naphthalen-2-yl)-3a,6a-dihydro4'H,6H,6' $H$-spiro[furo[3,4-d][1,3]dioxole-4,7'-[1,2,3]triazolo[5,1c][1,4]oxazin]-6-yl)methyl benzoate $16 \mathrm{~d}$ 
Chromatography of the crude residue over silica gel (hexane/ethy acetate $8 / 2$ ) gave the pure triazolooxazine $16 \mathrm{~d}$ ( $433 \mathrm{mg}, 94 \%$ yield) Data for 16d: Colourless oil, $[\alpha]_{D}{ }^{20}=-36.46\left(\mathrm{c}=0.015, \mathrm{CHCl}_{3}\right) .{ }^{1} \mathrm{H}-\mathrm{NMR}$ $\left(400 \mathrm{MHz}, \mathrm{CDCl}_{3}\right): 1.42\left(3 \mathrm{H}, \mathrm{s}, \mathrm{CH}_{3}\right), 1.63\left(3 \mathrm{H}, \mathrm{s}, \mathrm{CH}_{3}\right), 4.29(1 \mathrm{H}, \mathrm{d}, J=$ $\left.12.8, \mathrm{H}-\mathrm{1}_{\mathrm{a}}\right), 4.34\left(1 \mathrm{H}, \mathrm{d}, \mathrm{J}=12.4, \mathrm{H}-\mathrm{1}_{\mathrm{b}}\right), 4.70-4.77\left(3 \mathrm{H}, \mathrm{m}, \mathrm{H}-5, \mathrm{H}-\mathrm{6}_{\mathrm{a}, \mathrm{b}}\right)$, $4.81\left(1 \mathrm{H}, \mathrm{d}, J=15.2, \mathrm{H}-1^{\prime}{ }_{\mathrm{a}}\right), 4.97\left(1 \mathrm{H}, \mathrm{d}, J=15.2, \mathrm{H}-1^{\prime}{ }_{\mathrm{b}}\right), 5.29(1 \mathrm{H}, \mathrm{d}, J$ $=6.0, \mathrm{H}-3), 5.39(1 \mathrm{H}, \mathrm{dd}, J=5.6,2.4, \mathrm{H}-4), 7.40-7.46(3 \mathrm{H}, \mathrm{m}, \mathrm{H}-\mathrm{Naph}$, $\left.2 \times \mathrm{H}_{m}\right), 7.47-7.55\left(4 \mathrm{H}, \mathrm{m}, 3 \times \mathrm{H}-\mathrm{Naph}, \mathrm{H}_{p}\right), 7.89-7.91(2 \mathrm{H}, \mathrm{m}, 2 \times \mathrm{H}-$ $\mathrm{Naph}$ ), 8.09-8.015 (3H, m, H-Naph, $\left.2 \times \mathrm{H}_{0}\right) .{ }^{13} \mathrm{C}-\mathrm{NMR}\left(100 \mathrm{MHz}, \mathrm{CDCl}_{3}\right)$ : $25.4\left(\mathrm{CH}_{3}\right), 26.9\left(\mathrm{CH}_{3}\right), 63.2\left(\mathrm{C}-1^{\prime}\right), 64.6(\mathrm{C}-6), 69.1(\mathrm{C}-1), 83.2(\mathrm{C}-4)$, 85.3 (C-5), 86.3 (C-6), 93.5 (C-2), $114.5\left(\mathrm{C}\left(\mathrm{CH}_{3}\right)_{2}\right), 125.2,125.5,126.3$, 126.6 (Naph), 127.4 (C-3'), $128.4\left(C_{m}\right), 128.5,129.3$ (Naph), 129.7 $\left(C_{\text {ipso }}\right), 129.8\left(C_{o}\right), 129.9$ (Naph), $131.4\left(\mathrm{C}-2^{\prime}\right), 133.1\left(C_{p}\right), 133.9$ (Naph), 141.0 (C ipso -Naph), 166.2 (COPh). IR ( $\left.\mathrm{CHCl}_{3}, \mathrm{~cm}^{-1}\right): 2990$ (w), 1719 (s) 1271 (s), 1097 (s), 1069 (s), 1025 (m), 751 (s), 710 (s). HRMS required for $\mathrm{C}_{29} \mathrm{H}_{28} \mathrm{~N}_{3} \mathrm{O}_{6}{ }^{+}$is 514.1973, found 514.1970.

((3aR,4R,6R,6aR)-2,2-dimethyl-3'-phenyl-3a,6a-dihydro4' $H, 6 H, 6^{\prime} H$-spiro[furo[3,4-d][1,3]dioxole-4,7'-[1,2,3]triazolo[5,1c] $[1,4]$ oxazin]-6-yl)methyl benzoate $16 \mathrm{e}$

Chromatography of the crude residue over silica gel (hexane/ethyl acetate $8 / 2$ ) gave the pure triazolooxazine 16 e $(291 \mathrm{mg}, 44 \%$ yield over two steps) as a white solid. Data for $16 \mathrm{e}: \mathrm{Mp}=72-73^{\circ} \mathrm{C} .[\alpha]_{\mathrm{D}}{ }^{20}=$ - 31.6 (c= 0.01, $\mathrm{CHCl}_{3}$ ). ${ }^{1} \mathrm{H}-\mathrm{NMR}\left(400 \mathrm{MHz}, \mathrm{CDCl}_{3}\right): 1.40\left(3 \mathrm{H}, \mathrm{s}, \mathrm{CH}_{3}\right)$, $1.61\left(3 \mathrm{H}, \mathrm{s}, \mathrm{CH}_{3}\right), 4.25\left(1 \mathrm{H}, \mathrm{d}, J=12.8, \mathrm{H}-1_{\mathrm{a}}\right), 4.29(1 \mathrm{H}, \mathrm{d}, J=12.8, \mathrm{H}-$ 1b), 4.58-4.72 (3H, m, H-5, H-6, $\left.6_{a, b}\right), 5.01\left(1 \mathrm{H}, \mathrm{d}, J=15.2, \mathrm{H}-1^{\prime}{ }_{\mathrm{a}}\right), 5.21$ $\left(1 \mathrm{H}, \mathrm{d}, J=15.2, \mathrm{H}-1^{\prime}{ }_{\mathrm{b}}\right), 5.21(1 \mathrm{H}, \mathrm{d}, J=6.0, \mathrm{H}-3), 5.33(1 \mathrm{H}, \mathrm{dd}, J=5.8$ $2.8, \mathrm{H}-4), 7.35\left(1 \mathrm{H}, \mathrm{t}, J=7.2, \mathrm{H}-7^{\prime}\right), 7.40-7.47\left(4 \mathrm{H}, \mathrm{m}, 2 \times \mathrm{H}-6^{\prime}, 2 \times \mathrm{H}_{m}\right)$, $7.55\left(1 \mathrm{H}, \mathrm{t}, J=7.2, \mathrm{H}_{p}\right), 7.62\left(2 \mathrm{H}, \mathrm{d}, J=7.6,2 \times \mathrm{H}-5^{\prime}\right), 8.06(2 \mathrm{H}, \mathrm{d}, J=$ 7.2, $\left.2 \times \mathrm{H}_{0}\right) \cdot{ }^{13} \mathrm{C}$-NMR $\left(100 \mathrm{MHz}, \mathrm{CDCl}_{3}\right): 25.3\left(\mathrm{CH}_{3}\right), 26.8\left(\mathrm{CH}_{3}\right), 63.4(\mathrm{C}-$ 1'), 64.6 (C-6), 68.8 (C-1), 83.3 (C-4), 85.2 (C-3), 86.3 (C-5), 93.3 (C-2) $114.4\left(\mathrm{C}^{(}\left(\mathrm{CH}_{3}\right)_{2}\right), 126.2\left(\mathrm{C}-5^{\prime}\right), 127.2\left(\mathrm{C}-2^{\prime}\right), 128.2\left(\mathrm{C}-7^{\prime}\right), 128.4\left(\mathrm{C}_{m}\right)$ $129.0\left(\mathrm{c}-6^{\prime}\right), 129.8\left(\mathrm{C}_{\text {ipso }}\right), 129.9\left(\mathrm{C}_{o}\right), 130.3\left(\mathrm{C}-4^{\prime}\right), 133.1\left(\mathrm{C}_{p}\right), 141.4$ (C$\left.3^{\prime}\right), 166.2$ (COPh). IR ( $\left.\mathrm{CHCl}_{3}, \mathrm{~cm}^{-1}\right): 2924$ (w), 2358 (s), 1719 (s), 1270 (s), 1097 (s), 1069 (s),1025 (m), 749 (s), 709 (s). HRMS required for $\mathrm{C}_{25} \mathrm{H}_{26} \mathrm{~N}_{3} \mathrm{O}_{6}{ }^{+}$is 464.1816 , found 464.1813 .

((3aR,4R,6R,6aR)-3'-(4-chlorophenyl)-2,2-dimethyl-3a,6a-dihydro$4^{\prime} H, 6 H, 6^{\prime} H$-spiro[furo[3,4-d][1,3]dioxole-4,7'-[1,2,3]triazolo[5,1-

\section{c][1,4]oxazin]-6-yl)methyl benzoate $16 f$}

Chromatography of the crude residue over silica gel (hexane/ethy acetate $8 / 2$ ) gave the pure triazolooxazine $16 f(320 \mathrm{mg}, 45 \%$ yield over two steps ) as white solid. Data for $16 f: \mathrm{Mp}=74-75^{\circ} \mathrm{C} .[\alpha]_{\mathrm{D}}{ }^{20}=-$ 28.7 ( $\left.\mathrm{c}=0.01, \mathrm{CHCl}_{3}\right) .{ }^{1} \mathrm{H}-\mathrm{NMR}\left(400 \mathrm{MHz}, \mathrm{CDCl}_{3}\right): 1.39\left(3 \mathrm{H}, \mathrm{s}, \mathrm{CH}_{3}\right)$, $1.61\left(3 \mathrm{H}, \mathrm{s}, \mathrm{CH}_{3}\right), 4.25\left(1 \mathrm{H}, \mathrm{d}, J=12.8, \mathrm{H}-1_{\mathrm{a}}\right), 4.29(1 \mathrm{H}, \mathrm{d}, J=12.8, \mathrm{H}-$ $\left.1_{b}\right), 4.57-4.72\left(3 \mathrm{H}, \mathrm{m}, \mathrm{H}-5, \mathrm{H}-\mathrm{6}_{\mathrm{a}, \mathrm{b}}\right), 4.99\left(1 \mathrm{H}, \mathrm{d}, J=15.2, \mathrm{H}-\mathrm{1}_{\mathrm{a}}{ }_{\mathrm{a}}\right), 5.19$ $\left(1 \mathrm{H}, \mathrm{d}, J=15.2, \mathrm{H}-1^{\prime}{ }_{\mathrm{b}}\right), 5.21(1 \mathrm{H}, \mathrm{d}, J=6.0, \mathrm{H}-3), 5.32(1 \mathrm{H}, \mathrm{dd}, J=6.0$, 2.8, H-4), 7.41-7.45 (4H, m, $\left.2 \times \mathrm{H}-6^{\prime}, 2 \times \mathrm{H}_{m}\right),\left(2 \mathrm{H}, \mathrm{d}, J=7.2,2 \times \mathrm{H}-5^{\prime}\right)$, $8.06\left(2 \mathrm{H}, \mathrm{d}, J=7.2,2 \times \mathrm{H}_{0}\right) .{ }^{13} \mathrm{C}-\mathrm{NMR}\left(100 \mathrm{MHz}, \mathrm{CDCl}_{3}\right): 25.3\left(\mathrm{CH}_{3}\right), 26.8$ $\left(\mathrm{CH}_{3}\right), 63.3$ (C-1'), 64.6 (C-6), 68.8 (C-1), 83.2 (C-4), 85.2 (C-3), 86.3 (C-

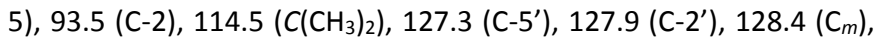
128.9 (C-4'), 129.3 (C-6'), $129.8\left(C_{\text {ipso }}\right), 129.9\left(C_{o}\right), 133.1\left(C_{p}\right), 134.0$ (C$\left.3^{\prime}\right), 166.1$ (COPh). IR ( $\left.\mathrm{CHCl}_{3}, \mathrm{~cm}^{-1}\right)$ : $2988(\mathrm{w}), 1718$ (s), 1491 (m), 1271 (s), 1090 (s), 1069 (s), 1025 (m), 1001 (s), 752 (s), 711(s). HRMS required for $\mathrm{C}_{25} \mathrm{H}_{25} \mathrm{~N}_{3} \mathrm{O}_{6} \mathrm{Cl}^{+}$is 498.1432 , found 498.1426 .
((3aR,4R,6R,6aR)-3'-(4-methoxyphenyl)-2,2-dimethyl-3a,6adihydro-4' $H, 6 H, 6$ 'H-spiro[furo[3,4-d][1,3]dioxole-4,7'$[1,2,3]$ triazolo[5,1-c][1,4]oxazin]-6-yl)methyl benzoate $16 \mathrm{~g}$ Chromatography of the crude residue over silica gel (hexane/ethyl acetate $7 / 3$ ) gave the pure triazolooxazine $16 \mathrm{~g}$ (303 $\mathrm{mg}, 43 \%$ yield over two steps) as white solid. Data for $16 \mathrm{~g}: \mathrm{Mp}=128-129^{\circ} \mathrm{C}$. $[\alpha]_{\mathrm{D}}{ }^{20}=$ - 32.6 ( $\left.\mathrm{c}=0.01, \mathrm{CHCl}_{3}\right) .{ }^{1} \mathrm{H}-\mathrm{NMR}\left(400 \mathrm{MHz}, \mathrm{CDCl}_{3}\right): 1.39\left(3 \mathrm{H}, \mathrm{s}, \mathrm{CH}_{3}\right)$, $1.60\left(3 \mathrm{H}, \mathrm{s}, \mathrm{CH}_{3}\right), 3.84\left(3 \mathrm{H}, \mathrm{s}, \mathrm{OCH}_{3}\right), 4.23\left(1 \mathrm{H}, \mathrm{d}, J=12.4, \mathrm{H}-1_{\mathrm{a}}\right), 4.28$ $\left(1 \mathrm{H}, \mathrm{d}, J=12.8, \mathrm{H}-\mathrm{1}_{\mathrm{b}}\right), 4.58-4.71\left(3 \mathrm{H}, \mathrm{m}, \mathrm{H}-5, \mathrm{H}-\mathrm{G}_{\mathrm{a}, \mathrm{b}}\right), 4.97(1 \mathrm{H}, \mathrm{d}, J=$ 14.8, H-1 ${ }^{\prime}$ a), $5.17\left(1 \mathrm{H}, \mathrm{d}, J=15.2, \mathrm{H}-1^{\prime}{ }_{\mathrm{b}}\right), 5.20(1 \mathrm{H}, \mathrm{d}, J=6.4, \mathrm{H}-3), 5.32$ $(1 \mathrm{H}, \mathrm{dd}, J=5.8,2.8, \mathrm{H}-4), 6.98\left(2 \mathrm{H}, \mathrm{d}, J=8.8,2 \times \mathrm{H}-6^{\prime}\right) 7.42(2 \mathrm{H}, \mathrm{t}, J=$ 7.6, $\left.2 \times \mathrm{H}_{m}\right), 7.52-7.56\left(1 \mathrm{H}, \mathrm{m}, \mathrm{H}_{p}\right), 7.52\left(2 \mathrm{H}, \mathrm{d}, J=8.8,2 \times \mathrm{H}-5^{\prime}\right), 8.06$ $\left(2 \mathrm{H}, \mathrm{d}, J=7.2,2 \times \mathrm{H}_{0}\right) .{ }^{13} \mathrm{C}-\mathrm{NMR}\left(100 \mathrm{MHz}, \mathrm{CDCl}_{3}\right): 25.3\left(\mathrm{CH}_{3}\right), 26.8$ $\left(\mathrm{CH}_{3}\right), 55.3\left(\mathrm{OCH}_{3}\right), 63.4\left(\mathrm{C}-1^{\prime}\right), 64.7$ (C-6), $68.8(\mathrm{C}-1), 83.3(\mathrm{C}-4), 85.2$

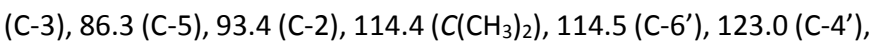
126.8 (C-2'), 127.5 (C-5'), $128.3\left(C_{m}\right), 129.8\left(C_{\text {ipso }}\right), 129.9\left(C_{o}\right), 133.1$ $\left(C_{p}\right), 141.2$ (C-3'), 160.0 (C-7'), 166.1 (COPh). IR ( $\left.\mathrm{CHCl}_{3}, \mathrm{~cm}^{-1}\right): 2938$ (w), 1720 (s), 1507 (s), 1271 (s), 1248 (s), 1098 (s), 1069 (s), 1025 (m), 753 (s), 711(s). HRMS required for $\mathrm{C}_{26} \mathrm{H}_{28} \mathrm{~N}_{3} \mathrm{O}_{7}+$ is 494.1922 , found 494.1922.

((3aR,4R,6R,6aR)-3'-(4-fluorophenyl)-2,2-dimethyl-3a,6a-dihydro4' $H, 6 H, 6$ ' $H$-spiro[furo[3,4-d][1,3]dioxole-4,7'-[1,2,3]triazolo[5,1$c][1,4]$ oxazin]-6-yl)methyl benzoate $16 \mathrm{~h}$

Chromatography of the crude residue over silica gel (hexane/ethyl acetate $8 / 2$ ) gave the pure triazolooxazine $16 \mathrm{~h}(296 \mathrm{mg}, 43 \%$ yield over two steps $d$ ) as colourless oil. Data for $16 \mathrm{~h}:[\alpha]_{D}{ }^{20}=-32.6$ (c= $\left.0.01, \mathrm{CHCl}_{3}\right) .{ }^{1} \mathrm{H}-\mathrm{NMR}\left(400 \mathrm{MHz}, \mathrm{CDCl}_{3}\right): 1.39\left(3 \mathrm{H}, \mathrm{s}, \mathrm{CH}_{3}\right), 1.61(3 \mathrm{H}, \mathrm{s}$, $\left.\mathrm{CH}_{3}\right), 4.24\left(1 \mathrm{H}, \mathrm{d}, J=12.4, \mathrm{H}-1_{\mathrm{a}}\right), 4.29\left(1 \mathrm{H}, \mathrm{d}, J=12.8, \mathrm{H}-1_{\mathrm{b}}\right), 4.57-4.72$ $\left(3 \mathrm{H}, \mathrm{m}, \mathrm{H}-5, \mathrm{H}-\mathrm{6}_{\mathrm{a}, \mathrm{b}}\right), 4.98\left(1 \mathrm{H}, \mathrm{d}, J=15.2, \mathrm{H}-\mathrm{1}_{\mathrm{a}}{ }_{\mathrm{a}}\right), 5.18(1 \mathrm{H}, \mathrm{d}, J=15.2$, $\left.\mathrm{H}-\mathrm{C}_{\mathrm{b}}{ }_{\mathrm{b}}\right), 5.21(1 \mathrm{H}, \mathrm{d}, J=6.0, \mathrm{H}-3), 5.32(1 \mathrm{H}, \mathrm{dd}, J=6.0,2.8, \mathrm{H}-4), 7.14$ $\left(2 \mathrm{H}, \mathrm{t}, J=8.8,2 \times \mathrm{H}-6^{\prime}\right), 7.42\left(2 \mathrm{H}\right.$, app t $\left., J=8.0,2 \times \mathrm{H}_{m}\right), 7.55(1 \mathrm{H}, \mathrm{t}, J=$ $\left.7.2, \mathrm{H}_{p}\right), 7.59\left(2 \mathrm{H}, \mathrm{dd}, J=8.2,5.2,2 \times \mathrm{H}-5^{\prime}\right), 8.06\left(2 \mathrm{H}, \mathrm{d}, J=7.2,2 \times \mathrm{H}_{0}\right)$. ${ }^{13} \mathrm{C}-\mathrm{NMR}\left(100 \mathrm{MHz}, \mathrm{CDCl}_{3}\right): 25.3\left(\mathrm{CH}_{3}\right), 26.8\left(\mathrm{CH}_{3}\right), 63.3\left(\mathrm{C}-1^{\prime}\right), 64.6$ (C6), 68.8 (C-1), 83.2 (C-4), 85.2 (C-3), 86.3 (C-5), 93.4 (C-2), 114.5 $\left(\mathrm{C}\left(\mathrm{CH}_{3}\right)_{2}\right), 116.1\left(\mathrm{~d},{ }^{2} \mathrm{~J}_{\mathrm{CF}}=22, \mathrm{C}-6^{\prime}\right), 126.5\left(\mathrm{~d},{ }^{4} J_{\mathrm{CF}}=3, \mathrm{C}-4^{\prime}\right), 127.5(\mathrm{C}-$ $\left.2^{\prime}\right), 127.9\left(\mathrm{~d},{ }^{3} J_{\mathrm{CF}}=8, \mathrm{C}-5^{\prime}\right), 128.4\left(\mathrm{C}_{m}\right), 129.7\left(\mathrm{C}_{\text {ipso }}\right), 129.8\left(\mathrm{C}_{o}\right), 133.1$ $\left(C_{p}\right), 140.5$ (C-3'), 162.5 (d, $\left.1^{1} \mathrm{CF}_{2}=246, \mathrm{C}^{\prime} 7^{\prime}\right), 166.1(\mathrm{COPh}) . \mathrm{IR}\left(\mathrm{CHCl}_{3}\right.$, cm-1): 2933 (w), 1719 (s), 1505 (s), 1272 (s), 1099 (s), 1069 (s), 1026 (m), 759 (s), 711(s). HRMS required for $\mathrm{C}_{25} \mathrm{H}_{25} \mathrm{~N}_{3} \mathrm{O}_{6} \mathrm{~F}^{+}$is 482.1722 , found 482.1720 .

((3aR,4R,6R,6aR)-3'-(3-fluorophenyl)-2,2-dimethyl-3a,6a-dihydro$4^{\prime} H, 6 H, 6^{\prime} H$-spiro[furo[3,4- $\left.d\right][1,3]$ dioxole-4,7'-[1,2,3]triazolo[5,1c][1,4]oxazin]-6-yl)methyl benzoate $16 i$

Chromatography of the crude residue over silica gel (hexane/ethyl acetate $8 / 2$ ) gave the pure triazolooxazine $16 \mathbf{i}(268 \mathrm{mg}, 39 \%$ yield over two steps) as colourless oil. Data for $16 \mathrm{i}:[\alpha]_{D}^{20}=-40.2(\mathrm{c}=0.01$, $\left.\mathrm{CHCl}_{3}\right) .{ }^{1} \mathrm{H}-\mathrm{NMR}\left(400 \mathrm{MHz}, \mathrm{CDCl}_{3}\right): 1.40\left(3 \mathrm{H}, \mathrm{s}, \mathrm{CH}_{3}\right), 1.61\left(3 \mathrm{H}, \mathrm{s}, \mathrm{CH}_{3}\right)$, $4.24\left(1 \mathrm{H}, \mathrm{d}, J=12.8, \mathrm{H}-1_{\mathrm{a}}\right), 4.30\left(1 \mathrm{H}, \mathrm{d}, J=12.8, \mathrm{H}-1_{\mathrm{b}}\right), 4.58-4.71(3 \mathrm{H}$, $\left.\mathrm{m}, \mathrm{H}-5, \mathrm{H}-6_{\mathrm{a}, \mathrm{b}}\right), 5.00\left(1 \mathrm{H}, \mathrm{d}, J=15.2, \mathrm{H}-1^{\prime}{ }_{\mathrm{a}}\right), 5.21(1 \mathrm{H}, \mathrm{dd}, J=15.2, \mathrm{H}-$ $\left.1^{\prime}{ }_{b}\right), 5.22(1 \mathrm{H}, \mathrm{d}, J=6.0, \mathrm{H}-3), 5.32(1 \mathrm{H}, \mathrm{dd}, J=6.0,2.8, \mathrm{H}-4), 7.05(1 \mathrm{H}$, $\left.\mathrm{td}, J=8.4,1.6, \mathrm{H}-7^{\prime}\right), 7.32-7.45\left(5 \mathrm{H}, \mathrm{m}, \mathrm{H}-5^{\prime}, \mathrm{H}-8^{\prime}, \mathrm{H}-9^{\prime}, 2 \times \mathrm{H}_{m}\right), 7.35$ $\left(1 \mathrm{H}, \mathrm{dd}, J=13.6,6.4, \mathrm{H}-7^{\prime}\right), 7.42\left(2 \mathrm{H}, \mathrm{t}, J=8.0, \mathrm{H}_{m}\right), 7.55(1 \mathrm{H}, \mathrm{t}, J=$ 6.8, $\left.\mathrm{H}_{p}\right), 8.07\left(2 \mathrm{H}, \mathrm{d}, J=7.6,2 \times \mathrm{H}_{o}\right) .{ }^{13} \mathrm{C}-\mathrm{NMR}\left(100 \mathrm{MHz}, \mathrm{CDCl}_{3}\right): 25.3$ 
$\left(\mathrm{CH}_{3}\right), 26.8\left(\mathrm{CH}_{3}\right), 63.3\left(\mathrm{C}-1^{\prime}\right), 64.6(\mathrm{C}-6), 68.8(\mathrm{C}-1), 83.2(\mathrm{C}-4), 85.2$ (C-3), $86.3(\mathrm{C}-5), 93.5(\mathrm{C}-2), 113.1\left(\mathrm{~d},{ }^{2} \mathrm{~J}_{\mathrm{CF}}=23, \mathrm{C}-5^{\prime}\right), 114.5\left(\mathrm{C}\left(\mathrm{CH}_{3}\right)_{2}\right)$, $115.0\left(\mathrm{~d},{ }^{2} J_{\mathrm{CF}}=22, \mathrm{C}^{\prime} \mathrm{7}^{\prime}\right), 121.7\left(\mathrm{~d},{ }^{4} J_{\mathrm{CF}}=3, \mathrm{C}-9^{\prime}\right), 128.2\left(\mathrm{C}-2^{\prime}\right), 128.4$ $\left(C_{m}\right), 129.7\left(C_{\text {ipso }}\right), 129.9\left(C_{o}\right), 130.6\left(d,{ }^{3} J_{C F}=8, C-8{ }^{\prime}\right), 132.4\left(d,{ }^{3} J_{C F}=8\right.$, C-4'), $133.1\left(C_{p}\right), 140.3\left(d,{ }^{4} J_{C F}=3, C-3^{\prime}\right), 163.2\left(d,{ }^{1} J_{C F}=245, C-6^{\prime}\right)$, 166.1 (COPh). IR ( $\left.\mathrm{CHCl}_{3}, \mathrm{~cm}^{-1}\right): 2987$ (w), 1718 (s), 1270 (s), 1097 (s), $1070(\mathrm{~s}), 1026(\mathrm{~m}), 754(\mathrm{~s}), 711(\mathrm{~s})$. HRMS required for $\mathrm{C}_{25} \mathrm{H}_{25} \mathrm{~N}_{3} \mathrm{O}_{6} \mathrm{~F}^{+}$ is 482.1722 , found 482.1722 .

((3aR,4R,6R,6aR)-3'-(2-fluorophenyl)-2,2-dimethyl-3a,6a-dihydro4' $H, 6 H, 6$ ' $H$-spiro[furo[3,4-d][1,3]dioxole-4,7'-[1,2,3]triazolo[5,1c][1,4]oxazin]-6-yl)methyl benzoateSpirocylic triazolo-oxazine 16j Chromatography of the crude residue over silica gel (hexane/ethyl acetate $8 / 2$ ) gave the pure triazolooxazine $16 \mathbf{j}$ (310 $\mathrm{mg}, 45 \%$ yield over two steps) as colourless oil. Data for 16j: $[\alpha]_{D}{ }^{20}=-36.5$ (c=0.01, $\left.\mathrm{CHCl}_{3}\right) .{ }^{1} \mathrm{H}-\mathrm{NMR}\left(400 \mathrm{MHz}, \mathrm{CDCl}_{3}\right): 1.39\left(3 \mathrm{H}, \mathrm{s}, \mathrm{CH}_{3}\right), 1.60\left(3 \mathrm{H}, \mathrm{s}, \mathrm{CH}_{3}\right)$, $4.25\left(1 \mathrm{H}, \mathrm{d}, J=14.0, \mathrm{H}-1_{\mathrm{a}}\right), 4.29\left(1 \mathrm{H}, \mathrm{d}, J=13.6, \mathrm{H}-1_{\mathrm{b}}\right), 4.59-4.74(3 \mathrm{H}$, $\left.\mathrm{m}, \mathrm{H}-5, \mathrm{H}-6_{\mathrm{a}, \mathrm{b}}\right), 4.92\left(1 \mathrm{H}, \mathrm{dd}, J=15.8,2.4, \mathrm{H}-\mathrm{1}_{\mathrm{a}}{ }_{\mathrm{a}}\right), 5.09(1 \mathrm{H}, \mathrm{dd}, J=15.8$, 2.4, $\left.\mathrm{H}-\mathrm{1}_{\mathrm{b}}{ }_{\mathrm{b}}\right), 5.20(1 \mathrm{H}, \mathrm{d}, J=6.0, \mathrm{H}-3), 5.34(1 \mathrm{H}, \mathrm{dd}, J=5.6,2.8, \mathrm{H}-4)$, $7.11\left(1 \mathrm{H}, \mathrm{t}, J=8.4, \mathrm{H}-6^{\prime}\right), 7.26\left(1 \mathrm{H}, \mathrm{t}, J=8.4, \mathrm{H}-8^{\prime}\right), 7.35(1 \mathrm{H}, \mathrm{dd}, J=$ 13.6, 6.4, H-7'), $7.42\left(2 \mathrm{H}, \mathrm{t}, J=8.0,2 \times \mathrm{H}_{m}\right), 7.55\left(1 \mathrm{H}, \mathrm{t}, J=6.8, \mathrm{H}_{p}\right), 7.98$ $\left(1 \mathrm{H}, \mathrm{td}, J=7.6,1.6, \mathrm{H}-9^{\prime}\right), 8.07\left(2 \mathrm{H}, \mathrm{d}, J=7.2,2 \times \mathrm{H}_{0}\right) .{ }^{13} \mathrm{C}-\mathrm{NMR}(100$ $\left.\mathrm{MHz}, \mathrm{CDCl}_{3}\right): 25.3\left(\mathrm{CH}_{3}\right), 26.8\left(\mathrm{CH}_{3}\right), 63.8\left(\mathrm{~d}, 5 \mathrm{~J}_{\mathrm{CF}}=18, \mathrm{C}-1^{\prime}\right), 64.7(\mathrm{C}-$ 6), 68.8 (C-1), 83.2 (C-4), 85.2 (C-3), 86.3 (C-5), 93.6 (C-2), 114.4 $\left(C\left(\mathrm{CH}_{3}\right)_{2}\right), 115.7\left(\mathrm{~d},{ }^{2} J_{\mathrm{CF}}=21, \mathrm{C}-6^{\prime}\right), 118.1\left(\mathrm{~d},{ }^{2} J_{\mathrm{CF}}=15, \mathrm{C}-4^{\prime}\right), 124.8(\mathrm{~d}$, $\left.{ }^{4} J_{C F}=3, C-8^{\prime}\right), 128.3\left(C_{m}\right), 129.6\left(C-2^{\prime}\right), 129.7\left(C_{\text {ipso }}\right), 129.8\left(C_{o}\right), 129.9$ $\left(d, 5 J_{C F}=4, C-9^{\prime}\right) 130.2\left(d,{ }^{3} J_{C F}=9, C-7^{\prime}\right), 133.1\left(C_{p}\right), 136.1\left(C-3^{\prime}\right), 162.5$ $\left(d,{ }^{1} J_{C F}=244, C-5^{\prime}\right), 166.1(\mathrm{COPh}) . \mathrm{IR}\left(\mathrm{CHCl}_{3}, \mathrm{~cm}^{-1}\right): 2986(\mathrm{w}), 1720(\mathrm{~s})$, $1272(\mathrm{~s}), 1097$ (s), 1101 (s), 1069 (m), 757 (s), 711(s). HRMS required for $\mathrm{C}_{25} \mathrm{H}_{25} \mathrm{~N}_{3} \mathrm{O}_{6} \mathrm{~F}^{+}$is 482.1722 , found 482.1722 .

((3aR,4R,6R,6aR)-2,2-dimethyl-3'-(4-pentylphenyl)-3a,6a-dihydro4' $H, 6 H, 6^{\prime} H$-spiro[furo[3,4-d][1,3]dioxole-4,7'-[1,2,3]triazolo[5,1c][1,4]oxazin]-6-yl)methyl benzoate $16 \mathrm{k}$

Chromatography of the crude residue over silica gel (hexane/ethyl acetate $8 / 2$ ) gave the pure triazolooxazine $16 \mathbf{k}(235 \mathrm{mg}, 93 \%$ yield). Data for 16k: Colourless oil, $[\alpha]_{D}{ }^{20}=-28.5\left(\mathrm{c}=0.01, \mathrm{CHCl}_{3}\right) .{ }^{1} \mathrm{H}-\mathrm{NMR}$ $\left(400 \mathrm{MHz}, \mathrm{CDCl}_{3}\right): \delta 0.89\left(3 \mathrm{H}, \mathrm{t}, J=7.2,3 \times \mathrm{H}-8^{\prime}\right), 1.25-1.33(4 \mathrm{H}, \mathrm{m}$, $\left.2 \times \mathrm{H}-6^{\prime}, 2 \times \mathrm{H}-7^{\prime}\right), 1.33\left(3 \mathrm{H}, \mathrm{s}, \mathrm{CH}_{3}\right), 1.60\left(3 \mathrm{H}, \mathrm{s}, \mathrm{CH}_{3}\right), 1.64(2 \mathrm{H}$, quint, $J$ $\left.=7.2,2 \times \mathrm{H}-5^{\prime}\right), 2.63\left(2 \mathrm{H}, \mathrm{td}, J=7.8,2.4,2 \times \mathrm{H}-4^{\prime}\right), 4.17(1 \mathrm{H}, \mathrm{d}, J=12.8$, $\left.\mathrm{H}-1_{\mathrm{a}}\right), 4.23\left(1 \mathrm{H}, \mathrm{d}, J=12.8, \mathrm{H}-1_{\mathrm{b}}\right), 4.54-4.67\left(3 \mathrm{H}, \mathrm{m}, \mathrm{H}-5, \mathrm{H}-6_{\mathrm{a}, \mathrm{b}}\right), 4.74$ $\left(1 \mathrm{H}, \mathrm{d}, J=14.8, \mathrm{H}-1^{\prime}{ }_{\mathrm{a}}\right), 4.95\left(1 \mathrm{H}, \mathrm{d}, J=15.2, \mathrm{H}-\mathrm{1}^{\prime}{ }_{\mathrm{b}}\right), 5.14(1 \mathrm{H}, \mathrm{d}, J=6.0$, $\mathrm{H}-3), 5.298(1 \mathrm{H}, \mathrm{dd}, J=6.0,2.4, \mathrm{H}-4), 7.43\left(2 \mathrm{H}, \mathrm{t}, J=7.2,2 \times \mathrm{H}_{m}\right), 7.55$ $\left(1 \mathrm{H}, \mathrm{t}, J=7.2, \mathrm{H}_{p}\right), 8.05\left(2 \mathrm{H}, \mathrm{d}, J=7.2,2 \times \mathrm{H}_{0}\right) .{ }^{13} \mathrm{C}-\mathrm{NMR}(100 \mathrm{MHz}$, $\left.\mathrm{CDCl}_{3}\right): 14.0\left(\mathrm{C}-8^{\prime}\right), 22.4$ ( C-7'), $25.0\left(\mathrm{C}-4^{\prime}\right), 25.3\left(\mathrm{CH}_{3}\right), 26.8\left(\mathrm{CH}_{3}\right), 28.6$ (C-5'), $31.5\left(\mathrm{C}-6^{\prime}\right), 62.5\left(\mathrm{C}-1^{\prime}\right), 64.6$ (C-6), 68.9 (C-1), 83.2 (C-4), 85.1

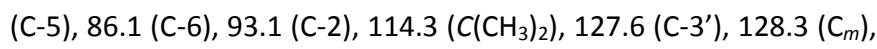
$129.8\left(\mathrm{C}_{\text {ipso }}\right), 129.8\left(\mathrm{C}_{o}\right), 133.1\left(\mathrm{C}_{p}\right), 141.7$ (C-2'), 166.1 (COPh). IR $\left(\mathrm{CHCl}_{3}, \mathrm{~cm}^{-1}\right): 2931$ (w), 1720 (s), $1450(\mathrm{~m}), 1271$ (s), 1097 (s), 1070 (m), 711 (s). HRMS required for $\mathrm{C}_{21} \mathrm{H}_{26} \mathrm{~N}_{3} \mathrm{O}_{6}{ }^{+}$is 416.1803 , found 416.1809 .

\section{3,4-O-isopropylidene spirocyclic triazolo-oxazine nucleoside 17a} Benzoate ester 16a was dissolved in a solution of $7 \mathrm{~N} \mathrm{NH}_{3} / \mathrm{MeOH}$ ( $0.06 \mathrm{M}$ concentration) and the resulting solution was stirred for $4 \mathrm{~h}$. After evaporation of the solvent under reduced pressure, the crude product was purified on silica gel. Chromatography of the crude residue over silica gel (hexane/ethyl acetate 1/1) gave the pure spironucleoside 17a (358 mg, 98\% yield). Colourless needle crystals were obtained after recrystallisation with chloroform/hexane $1 / 3$. Data for 17a: $\mathrm{Mp}=130-132{ }^{\circ} \mathrm{C}$. $[\alpha]_{\mathrm{D}}{ }^{20}=-120.80\left(\mathrm{c}=0.0025, \mathrm{CHCl}_{3}\right)$. ${ }^{1} \mathrm{H}-\mathrm{NMR}\left(400 \mathrm{MHz}, \mathrm{CDCl}_{3}\right): \delta 1.39\left(3 \mathrm{H}, \mathrm{s}, \mathrm{CH}_{3}\right), 1.61\left(3 \mathrm{H}, \mathrm{s}, \mathrm{CH}_{3}\right), 3.84$ $\left(1 \mathrm{H}, \mathrm{ddd}, J=11.2,9.6,4.0, \mathrm{H}-6_{\mathrm{a}}\right), 3.86-3.96\left(1 \mathrm{H}, \mathrm{m}, \mathrm{H}-6_{\mathrm{b}}\right), 3.98(1 \mathrm{H}, \mathrm{d}$, $\left.J=12.4, \mathrm{H}-1_{\mathrm{a}}\right), 3.21(1 \mathrm{H}, \mathrm{bdd}, J=9.8,2.4, \mathrm{OH}), 4.31(1 \mathrm{H}, \mathrm{d}, J=12.4$, $\left.\mathrm{H}-1_{\mathrm{b}}\right), 4.55(1 \mathrm{H}, \mathrm{m}, \mathrm{H}-5), 4.88\left(1 \mathrm{H}, \mathrm{d}, J=15.2, \mathrm{H}-1^{\prime}{ }_{\mathrm{a}}\right), 4.97(1 \mathrm{H}, \mathrm{d}, J=$ 15.2, H-1 ${ }^{\prime}$ b), $5.20(1 \mathrm{H}, \mathrm{d}, J=6.0, \mathrm{H}-3), 5.29(1 \mathrm{H}, \mathrm{dd}, J=6.0,2.0, \mathrm{H}-4)$, $7.54\left(1 \mathrm{H}, \mathrm{s}, \mathrm{H}-3^{\prime}\right) .{ }^{13} \mathrm{C}-\mathrm{NMR}\left(100 \mathrm{MHz}, \mathrm{CDCl}_{3}\right): 24.6\left(\mathrm{CH}_{3}\right), 26.1\left(\mathrm{CH}_{3}\right)$, $62.4(\mathrm{C}-6), 63.8\left(\mathrm{C}-1^{\prime}\right), 69.7$ (C-1), 82.2 (C-4), 86.2 (C-3), $88.4(\mathrm{C}-5)$,

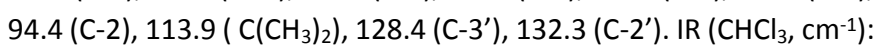
3352 (br), 2927 (w), 1095 (s), 1044 (m). HRMS required for $\mathrm{C}_{12} \mathrm{H}_{18} \mathrm{~N}_{3} \mathrm{O}_{5}$ is 284.1241 , found 284.1242 .

\section{General procedure for benzoyl and isopropyl group removal to give $18 a-k^{14}$}

Protected spirocyclic triazolo-oxazine nucleoside 16a-k (0.65 mmol) was dissolved in a solution of $7 \mathrm{~N}$ of $\mathrm{NH}_{3}$ in $\mathrm{MeOH}(10.8 \mathrm{~mL})$ and the resulting solution was stirred at room temperature until TLC indicated the reaction was complete (ca. $4 \mathrm{~h}$ ). After evaporation of all volatiles under reduced pressure, the crude residue was dissolved in a solution of methanol/water $8 / 2(26 \mathrm{~mL})$ and Dowex $50 \mathrm{WX} 8$ hydrogen form ( $3.38 \mathrm{~g}$ ) was added in one portion. The resulting suspension was stirred vigorously for $4-6 \mathrm{~h}$ at $50{ }^{\circ} \mathrm{C}$, then the resin was filtered off and washed with methanol. The filtrate was concentrated to dryness under reduced pressure to afford a crude residue which was purified by column chromatography.

\section{(2R,3R,4S,5R)-5-(hydroxymethyl)-4,5-dihydro-3H, ' $^{\prime} H, 6^{\prime} H$ - spiro[furan-2,7'-[1,2,3]triazolo[5,1-c][1,4]oxazine]-3,4-diol 18a} Chromatography of the crude residue over silica gel (dichloromethane/methanol 9/1) gave the pure anomeric spironucleoside $18 \mathrm{a}$ ( $88 \mathrm{mg}, 56 \%$ yield) as colourless syrup. Data for 18a: $[\alpha]_{D}{ }^{20}=-38.31\left(\mathrm{c}=0.0065, \mathrm{CH}_{3} \mathrm{OH}\right) .{ }^{1} \mathrm{H}-\mathrm{NMR}\left(400 \mathrm{MHz}, \mathrm{CD}_{3} \mathrm{OD}\right)$ : $\delta 3.64\left(1 \mathrm{H}, \mathrm{dd}, J=12.0,6.4, \mathrm{H}-6_{\mathrm{a}}\right), 3.73\left(1 \mathrm{H}, \mathrm{dd}, J=12.0,4.0, \mathrm{H}-6_{\mathrm{b}}\right)$, $4.02\left(1 \mathrm{H}, \mathrm{d}, J=12.4, \mathrm{H}-1_{\mathrm{a}}\right), 4.03-4.07(1 \mathrm{H}, \mathrm{m}, \mathrm{H}-5), 4.21(1 \mathrm{H}, \mathrm{d}, J=$ $\left.12.8, \mathrm{H}-1_{\mathrm{b}}\right), 4.44(1 \mathrm{H}, \mathrm{d}, J=4.8, \mathrm{H}-3), 4.62(1 \mathrm{H}, \mathrm{dd}, J=6.6,4.8, \mathrm{H}-4)$, $4.73\left(1 \mathrm{H}, \mathrm{d}, J=15.2, \mathrm{H}-1^{\prime}{ }_{\mathrm{a}}\right), 4.89\left(1 \mathrm{H}, \mathrm{d}, J=15.2, \mathrm{H}-1^{\prime}{ }_{\mathrm{b}}\right), 7.46(1 \mathrm{H}, \mathrm{s}$, H-3'). ${ }^{13} \mathrm{C}-\mathrm{NMR}\left(100 \mathrm{MHz}, \mathrm{CD}_{3} \mathrm{OD}\right): 63.1$ (C-1'), 64.0 (C-6), 70.1 (C-1), 72.6 (C-4), 77.0 (C-3), 86.6 (C-5), 94.2 (C-2), 128.9 (C-3'), 134.4 (C-2'). IR ( $\left.\mathrm{CH}_{3} \mathrm{OH}, \mathrm{cm}^{-1}\right)$ : 3360 (br), 2924 (m), 1615 (br), 1093 (s), 1020 (s). HRMS required for $\mathrm{C}_{9} \mathrm{H}_{14} \mathrm{~N}_{3} \mathrm{O}_{5}{ }^{+}$is 244.0928 , found 244.0928 .

\section{(2R,3R,4S,5R)-5-(hydroxymethyl)-3'-methyl-4,5-dihydro- $3 H, 4^{\prime} H, 6^{\prime} H$-spiro[furan-2,7'-[1,2,3]triazolo[5,1-c][1,4]oxazine]-3,4- diol 18b}

Chromatography of the crude residue over silica gel (dichloromethane/methanol 9/1) gave the pure spironucleoside 18b (78 mg, 47\% yield) as colourless syrup. Data for $18 \mathrm{~b}$ : $[\alpha]_{\mathrm{r}}{ }^{20}=-57.1$ (c $\left.=0.01, \mathrm{CH}_{3} \mathrm{OH}\right) .{ }^{1} \mathrm{H}-\mathrm{NMR}\left(500 \mathrm{MHz}, \mathrm{CD}_{3} \mathrm{OD}\right): \delta 2.26\left(3 \mathrm{H}, \mathrm{s}, 3 \times \mathrm{H}-4^{\prime}\right)$, $3.77\left(1 \mathrm{H}, \mathrm{dd}, J=12.0,6.0, \mathrm{H}-6_{\mathrm{a}}\right), 3.86\left(1 \mathrm{H}, \mathrm{dd}, J=12.0,3.5, \mathrm{H}-6_{\mathrm{b}}\right), 4.12$ 
$\left(1 \mathrm{H}, \mathrm{d}, J=12.5, \mathrm{H}-1_{\mathrm{a}}\right), 4.15-4.20(1 \mathrm{H}, \mathrm{m}, \mathrm{H}-5), 4.31(1 \mathrm{H}, \mathrm{d}, J=12.5, \mathrm{H}$ $1 \mathrm{~b}), 4.56(1 \mathrm{H}, \mathrm{d}, J=5.0, \mathrm{H}-3), 4.73(1 \mathrm{H}, \mathrm{dd}, J=6.5,5.0, \mathrm{H}-4), 4.80(1 \mathrm{H}$ $\left.\mathrm{d}, J=15.0, \mathrm{H}-1^{\prime}{ }_{\mathrm{a}}\right), 4.94\left(1 \mathrm{H}, \mathrm{d}, J=15.0, \mathrm{H}-1^{\prime}{ }_{\mathrm{b}}\right) .{ }^{13} \mathrm{C}-\mathrm{NMR}(125 \mathrm{MHz}$, $\mathrm{CD}_{3} \mathrm{OD}$ ): ppm 9.5 (C-4'), 62.8 (C-1'), 64.0 (C-6), 69.8 (C-1), 72.6 (C-4), 76.9 (C-3), 86.5 (C-5), 94.2 (C-2), 130.6 (C-3'), 137.8 (C-2'). IR ( $\mathrm{CH}_{3} \mathrm{OH}$, $\left.\mathrm{cm}^{-1}\right): 3321(\mathrm{br}), 2993(\mathrm{~m}), 1099(\mathrm{~s}), 1071(\mathrm{~m})$. HRMS required for $\mathrm{C}_{10} \mathrm{H}_{16} \mathrm{~N}_{3} \mathrm{O}_{5}{ }^{+}$is 258.1084 , found 258.1086 .

(2R,3R,4S,5R)-3'-ethyl-5-(hydroxymethyl)-4,5-dihydro-3H, 4' $H, 6^{\prime} H$ spiro[furan-2,7'-[1,2,3]triazolo[5,1-c][1,4]oxazine]-3,4-diol 18c

Chromatography of the crude residue over silica gel (dichloromethane/methanol 9/1) gave the pure spironucleoside 18c (90 mg, 51\% yield) as colourless syrup. Data for $18 \mathrm{c}$ : $[\alpha]_{\mathrm{\gamma}} \mathrm{\gamma}^{20}=-34.6$ (c $\left.=0.01, \mathrm{CH}_{3} \mathrm{OH}\right) .{ }^{1} \mathrm{H}-\mathrm{NMR}\left(400 \mathrm{MHz}, \mathrm{CD}_{3} \mathrm{OD}\right): \delta 1.25(3 \mathrm{H}, \mathrm{t}, J=7.6$, $\left.3 \times \mathrm{H}^{-} 4^{\prime}\right), 2.67\left(2 \mathrm{H}, \mathrm{q}, J=7.6,3 \times \mathrm{H}-3^{\prime}\right), 3.75(1 \mathrm{H}, \mathrm{dd}, J=12.0,6.4, \mathrm{H}-6 \mathrm{a})$ $3.84\left(1 \mathrm{H}, \mathrm{dd}, J=12.0,3.6, \mathrm{H}-6_{\mathrm{b}}\right), 4.12\left(1 \mathrm{H}, \mathrm{d}, J=12.4, \mathrm{H}-1_{\mathrm{a}}\right), 4.13-4.18$ $(1 \mathrm{H}, \mathrm{m}, \mathrm{H}-5), 4.30\left(1 \mathrm{H}, \mathrm{d}, J=12.4, \mathrm{H}-\mathrm{I}_{\mathrm{b}}\right), 4.55(1 \mathrm{H}, \mathrm{d}, J=4.8, \mathrm{H}-3), 4.72$ $(1 \mathrm{H}, \mathrm{dd}, J=6.4,4.8, \mathrm{H}-4), 4.81\left(1 \mathrm{H}, \mathrm{d}, J=15.2, \mathrm{H}^{\prime}{ }^{\prime}{ }_{\mathrm{a}}\right), 4.96(1 \mathrm{H}, \mathrm{d}, J=$ 15.2, H-1 ${ }^{\prime}$ ). ${ }^{13} \mathrm{C}-\mathrm{NMR}\left(100 \mathrm{MHz}, \mathrm{CD}_{3} \mathrm{OD}\right): 13.6$ (C-5'), 18.9 ( C-4'), 63.0 (C-6), 64.0 (C-1'), 70.0 (C-1), 72.7 (C-4), 76.9 (C-3), 86.4 (C-5), 94.2 (C2), 130.2 (C-2'), 143.6 (C-3'). IR ( $\left.\mathrm{CH}_{3} \mathrm{OH}, \mathrm{cm}^{-1}\right): 3392(\mathrm{br}), 2922(\mathrm{~m})$, $1642(\mathrm{br}), 1101$ (s), 1033 (s), $940(\mathrm{~m})$. HRMS required for $\mathrm{C}_{11} \mathrm{H}_{18} \mathrm{~N}_{3} \mathrm{O}_{5}{ }^{+}$ is 272.1241 , found 272.1242 .

(2R,3R,4S,5R)-5-(hydroxymethyl)-3'-(naphthalen-2-yl)-4,5-dihydro$3 H, 4^{\prime} H, 6^{\prime} H$-spiro[furan-2,7'-[1,2,3]triazolo[5,1-c][1,4]oxazine]-3,4diol 18d

Chromatography of the crude residue over silica gel (hexane/ ethyl acetate 15/85) gave the pure spironucleoside 18d (120 mg, 50\% yield) as white solid. Data for $18 \mathrm{~d}: \mathrm{Mp}=101-102^{\circ} \mathrm{C}$. $[\alpha]_{\gamma^{20}}=-65.5(\mathrm{c}$ $\left.=0.01, \mathrm{CHCl}_{3}\right) .{ }^{1} \mathrm{H}-\mathrm{NMR}\left(400 \mathrm{MHz}, \mathrm{CDCl}_{3}\right): \delta 3.89(1 \mathrm{H}, \mathrm{bd}, J=11.6, \mathrm{H}-$ $6 \mathrm{a}), 4.00(1 \mathrm{H}, \mathrm{bd}, J=11.6, \mathrm{H}-6 \mathrm{~b}), 4.09(1 \mathrm{H}, \mathrm{br}, \mathrm{OH}), 4.12(1 \mathrm{H}, \mathrm{d}, J=$ 12.8, H-1 $\left.\mathrm{a}_{\mathrm{a}}\right), 4.25-4.28(1 \mathrm{H}, \mathrm{m}, \mathrm{H}-4), 4.37\left(1 \mathrm{H}, \mathrm{d}, J=12.4, \mathrm{H}-1_{\mathrm{b}}\right), 4.55$ $(1 \mathrm{H}, \mathrm{br}, \mathrm{OH}), 4.66\left(1 \mathrm{H}, \mathrm{d}, \mathrm{J}=15.6, \mathrm{H}-1^{\prime}{ }_{\mathrm{a}}\right), 4.75(1 \mathrm{H}, \mathrm{br}, \mathrm{H}-3), 4.78(1 \mathrm{H}$, $\left.\mathrm{d}, J=15.2, \mathrm{H}-1^{\prime}{ }_{\mathrm{b}}\right), 5.10(1 \mathrm{H}, \mathrm{br}, \mathrm{OH}), 5.26(1 \mathrm{H}, \mathrm{br}, \mathrm{H}-5), 7.30(1 \mathrm{H}, \mathrm{d}, J$ $=7.2, \mathrm{H}-\mathrm{Naph}), 7.34-7.51(3 \mathrm{H}, \mathrm{m}, 3 \times \mathrm{H}-\mathrm{Naph}), 7.93(3 \mathrm{H}, \mathrm{t}, \mathrm{J}=8.4,3 \times \mathrm{H}-$ Naph). ${ }^{13} \mathrm{C}-\mathrm{NMR}\left(100 \mathrm{MHz}, \mathrm{CDCl}_{3}\right.$ ): 62.1 (C-6), 62.8 (C-1), 68.9 (C-1'), 70.9 (C-5), 76.4 (C-3), 85.2 (C-4), 93.4 (C-2), 124.9, 125.3, 126.4, 126.5, 126.9 (Naph), 127.5 (C-3'), 128.6 (Naph), 129.6 (C-2'), 130.8, 131.2, 133.9 (Naph), 140.6 ( $\mathrm{C}_{\text {ipso }}$-Naph). IR ( $\left.\mathrm{cm}^{-1}\right)$ : 3381 (br), $2992(\mathrm{w})$, $1211(\mathrm{~s}), 1095$ (s), $1076(\mathrm{~m}), 777(\mathrm{~m}), 751(\mathrm{~s})$. IR $\left(\mathrm{CHCl}_{3}, \mathrm{~cm}^{-1}\right)$ : 3349 (br), $2926(\mathrm{w}), 1103(\mathrm{~s}), 1035$ (m), 777 (m), 757 (s). HRMS required for $\mathrm{C}_{19} \mathrm{H}_{20} \mathrm{~N}_{3} \mathrm{O}_{5}{ }^{+}$is 370.1397 , found 370.1399 .

\section{(2R,3R,4S,5R)-5-(hydroxymethyl)-3'-phenyl-4,5-dihydro-} $3 H, 4^{\prime} H, 6$ 'H-spiro[furan-2,7'-[1,2,3]triazolo[5,1-c][1,4]oxazine]-3,4diol $18 \mathrm{e}$

Chromatography of the crude residue over silica gel (hexane/ ethyl acetate $1 / 9)$ gave the pure spironucleoside $18 \mathrm{e}(139 \mathrm{mg}, 67 \%$ overall yield) as white foam. Data for 18e: $[\alpha]_{D}{ }^{20}=-36.1\left(\mathrm{c}=0.01, \mathrm{CHCl}_{3}\right) .{ }^{1} \mathrm{H}-$ NMR (400 MHz, CD $\left.{ }_{3} \mathrm{OD}\right): \delta 3.80$ (1H, dd, $\left.J=12.0,6.4, \mathrm{H}-6_{\mathrm{a}}\right), 3.80(1 \mathrm{H}$, $\left.\mathrm{dd}, J=12.4,3.2, \mathrm{H}-6_{\mathrm{b}}\right), 4.20\left(1 \mathrm{H}, \mathrm{d}, J=12.0, \mathrm{H}-1_{\mathrm{a}}\right), 4.19-4.23(1 \mathrm{H}, \mathrm{m}$, $\mathrm{H}-5), 4.38\left(1 \mathrm{H}, \mathrm{d}, J=12.4, \mathrm{H}-1_{\mathrm{b}}\right), 4.64(1 \mathrm{H}, \mathrm{d}, J=5.2, \mathrm{H}-3), 4.73(1 \mathrm{H}$, $\mathrm{dd}, J=6.4,5.2, \mathrm{H}-4), 5.02\left(1 \mathrm{H}, \mathrm{d}, J=15.2,{\mathrm{H}-1^{\prime}}_{\mathrm{a}}\right), 5.17(1 \mathrm{H}, \mathrm{d}, J=15.2$,
$\left.\mathrm{H}-1^{\prime} \mathrm{b}\right), 7.38\left(1 \mathrm{H}, \mathrm{t}, J=7.6, \mathrm{H}-7^{\prime}\right), 7.48\left(2 \mathrm{H}, \mathrm{t}, J=7.6,2 \times \mathrm{H}-6^{\prime}\right), 7.62(2 \mathrm{H}$, $\left.\mathrm{d}, J=8.0,2 \times \mathrm{H}-5^{\prime}\right) .{ }^{13} \mathrm{C}-\mathrm{NMR}\left(100 \mathrm{MHz}, \mathrm{CD}_{3} \mathrm{OD}\right): 63.8$ (C-6), 63.9 (C-1'), 69.8 (C-1), 72.7 (C-4), 77.0 (C-3), 86.6 (C-5), 94.5 (C-2), 127.3(C-5'), 129.3(C-2'), 130.1 (C-6'), 130.5 (C-7'), 131.5 (C-4'), 142.2 (C-3'). IR $\left(\mathrm{CH}_{3} \mathrm{OH}, \mathrm{cm}^{-1}\right)$ : 3324 (br), 2922 (m), 1438 (s), 1101 (s), 1045 (s), 1006 (s), $943(\mathrm{~m})$. HRMS required for $\mathrm{C}_{25} \mathrm{H}_{26} \mathrm{~N}_{3} \mathrm{O}_{6}{ }^{+}$is 464.1816 , found 464.1813.

(2R,3R,4S,5R)-3'-(4-chlorophenyl)-5-(hydroxymethyl)-4,5-dihydro$3 H, 4^{\prime} H, 6^{\prime} H$-spiro[furan-2,7'-[1,2,3]triazolo[5,1-c][1,4]oxazine]-3,4diol $18 f$

Chromatography of the crude residue over silica gel (hexane/ ethyl acetate 1/9) gave the pure spironucleoside $18 \mathrm{f}(145 \mathrm{mg}, 63 \%$ overall yield) as colourless oil. Data for 18f: $[\alpha]_{D}{ }^{20}=-31.0\left(\mathrm{c}=0.01, \mathrm{CHCl}_{3}\right)$. ${ }^{1} \mathrm{H}-\mathrm{NMR}\left(500 \mathrm{MHz}, \mathrm{CD}_{3} \mathrm{OD}\right): \delta 3.77\left(1 \mathrm{H}, \mathrm{dd}, J=12.2,6.0, \mathrm{H}-6_{\mathrm{a}}\right.$ ), 3.85 $\left(1 \mathrm{H}, \mathrm{dd}, J=12.2,3.0, \mathrm{H}-6_{\mathrm{b}}\right), 4.17\left(1 \mathrm{H}, \mathrm{d}, J=12.5, \mathrm{H}-1_{\mathrm{a}}\right), 4.15-4.19(1 \mathrm{H}$, $\mathrm{m}, \mathrm{H}-5), 4.35\left(1 \mathrm{H}, \mathrm{d}, J=12.5, \mathrm{H}-\mathrm{1}_{\mathrm{b}}\right), 4.61(1 \mathrm{H}, \mathrm{d}, J=5.0, \mathrm{H}-3), 4.75(1 \mathrm{H}$, $\mathrm{dd}, J=7.0,5.0, \mathrm{H}-4), 5.03\left(1 \mathrm{H}, \mathrm{d}, J=15.5, \mathrm{H}-1^{\prime}{ }_{\mathrm{a}}\right), 5.15(1 \mathrm{H}, \mathrm{d}, J=15.5$, $\left.\mathrm{H}-1^{\prime}{ }_{b}\right), 7.47\left(2 \mathrm{H}, \mathrm{d}, J=8.5,2 \times \mathrm{H}-6^{\prime}\right), 7.60\left(2 \mathrm{H}, \mathrm{d}, J=8.5,2 \times \mathrm{H}-5^{\prime}\right) .{ }^{13} \mathrm{C}-$ NMR (125 MHz, CD $\left.{ }_{3} \mathrm{OD}\right): 62.4$ (C-6), 63.5 (C-1'), 68.4 (C-1), 71.3 (C-4), 75.6 (C-3), 85.2 (C-5), 93.2 (C-2), 127.3 (C-5'),128.9 (C-6'), 129.0 (C$\left.2^{\prime}\right), 129.4\left(\mathrm{C}-4^{\prime}\right), 133.7$ (C-7'), 139.7 (C-3'). IR ( $\left.\mathrm{CH}_{3} \mathrm{OH}, \mathrm{cm}^{-1}\right)$ : 3361 (br), $2922(\mathrm{~m}), 1636(\mathrm{w}), 1491(\mathrm{~s}), 1090(\mathrm{~s}), 1037(\mathrm{~s}), 1002(\mathrm{~s}), 943(\mathrm{~m}), 831$ (m). HRMS required for $\mathrm{C}_{15} \mathrm{H}_{17} \mathrm{~N}_{3} \mathrm{O}_{5} \mathrm{Cl}^{+}$is 354.0851 , found 354.0851 .

\section{(2R,3R,4S,5R)-5-(hydroxymethyl)-3'-(4-methoxyphenyl)-4,5-} dihydro-3H,4'H,6'H-spiro[furan-2,7'-[1,2,3]triazolo[5,1c][1,4]oxazine]-3,4-diol 18g

Chromatography of the crude residue over silica gel (dichloromethane/methanol 95/5) gave the pure spironucleoside $66 \mathrm{~g}$ (118 mg, 52\% overall yield). White needle crystals were obtained after recrystallisation with hexane/ $\mathrm{Et}_{2} \mathrm{O} / \mathrm{CH}_{3} \mathrm{OH}$ 6:3:1. Data for 66g: $\mathrm{Mp}=119-120^{\circ} \mathrm{C} .[\alpha]_{\mathrm{D}}{ }^{20}=-51.3\left(\mathrm{c}=0.01, \mathrm{CHCl}_{3}\right) .{ }^{1} \mathrm{H}-\mathrm{NMR}(400 \mathrm{MHz}$, $\left.\mathrm{CD}_{3} \mathrm{OD}\right): \delta 3.80\left(1 \mathrm{H}, \mathrm{dd}, J=12.4,6.4, \mathrm{H}-6_{\mathrm{a}}\right), 3.84\left(3 \mathrm{H}, \mathrm{s}, \mathrm{OCH}_{3}\right), 3.88$ $\left(1 \mathrm{H}, \mathrm{dd}, J=12.0,3.2, \mathrm{H}-6_{\mathrm{b}}\right), 4.18\left(1 \mathrm{H}, \mathrm{d}, J=12.4, \mathrm{H}-1_{\mathrm{a}}\right), 4.18-4.22(1 \mathrm{H}$, $\mathrm{m}, \mathrm{H}-5), 4.36\left(1 \mathrm{H}, \mathrm{d}, J=12.8, \mathrm{H}-1_{\mathrm{b}}\right), 4.63(1 \mathrm{H}, \mathrm{d}, J=5.2, \mathrm{H}-3), 4.78(1 \mathrm{H}$, $\mathrm{dd}, J=6.4,5.2, \mathrm{H}-4), 5.00\left(1 \mathrm{H}, \mathrm{d}, J=15.2,{\mathrm{H}-1^{\prime}}_{\mathrm{a}}\right), 5.12(1 \mathrm{H}, \mathrm{d}, J=15.2$, $\left.\mathrm{H}-1^{\prime}{ }_{b}\right), 7.02\left(2 \mathrm{H}, \mathrm{d}, J=8.8,2 \times \mathrm{H}-6^{\prime}\right), 7.52\left(2 \mathrm{H}, \mathrm{d}, J=8.8,2 \times \mathrm{H}-5^{\prime}\right) .{ }^{13} \mathrm{C}-$ NMR $\left(100 \mathrm{MHz}, \mathrm{CD}_{3} \mathrm{OD}\right): 55.8\left(\mathrm{OCH}_{3}\right), 63.9$ (C-6), $64.0\left(\mathrm{C}-1^{\prime}\right), 69.8$ (C1), 72.7 (C-4), 77.0 (C-3), 86.6 (C-5), 94.5 (C-2), 115.5 (C-6'), 123.9 (C-

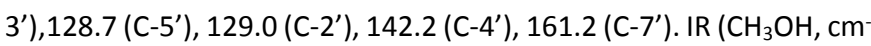
1): 3373 (br), 2925 (m), 1615 (m), 1508 (s), 1249 (s), 1097 (s), 1038 $(\mathrm{s}), 999(\mathrm{~s}), 943(\mathrm{~m}), 833(\mathrm{~m})$. HRMS required for $\mathrm{C}_{16} \mathrm{H}_{20} \mathrm{~N}_{3} \mathrm{O}_{6}{ }^{+}$is 494.1922, found 494.1922 .

\section{(2R,3R,4S,5R)-3'-(4-fluorophenyl)-5-(hydroxymethyl)-4,5-dihydro-} $3 H, 4^{\prime} H, 6^{\prime} H$-spiro[furan-2,7'-[1,2,3]triazolo[5,1-c][1,4]oxazine]-3,4diol $18 \mathrm{~h}$

Chromatography of the crude residue over silica gel (hexane/ ethyl acetate $1 / 9$ ) gave the pure spironucleoside $18 \mathrm{~h}(175 \mathrm{mg}, 80 \%$ overall yield) as white solid. Data for $18 \mathrm{~h}:[\alpha]_{\mathrm{D}}{ }^{20}=-40.8\left(\mathrm{c}=0.01, \mathrm{CHCl}_{3}\right) .{ }^{1} \mathrm{H}-$ NMR (400 MHz, CD $\left.{ }_{3} \mathrm{OD}\right): \delta 3.76\left(1 \mathrm{H}, \mathrm{dd}, J=12.5,6.3, \mathrm{H}-6_{\mathrm{a}}\right), 3.86(1 \mathrm{H}$, $\left.\mathrm{dd}, J=12.5,3.3, \mathrm{H}-6_{\mathrm{b}}\right), 4.18\left(1 \mathrm{H}, \mathrm{d}, J=12.2, \mathrm{H}-1_{\mathrm{a}}\right), 4.16-4.20(1 \mathrm{H}, \mathrm{m}$, $\mathrm{H}-5), 4.36\left(1 \mathrm{H}, \mathrm{d}, J=12.6, \mathrm{H}-1_{\mathrm{b}}\right), 4.62(1 \mathrm{H}, \mathrm{d}, J=4.9, \mathrm{H}-3), 4.76(1 \mathrm{H}, \mathrm{t}$, 
$J=6.2, \mathrm{H}-4), 5.03\left(1 \mathrm{H}, \mathrm{d}, J=15.3, \mathrm{H}-1^{\prime}{ }_{\mathrm{a}}\right), 5.15\left(1 \mathrm{H}, \mathrm{d}, J=15.3, \mathrm{H}-1^{\prime}{ }_{\mathrm{b}}\right)$, $7.21\left(2 \mathrm{H}, \mathrm{t}, J=8.7,2 \times \mathrm{H}-6^{\prime}\right), 7.60\left(2 \mathrm{H}, \mathrm{dd}, J=8.4,5.4,2 \times \mathrm{H}-5^{\prime}\right) .{ }^{13} \mathrm{C}-$ NMR (100 MHz, CD 30 D): 63.8 (C-6), 63.9 (C-1'), 69.8 (C-1), 72.7 (C-4), 77.0 (C-3), 86.6 (C-5), 94.9 (C-2), 117.0 (d, 2 J $_{\mathrm{CF}}=22, \mathrm{C}-6^{\prime}$ ), 128.0 (C$\left.4^{\prime}\right), 129.3\left(\mathrm{~d},{ }^{3} J_{\mathrm{CF}}=9, \mathrm{C}^{\prime} 5^{\prime}\right), 130.8\left(\mathrm{C}-2^{\prime}\right), 141.5\left(\mathrm{C}-3^{\prime}\right), 164.1\left(\mathrm{~d},{ }^{1} J_{\mathrm{CF}}=\right.$ 277, C-7'). IR ( $\left.\mathrm{CH}_{3} \mathrm{OH}, \mathrm{cm}^{-1}\right)$ : $3363(\mathrm{br}), 2921(\mathrm{~m}), 1646(\mathrm{~m}), 1506(\mathrm{~s})$, $1230(\mathrm{~m}), 1098$ (s), 1038 (s), 1004 (s), 944 (m), 838 (m). HRMS required for $\mathrm{C}_{15} \mathrm{H}_{17} \mathrm{~N}_{3} \mathrm{O}_{5} \mathrm{~F}^{+}$is 338.1147 , found 338.1147 .

(2R,3R,4S,5R)-3'-(3-fluorophenyl)-5-(hydroxymethyl)-4,5-dihydro$3 H, 4^{\prime} H, 6^{\prime} H$-spiro[furan-2,7'-[1,2,3]triazolo[5,1-c][1,4]oxazine]-3,4diol $18 \mathrm{i}$

Chromatography of the crude residue over silica gel (hexane/ ethyl acetate $1 / 9$ ) gave the pure spironucleoside $18 \mathbf{i}(162 \mathrm{mg}, 74 \%$ overall yield) as colourless oil. Data for $18 \mathrm{i}$ : $[\alpha]_{D}{ }^{20}=-46.6\left(\mathrm{c}=0.01, \mathrm{CHCl}_{3}\right)$. ${ }^{1} \mathrm{H}-\mathrm{NMR}\left(400 \mathrm{MHz}, \mathrm{CD}_{3} \mathrm{OD}\right): \delta 3.79\left(1 \mathrm{H}, \mathrm{dd}, J=12.0,6.3, \mathrm{H}-6_{\mathrm{a}}\right.$ ), 3.86 $\left(1 \mathrm{H}, \mathrm{dd}, J=12.0,3.2, \mathrm{H}-6_{\mathrm{b}}\right), 4.17\left(1 \mathrm{H}, \mathrm{d}, J=12.7, \mathrm{H}-1_{\mathrm{a}}\right), 4.17-4.21(1 \mathrm{H}$, $\mathrm{m}, \mathrm{H}-5), 4.35\left(1 \mathrm{H}, \mathrm{d}, J=12.6, \mathrm{H}-1_{\mathrm{b}}\right), 4.63(1 \mathrm{H}, \mathrm{d}, J=4.9, \mathrm{H}-3), 4.77(1 \mathrm{H}$, $\mathrm{t}, J=6.3, \mathrm{H}-4), 5.02\left(1 \mathrm{H}, \mathrm{d}, J=15.3, \mathrm{H}-1^{\prime}{ }_{\mathrm{a}}\right), 5.15\left(1 \mathrm{H}, \mathrm{d}, J=15.3, \mathrm{H}-\mathrm{1}_{\mathrm{b}}{ }_{\mathrm{b}}\right)$, $7.09\left(1 \mathrm{H}, \mathrm{td}, J=8.3,2.2, \mathrm{H}-7^{\prime}\right), 7.33-7.40\left(2 \mathrm{H}, \mathrm{m}, \mathrm{H}-5^{\prime}, \mathrm{H}-9^{\prime}\right), 7.46(1 \mathrm{H}$, m, H-8'). ${ }^{13} \mathrm{C}-N M R\left(100 \mathrm{MHz}, \mathrm{CD}_{3} \mathrm{OD}\right): 63.8$ (C-6), 63.9 (C-1'), 69.8 (C1), 72.7 (C-4), 77.0 (C-3), 86.6 (C-5), 94.6 (C-2), 113.8 (d, ${ }^{2}$ J $_{\mathrm{CF}}=23, \mathrm{C}-$ $\left.5^{\prime}\right), 115.9\left(d,{ }^{2} J_{\mathrm{CF}}=22, \mathrm{C}-7^{\prime}\right), 123.0\left(\mathrm{~d},{ }^{4} J_{\mathrm{CF}}=3, \mathrm{C}-9^{\prime}\right), 131.0\left(\mathrm{C}-2^{\prime}\right), 132.0$ $\left(\mathrm{d},{ }^{3} J_{\mathrm{CF}}=9, \mathrm{C}-8^{\prime}\right), 133.9\left(\mathrm{~d},{ }^{3} J_{\mathrm{CF}}=8, \mathrm{C}-4^{\prime}\right), 141.0\left(\mathrm{~d},{ }^{4} J_{\mathrm{CF}}=2, \mathrm{C}-3^{\prime}\right), 164.6$ $\left(\mathrm{d},{ }^{2} J_{\mathrm{CF}}=243, \mathrm{C}-6^{\prime}\right) . \mathrm{IR}\left(\mathrm{CH}_{3} \mathrm{OH}, \mathrm{cm}^{-1}\right): 3362(\mathrm{br}), 2921(\mathrm{~m}), 1496(\mathrm{~m})$, $1102(\mathrm{~s}), 1043(\mathrm{~s}), 1005(\mathrm{~s}), 943(\mathrm{~m}), 821(\mathrm{~m})$. HRMS required for $\mathrm{C}_{15} \mathrm{H}_{17} \mathrm{~N}_{3} \mathrm{O}_{5} \mathrm{~F}^{+}$is 338.1147 , found 338.1147 .

(2R,3R,4S,5R)-3'-(2-fluorophenyl)-5-(hydroxymethyl)-4,5-dihydro$3 H, 4^{\prime} H, 6^{\prime} H$-spiro[furan-2,7'-[1,2,3]triazolo[5,1-c][1,4]oxazine]-3,4diol 18j

Chromatography of the crude residue over silica gel (hexane/ ethyl acetate $1 / 9$ ) gave the pure spironucleoside $18 \mathbf{j}$ (160 mg, 73\% overall yield) as colourless oil. Data for $18 \mathrm{j}$ : $[\alpha]_{\mathrm{D}}{ }^{20}=-48.2\left(\mathrm{c}=0.01, \mathrm{CHCl}_{3}\right)$. ${ }^{1} \mathrm{H}-\mathrm{NMR}\left(400 \mathrm{MHz}, \mathrm{CD}_{3} \mathrm{OD}\right): \delta 3.68\left(1 \mathrm{H}, \mathrm{dd}, J=12.0,6.3, \mathrm{H}-6_{\mathrm{a}}\right.$ ), 3.75 $\left(1 \mathrm{H}, \mathrm{dd}, J=12.0,3.3, \mathrm{H}-6_{\mathrm{b}}\right), 4.08\left(1 \mathrm{H}, \mathrm{d}, J=12.4, \mathrm{H}-1_{\mathrm{a}}\right), 4.06-4.10(1 \mathrm{H}$, $\mathrm{m}, \mathrm{H}-5), 4.25\left(1 \mathrm{H}, \mathrm{d}, J=12.6, \mathrm{H}-1_{\mathrm{b}}\right), 4.52(1 \mathrm{H}, \mathrm{d}, J=4.9, \mathrm{H}-3), 4.66(1 \mathrm{H}$, $\mathrm{t}, J=6.0, \mathrm{H}-4), 4.78\left(1 \mathrm{H}, \mathrm{d}, J=15.4, \mathrm{H}-1^{\prime}{ }_{\mathrm{a}}\right), 4.90\left(1 \mathrm{H}, \mathrm{d}, J=15.4, \mathrm{H}-\mathrm{1}_{\mathrm{b}}{ }_{\mathrm{b}}\right)$, $7.11\left(1 \mathrm{H}, \mathrm{t}, J=10.8, \mathrm{H}-6^{\prime}\right), 7.19\left(1 \mathrm{H}, \mathrm{t}, J=7.6, \mathrm{H}-8^{\prime}\right), 7.33(2 \mathrm{H}, \mathrm{dd}, J=$ $\left.14.3,6.9, \mathrm{H}-7^{\prime}\right), 7.46\left(1 \mathrm{H}, \mathrm{t}, J=7.2, \mathrm{H}-8^{\prime}\right) .{ }^{13} \mathrm{C}-\mathrm{NMR}\left(100 \mathrm{MHz}, \mathrm{CD}_{3} \mathrm{OD}\right)$ : 63.9 (C-6), 64.0 (C-1'), 70.0 (C-1), 72.7 (C-4), 77.1 (C-3), 86.6 (C-5), $94.6(C-2), 117.0\left(d,{ }^{2} J_{C F}=24, C-6^{\prime}\right), 119.2\left(d,{ }^{2} J_{C F}=26, C-4^{\prime}\right), 126.0(d$, $\left.{ }^{4} J_{C F}=4, C-8^{\prime}\right), 130.9\left(d,{ }^{5} J_{C F}=3, C-9^{\prime}\right), 131.8\left(d,{ }^{3} J_{C F}=10, C-7^{\prime}\right), 132.0$ $\left(\mathrm{C}-2^{\prime}\right), 137.3\left(\mathrm{C}-3^{\prime}\right), 160.6\left(\mathrm{~d},{ }^{2} \mathrm{~J}_{\mathrm{CF}}=240, \mathrm{C}-5^{\prime}\right) . \mathrm{IR}\left(\mathrm{CH}_{3} \mathrm{OH}, \mathrm{cm}^{-1}\right): 3381$ (br), $2922(\mathrm{~m}), 1496(\mathrm{~m}), 1102(\mathrm{~s}), 1043(\mathrm{~s}), 1004(\mathrm{~s}), 945(\mathrm{~m}), 823$ (m). HRMS required for $\mathrm{C}_{15} \mathrm{H}_{17} \mathrm{~N}_{3} \mathrm{O}_{5} \mathrm{~F}^{+}$is 338.1147 , found 338.1147 .

\section{(2R,3R,4S,5R)-5-(hydroxymethyl)-3'-pentyl-4,5-dihydro-} $3 H, 4^{\prime} H, 6$ ' $H$-spiro[furan-2,7'-[1,2,3]triazolo[5,1-c][1,4]oxazine]-3,4diol $18 \mathrm{k}$

Chromatography of the crude residue over silica gel (hexane/ ethyl acetate $2 / 8$ ) gave the pure spironucleoside $18 \mathbf{k}$ (140 $\mathrm{mg}, 69 \%$ yield) as colourless syrup. Data for 18k: $[\alpha]_{\mathrm{D}}{ }^{20}=-47.2\left(\mathrm{c}=0.01, \mathrm{CHCl}_{3}\right) .{ }^{1} \mathrm{H}-$ NMR (400 MHz, CD $\left.{ }_{3} \mathrm{OD}\right): \delta 0.92\left(3 \mathrm{H}, \mathrm{t}, J=6.6,3 \times \mathrm{H}-8^{\prime}\right), 1.26-1.39(4 \mathrm{H}$, $\left.\mathrm{m}, 2 \times \mathrm{H}-6^{\prime}, 2 \times \mathrm{H}-7^{\prime}\right), 1.63\left(2 \mathrm{H}\right.$, quint $\left., J=7.2,2 \times \mathrm{H}-5^{\prime}\right), 2.63(2 \mathrm{H}, \mathrm{t}, J=$ 7.6, $\left.2 \times \mathrm{H}-4^{\prime}\right), 3.74\left(1 \mathrm{H}, \mathrm{dd}, J=12.0,6.3, \mathrm{H}-6_{\mathrm{a}}\right), 3.84(1 \mathrm{H}, \mathrm{dd}, J=12.0$, 3.2, H-6b), $4.11\left(1 \mathrm{H}, \mathrm{d}, J=12.8, \mathrm{H}-\mathrm{1}_{\mathrm{a}}\right), 4.12-4.16(1 \mathrm{H}, \mathrm{m}, \mathrm{H}-5), 4.29$ $\left(1 \mathrm{H}, \mathrm{d}, J=12.6, \mathrm{H}-1_{\mathrm{b}}\right), 4.54(1 \mathrm{H}, \mathrm{d}, J=4.9, \mathrm{H}-3), 4.70(1 \mathrm{H}$, app t, $J=$ 5.5, H-4), $4.78\left(1 \mathrm{H}, \mathrm{d}, J=15.0, \mathrm{H}-1^{\prime}{ }_{\mathrm{a}}\right), 4.89\left(1 \mathrm{H}, \mathrm{d}, J=13.0, \mathrm{H}-1^{\prime}{ }_{\mathrm{b}}\right) .{ }^{13} \mathrm{C}-$ NMR (100 MHz, CD ${ }_{3} \mathrm{OD}$ ): 14.3 (C-8'), 23.4 ( C-7'), 25.5 (C-4'), 29.8 (C5'), 32.5 (C-6'), 62.9 (C-1'), 64.0 (C-6), 70.1 (C-1), 72.6 (C-4), 77.0 (C3), 86.2 (C-5), 94.2 (C-2), 130.4 (C-2'), $142.5\left(\mathrm{C}-3^{\prime}\right) . \mathrm{IR}\left(\mathrm{CH}_{3} \mathrm{OH}, \mathrm{cm}^{-1}\right)$ : 3321 (br), 2922 (s), 1636 (br), $1456(\mathrm{~m}), 1100$ (s), $1036(\mathrm{~s}), 941(\mathrm{~m})$. HRMS required for $\mathrm{C}_{14} \mathrm{H}_{24} \mathrm{~N}_{3} \mathrm{O}_{5}{ }^{+}$is 314.1716 , found 314.1710 .

\section{(3aR,4R,6S,6aS)-2,2-Dimethyl-3a,6a-dihydro-4' $\mathrm{H}, 6 \mathrm{H}$, 6' $^{\prime} \mathrm{H}$ - spiro[furo[3,4-d][1,3]dioxole-4,7'-[1,2,3]triazolo[5,1- c][1,4]oxazine]-6-carbaldehyde 19}

Primary alcohol 17a (0.97 mmol) was dissolved in dichloromethane $(10 \mathrm{~mL})$. Sodium bicarbonate $(2.91 \mathrm{mmol})$ and Dess-Martin periodinane $(1.16 \mathrm{mmol})$ were added sequentially in one portion at $0^{\circ} \mathrm{C}$ and the resulting mixture stirred vigorously at the same temperature until TLC analysis showed the reaction was complete (2 h). The reaction was quenched with $10 \%$ thiosulfate aq. solution ( 2 $\mathrm{mL}$ ) and the mixture partitioned between saturated aq. $\mathrm{NaHCO}_{3}$ and dichloromethane. The organic layer was washed with brine, dried over $\mathrm{MgSO}_{4}$, filtered and concentrated to dryness under reduced pressure. Chromatography of the crude residue over silica gel (dichloromethane/methanol 95/5) gave the pure aldehyde 19 (217 $\mathrm{mg}, 80 \%$ yield) as white solid. Data for $19: \mathrm{Mp}=74-75^{\circ} \mathrm{C}$. $[\alpha]_{\mathrm{D}}{ }^{25}=-$ $60.0\left(\mathrm{c}=0.01, \mathrm{I}=0.025 \mathrm{dm}, \mathrm{CHCl}_{3}\right.$ ). ${ }^{1} \mathrm{H}-\mathrm{NMR}\left(400 \mathrm{MHz}, \mathrm{CDCl}_{3}\right): \delta 1.38$ $\left(3 \mathrm{H}, \mathrm{s}, \mathrm{CH}_{3}\right), 1.58\left(3 \mathrm{H}, \mathrm{s}, \mathrm{CH}_{3}\right), 4.26\left(1 \mathrm{H}, \mathrm{d}, J=12.8, \mathrm{H}-1_{\mathrm{a}}\right), 4.33(1 \mathrm{H}, \mathrm{d}$, $\left.J=12.8, \mathrm{H}-1_{\mathrm{b}}\right), 4.63(1 \mathrm{H}, \mathrm{d}, J=1.2, \mathrm{H}-3), 4.84\left(1 \mathrm{H}, \mathrm{d}, J=15.2, \mathrm{H}-1^{\prime}{ }_{\mathrm{a}}\right)$, $4.98(1 \mathrm{H}, \mathrm{d}, J=6.0, \mathrm{H}-5), 5.08\left(1 \mathrm{H}, \mathrm{d}, J=15.2, \mathrm{H}-1^{\prime}{ }_{\mathrm{b}}\right), 5.50(1 \mathrm{H}, \mathrm{dd}, J=$ $5.8,1.3, \mathrm{H}-4), 7.55\left(1 \mathrm{H}, \mathrm{s}, \mathrm{H}-3^{\prime}\right), 9.31(1 \mathrm{H}, \mathrm{s}, \mathrm{H}-6) .{ }^{13} \mathrm{C}-\mathrm{NMR}(100 \mathrm{MHz}$, $\left.\mathrm{CDCl}_{3}\right)$ : $24.6\left(\mathrm{CH}_{3}\right), 26.1\left(\mathrm{CH}_{3}\right), 62.4(\mathrm{C}-6), 63.8\left(\mathrm{C}-1^{\prime}\right), 69.7(\mathrm{C}-1), 82.2$ (C-4), 86.2 (C-3), 88.4 (C-5), 94.4 (C-2), $\left.113.9\left(\mathrm{C}_{\left(\mathrm{CH}_{3}\right)}\right)_{2}\right), 128.4\left(\mathrm{C}-3^{\prime}\right)$, 132.3 (C-2'). IR ( $\left.\mathrm{CHCl}_{3}, \mathrm{~cm}^{-1}\right)$ : 2990 (w), 1732 (m, C=O), 1377 (m), 1211 (m), 1096 (s), $864(\mathrm{~m}), 732$ (s). HRMS required for $\mathrm{C}_{12} \mathrm{H}_{18} \mathrm{~N}_{3} \mathrm{O}_{5}$ is 284.1241, found 284.1242 .

\section{Diethyl (2-((3aR,4R,6R,6aR)-2,2-dimethyl-3a,6a-dihydro- 4' $H, 6 H, 6^{\prime} H$-spiro[furo[3,4- $\left.d\right][1,3]$ dioxole-4,7'-[1,2,3]triazolo[5,1- c][1,4]oxazin]-6-yl)vinyl)phosphonate 20}

Sodium hydride (60\% dispersion in mineral oil, $59 \mathrm{mg}, 1.47 \mathrm{mmol}$ ) was suspended in dry THF $(1 \mathrm{~mL})$ at $0{ }^{\circ} \mathrm{C}$ under an inert atmosphere of argon. A solution of tetraethyl methylenediphosphonate $(443 \mathrm{mg}$, $1.54 \mathrm{mmol})$ in dry THF $(0.5 \mathrm{~mL})$ was then added dropwise. The suspension was allowed to warm to room temperature and stirred for $45 \mathrm{~min}$. Reaction mixture cooled down to $0^{\circ} \mathrm{C}$ and a solution of aldehyde 19 (197 mg, $0.70 \mathrm{mmol})$ in THF (1.5 mL) added dropwise. The resulting mixture was allowed to warm to room temperature and stirred for $2 \mathrm{~h}$. The reaction mixture was treated with methanol, diluted with saturated $\mathrm{NaHCO}_{3}$ solution and extracted with ethyl acetate. The organic phase was then washed with brine, dried over $\mathrm{MgSO}_{4}$, filtered and concentrated to dryness under reduced pressure. Chromatography of the crude residue over silica gel (dichloromethane/methanol 96/4) gave $218 \mathrm{mg}$ ( $80 \%$ yield) of $\mathbf{2 0}$ as 
an inseparable 1:4 mixture of $E$ and $Z$ alkene isomers. Data for $Z$ isomer 20: Colourless syrup. $[\alpha]_{D} 25=+84.0(c=0.01, l=0.025 \mathrm{dm}$ $\left.\mathrm{CHCl}_{3}\right) .{ }^{1} \mathrm{H}-\mathrm{NMR}\left(400 \mathrm{MHz}, \mathrm{CDCl}_{3}\right): \delta 122-1.38(6 \mathrm{H}, \mathrm{m}, 6 \times \mathrm{H}-9), 1.40$ $\left(3 \mathrm{H}, \mathrm{s}, \mathrm{CH}_{3}\right), 1.53\left(3 \mathrm{H}, \mathrm{s}, \mathrm{CH}_{3}\right), 3.97-4.07(4 \mathrm{H}, \mathrm{m}, 4 \times \mathrm{H}-8), 4.10-4.15(2 \mathrm{H}$ $\mathrm{m}, \mathrm{H}-3, \mathrm{H}-4), 4.22\left(1 \mathrm{H}, \mathrm{d}, J=12.8, \mathrm{H}-1_{a}\right), 4.32\left(1 \mathrm{H}, \mathrm{d}, J=13.2, \mathrm{H}-1_{\mathrm{b}}\right)$, $4.82\left(1 \mathrm{H}, \mathrm{d}, J=15.2, \mathrm{H}-1^{\prime}{ }_{\mathrm{a}}\right), 4.90(1 \mathrm{H}, \mathrm{q}, J=7.6, \mathrm{H}-5), 4.96(1 \mathrm{H}, \mathrm{d}, J=$ 5.7, H-7), $5.09\left(1 \mathrm{H}, \mathrm{d}, J=15.2, \mathrm{H}-1^{\prime}{ }_{\mathrm{b}}\right), 5.63(1 \mathrm{H}, \mathrm{dd}, J=5.7,3.2, \mathrm{H}-6)$, $7.53\left(1 \mathrm{H}, \mathrm{s}, \mathrm{H}-3^{\prime}\right) .{ }^{13} \mathrm{C}-\mathrm{NMR}\left(100 \mathrm{MHz}, \mathrm{CDCl}_{3}\right): 16.3\left(\mathrm{~d},{ }^{3} \mathrm{JP}_{\mathrm{CP}}=5, \mathrm{C}-9\right)$, $26.0\left(\mathrm{CH}_{3}\right), 26.7\left(\mathrm{CH}_{3}\right), 61.8\left(\mathrm{~d},{ }^{2} J_{\mathrm{CP}}=7, \mathrm{C}-8_{a}\right), 61.9\left(\mathrm{~d}, 2 \mathrm{~J}_{\mathrm{CP}}=6, \mathrm{C}-8_{b}\right)$, $62.4\left(\mathrm{C}-1^{\prime}\right), 68.1$ (C-1), 80.2 (C-3), 82.6 (C-5), $91.8(\mathrm{C}-2), 94.5\left(\mathrm{~d},{ }^{3}\right)_{\mathrm{CP}}=$

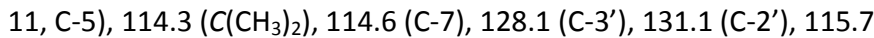
$\left(d,{ }^{2} J_{C P}=14, C-6\right) . I R\left(c^{-1}\right): 2987$ (w), 1251 (s, P=O), 1099 (s), 1026 (s, $\mathrm{P}-\mathrm{O}-\mathrm{C}), 968(\mathrm{~s}), 797(\mathrm{~m})$. HRMS required for $\mathrm{C}_{17} \mathrm{H}_{27} \mathrm{~N}_{3} \mathrm{O}_{7} \mathrm{P}^{+}$is 416.1587 found 416.1581 .

\section{Diethyl (2-((3aR,4R,6R,6aR)-2,2-dimethyl-3a,6a-dihydro- 4' $H, 6 H, 6 ' H$-spiro[furo[3,4-d][1,3]dioxole-4,7'-[1,2,3]triazolo[5,1- c][1,4]oxazin]-6-yl)ethyl)phosphonate 21}

In a hydrogenation vessel, vinyl phosphonate $\mathbf{2 0}(218 \mathrm{mg} 0.52 \mathrm{mmol})$ was dissolved in methanol $(4 \mathrm{~mL})$ and $\mathrm{Pd} / \mathrm{C} 10 \%(22 \mathrm{mg})$ was added in one portion. The reactor was purged three times with $\mathrm{N}_{2}$ and the mixture was agitated for 5 min. After purging with $\mathrm{H}_{2}$ three times, the reactor was pressurised to 4 bar and the resulting suspension stirred vigorously for $6 \mathrm{~h}$. The catalyst was filtered, and the filtrate was evaporated to dryness. Purification of the crude product by column chromatography (silica gel, dichloromethane/ methanol 96/4) gave pure alkyl phosphonate 21 (214 mg, 94\% yield) as colourless oil. Data for 21: Colourless syroup. $[\alpha]_{D}{ }^{25}=-380.0$ ( $c=0.01$, $\left.\mathrm{I}=0.025 \mathrm{dm}, \mathrm{CHCl}_{3}\right) .{ }^{1} \mathrm{H}-\mathrm{NMR}\left(400 \mathrm{MHz}, \mathrm{CDCl}_{3}\right): \delta 1.31(6 \mathrm{H}, \mathrm{td}, J=7.1$ $1.9,6 \times \mathrm{H}-9), 1.35\left(3 \mathrm{H}, \mathrm{s}, \mathrm{CH}_{3}\right), 1.53\left(3 \mathrm{H}, \mathrm{s}, \mathrm{CH}_{3}\right), 4.05-4.13(4 \mathrm{H}, \mathrm{m}, 4 \times \mathrm{H}-$ 8), $4.09\left(1 \mathrm{H}, \mathrm{d}, J=12.9, \mathrm{H}-1_{\mathrm{a}}\right), 4.21\left(1 \mathrm{H}, \mathrm{d}, J=12.8, \mathrm{H}-1_{\mathrm{b}}\right), 4.61(1 \mathrm{H}, \mathrm{t}$, $J=6.8, \mathrm{H}-5), 4.80\left(1 \mathrm{H}, \mathrm{d}, J=15.2, \mathrm{H}-1^{\prime}{ }_{\mathrm{a}}\right), 5.05\left(1 \mathrm{H}, \mathrm{d}, J=15.1, \mathrm{H}-1^{\prime}{ }_{\mathrm{b}}\right)$, 5.08-5.11 (2H, m, H-3, H-4), $7.51\left(1 \mathrm{H}, \mathrm{s}, \mathrm{H}-3^{\prime}\right) .{ }^{13} \mathrm{C}-\mathrm{NMR}(100 \mathrm{MHz}$, $\left.\mathrm{CDCl}_{3}\right): 16.4\left(\mathrm{~d},{ }^{3} \mathrm{JP}_{\mathrm{CP}}=6, \mathrm{C}-9\right), 22.0\left(\mathrm{~d},{ }^{1} J_{\mathrm{CP}}=142, \mathrm{C}-7\right), 22.1\left(\mathrm{~d},{ }^{2} J_{\mathrm{CP}}=4\right.$, C-6), $24.5\left(\mathrm{CH}_{3}\right), 25.9\left(\mathrm{CH}_{3}\right), 61.5\left(\mathrm{~d},{ }^{2} \mathrm{~J}_{\mathrm{CP}}=6, \mathrm{C}-8{ }_{a}\right), 61.6\left(\mathrm{~d},{ }^{2} \mathrm{~J}_{\mathrm{CP}}=7, \mathrm{C}-\right.$ 8b), $62.4\left(\mathrm{C}-1^{\prime}\right), 68.7$ (C-1), 81.2 (C-3), 82.5 (d, $\left.{ }^{3}{ }_{\mathrm{CP}}=19, \mathrm{C}-5\right), 85.5$ (C-

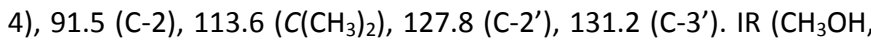
$\mathrm{cm}^{-1}$ ): $2983(\mathrm{br}), 1376(\mathrm{~m}), 1234$ (s, P=O), 1212 (s, P=O), 1098 (s, P-OC), $1029(\mathrm{P}-\mathrm{O}-\mathrm{C}), 963(\mathrm{~m})$. HRMS required for $\mathrm{C}_{17} \mathrm{H}_{29} \mathrm{~N}_{3} \mathrm{O}_{7} \mathrm{P}^{+}$is 418.1743 found 418.1736

\section{(2-((2R,3R,4S,5R)-3,4-Dihydroxy-4,5-dihydro-3H,4' H,6' $H$ - spiro[furan-2,7'-[1,2,3]triazolo[5,1-c][1,4]oxazin]-5- \\ yl)ethyl)phosphonic acid 23}

Phosphonate nucleoside 21 (213 mg, $0.51 \mathrm{mmol}$ ) was dissolved in a solution of methanol/water $8 / 2(20 \mathrm{~mL})$ and Dowex $50 \mathrm{WX} 8$ hydrogen form $(2.7 \mathrm{~g})$ was added in one portion. The resulting suspension was stirred vigorously for $4 \mathrm{~h}$ at $50^{\circ} \mathrm{C}$, then the resin was filtered off and washed with methanol. The filtrate was concentrated to dryness under reduced pressure to give diol $\mathbf{2 2}$ as yellow oil. This crude residue was dissolved in anhydrous dichloromethane $(2 \mathrm{~mL})$ in $10 \mathrm{~mL}$ round bottom flask. 2,6-Dimethylpyridine ( $672 \mu \mathrm{L}, 6.12 \mathrm{mmol}$ ) was added under inert atmosphere, followed by bromo(trimethyl)silane ( $538 \mu \mathrm{L}, 4.08 \mathrm{mmol})$. Reaction mixture was stirred for $2 \mathrm{~h}$, then quenched with ammonium hydroxide aq. solution $(5 \mathrm{~mL}$ ). Aqueous phase was washed up with isohexane (1 $\mathrm{mL}$ ), concentrated to dryness under vacuum to afford a crude residue which was purified by mass directed prep HPLC using a XBridge $\mathrm{dC}_{18}$ $5 \mu$ OBD $30 \times 100 \mathrm{~mm}$ prep column. RP-HPLC was conducted an elution gradient of $1-100 \%$ B over $11.40 \mathrm{~min}$, where $A$ is $\mathrm{H}_{2} \mathrm{O}$ in $10 \mathrm{mM}$ Ammonium Acetate and $\mathrm{B}$ is $\mathrm{CH}_{3} \mathrm{CN}$, to gave pure phosphonate nucleoside 23 (31 mg, 12\% over two steps). Data for 23: Colourless oil. $[\alpha]_{D}{ }^{25}=-44.0\left(\mathrm{c}=0.01, \mathrm{I}=0.025 \mathrm{dm}, \mathrm{CHCl}_{3}\right) .{ }^{1} \mathrm{H}-\mathrm{NMR}(400 \mathrm{MHz}$, $\left.\mathrm{CD}_{3} \mathrm{OD}\right): \delta$ 1.69-1.91 (2H, m, 2×H-7), 1.95-2.05 (2H, m, $\left.2 \times \mathrm{H}-6\right), 4.13$ $(1 \mathrm{H}, \mathrm{d}, J=12.6, \mathrm{H}-1 \mathrm{a}), 4.28(1 \mathrm{H}, \mathrm{d}, J=12.6, \mathrm{H}-1 \mathrm{~b}), 4.41(1 \mathrm{H}, \mathrm{dd}, J=$ 4.6, 3.2, H-4), $4.46(1 \mathrm{H}, \mathrm{td}, J=6.8,3.1, \mathrm{H}-5), 4.82(1 \mathrm{H}, \mathrm{d}, J=15.1, \mathrm{H}-$ $\left.1^{\prime} \mathrm{a}\right), 5.00\left(1 \mathrm{H}, \mathrm{d}, J=15.1, \mathrm{H}-1^{\prime} \mathrm{b}\right), 5.23(1 \mathrm{H}, \mathrm{d}, J=4.3, \mathrm{H}-3), 7.59(1 \mathrm{H}$, s, H-3'). ${ }^{13} \mathrm{C}-N M R\left(100 \mathrm{MHz}, \mathrm{CD}_{3} \mathrm{OD}\right): 22.6\left(\mathrm{~d},{ }^{3} \mathrm{~J}_{\mathrm{CP}}=3, \mathrm{C}-6\right), 23.1$ (d, $\left.{ }^{1} J_{C P}=85, C-7\right), 61.6\left(C-1^{\prime}\right), 69.9(C-1), 71.8(C-5), 77-3(C-3), 81.8$ (d, $\left.{ }^{4} J_{C P}=15, C-4\right), 92.0(C-2), 127.6$ (C-2'), 133.5 (C-3'). 31P-NMR (200 $\mathrm{MHz}, \mathrm{CD}_{3} \mathrm{OD}$ ): 29.43. IR ( $\left.\mathrm{CH}_{3} \mathrm{OH}, \mathrm{cm}^{-1}\right): 3094$ (br), $1628(\mathrm{~m}), 1396$ (s, $\mathrm{P}=\mathrm{O}), 1066$ (s, P-O-C), $915(\mathrm{~m})$. HRMS required for $\mathrm{C}_{10} \mathrm{H}_{17} \mathrm{~N}_{3} \mathrm{O}_{7} \mathrm{P}^{+}$is 322.080 found 322.080 .

\section{6-O-Benzyl-2-deoxy-3,4-O-isopropylidene-2-aminomethyl- $\beta$-D- psicofuranose 24}

Lithium aluminium hydride $(2.38 \mathrm{~g}, 62.6 \mathrm{mmol})$ was placed in a three necked round bottom flask equipped with thermometer, pressure equalising dropping funnel and stirrer under a nitrogen atmosphere. Anhydrous diethyl ether $(50 \mathrm{~mL})$ was charged at $0{ }^{\circ} \mathrm{C}$, maintaining an internal temperature of less than $25^{\circ} \mathrm{C}$. A solution of psicofuranosyl cyanide $11(10.0 \mathrm{~g}, 31.3 \mathrm{mmol})$ in anhydrous diethyl ether $(50 \mathrm{~mL})$ was then added dropwise at $0{ }^{\circ} \mathrm{C}$ with careful control of the exotherm. The reaction mixture was allowed to warm to room temperature and stirred for $2 \mathrm{~h}$. Excess $\mathrm{LiAlH}_{4}$ was carefully quenched with $7 \mathrm{~mL}$ of AcOEt at $0{ }^{\circ} \mathrm{C}$ added dropwise (CARE: violent reaction). The following treatment with $1.0 \mathrm{M} \mathrm{K}_{2} \mathrm{CO}_{3}$ gave a white precipitate that was removed under filtration over celite. The filtrate was evaporated under reduced pressure to afford the crude residue as colourless oil, which was pure enough to be used immediately for the next step. Purification of the crude product by column chromatography (silica gel, ethyl acetate / methanol / ammonium hydroxide 95/4/1) gave the pure amino alcohol 24 ( $9.9 \mathrm{~g}$, 98\% yield) as a colourless oil. Data for 24: Oil. $[\alpha]_{D} 25=+7.2$ ( $c=0.01, l=0.025$, $\left.\mathrm{CHCl}_{3}\right)$. ${ }^{1} \mathrm{H}-\mathrm{NMR}\left(400 \mathrm{MHz}, \mathrm{CDCl}_{3}\right): \delta 1.33\left(3 \mathrm{H}, \mathrm{s}, \mathrm{CH}_{3}\right), 1.53(3 \mathrm{H}, \mathrm{s}$, $\left.\mathrm{CH}_{3}\right), 2.88\left(1 \mathrm{H}, \mathrm{d}, J=13.0, \mathrm{H}-1^{\prime}{ }_{a}\right), 3.04\left(1 \mathrm{H}, \mathrm{d}, J=13.0, \mathrm{H}-1^{\prime}{ }_{b}\right), 3.53$ $\left(1 \mathrm{H}, \mathrm{dd}, J=10.4,4.3, \mathrm{H}-6_{a}\right), 3.60\left(1 \mathrm{H}, \mathrm{dd}, J=10.4,4.3, \mathrm{H}-6_{b}\right), 3.71(1 \mathrm{H}$, $\left.\mathrm{d}, J=11.8, \mathrm{H}-1_{a}\right), 3.81\left(1 \mathrm{H}, \mathrm{d}, J=11.8, \mathrm{H}-1_{b}\right), 4.18(1 \mathrm{H}, \mathrm{q}, J=4.1, \mathrm{H}-5)$, $4.51(2 \mathrm{H}, \mathrm{s}, 2 \times \mathrm{H}-7), 4.53-4.60(1 \mathrm{H}, \mathrm{m}, \mathrm{H}-3), 4.72(1 \mathrm{H}, \mathrm{dd}, J=6.5,4.4$, $\mathrm{H}-4), 7.25-7.36\left(5 \mathrm{H}, \mathrm{m}, 5 \times \mathrm{H}_{\text {Arom }}\right) .{ }^{13} \mathrm{C}-\mathrm{NMR}\left(100 \mathrm{MHz}, \mathrm{CDCl}_{3}\right): 24.5$ $\left(\mathrm{CH}_{3}\right), 26.6\left(\mathrm{CH}_{3}\right), 45.3\left(\mathrm{C}-1^{\prime}\right), 62.8$ (C-1), 70.4 (C-6), 73.5 (C-7), 82.1

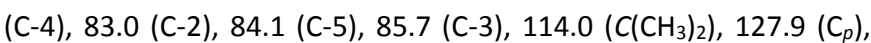
$127.9\left(\mathrm{C}_{o}\right), 128.5\left(\mathrm{C}_{\mathrm{m}}\right), 137.6\left(\mathrm{C}_{\text {ipso }}\right) . \mathrm{IR}\left(\mathrm{CHCl}_{3}, \mathrm{~cm}^{-1}\right)$ : $3200(\mathrm{br}), 2931$ $(\mathrm{m}), 1559(\mathrm{~m}), 1381(\mathrm{~m}), 1210(\mathrm{~m}), 1072(\mathrm{~s}), 866(\mathrm{~m})$. HRMS required for $\mathrm{C}_{17} \mathrm{H}_{26} \mathrm{NO}_{5}{ }^{+}$is 324.181 , found 324.180 .

\section{General procedure for sulfonyl amido ester protection:}


To a stirred solution of telescoped amino alcohol 24 (1.0 eq.) in $\mathrm{CH}_{2} \mathrm{Cl}_{2}$ (0.1 M concentration), triethylamine (4.0 eq.), 4dimethylaminopyridine (1.0 eq.) and an appropriate sulfonyl chloride (3.0 eq.) were added sequentially at $0{ }^{\circ} \mathrm{C}$. The resulting mixture was allowed to warm to room temperature and stirred for $16 \mathrm{~h}$. The reaction mixture was poured into water and the water layer was extracted with dichloromethane. The combined organic extracts were washed sequentially with $1.0 \mathrm{M} \mathrm{HCl}$, water and brine. dried over $\mathrm{MgSO}_{4}$, filtered and concentrated to dryness under reduced pressure and purified by column chromatography.

\section{6-O-Benzyl-2-deoxy-3,4-O-isopropylidene-1-O-mesyl-2- mesylaminomethyl- $\beta$-D-psicofuranose $25 \mathrm{a}^{16}$}

Chromatography of the crude residue over silica gel (isohexane/ ethyl acetate 1/1) gave the pure sulfonyl amidoester 25a (979 mg, $66 \%$ o.y.) as colourless oil. Data for $25 \mathrm{a}$ : Oil. $[\alpha]_{D}{ }^{20}=+3.1$ (c $=0.01$, $\left.\mathrm{CHCl}_{3}\right) .{ }^{1} \mathrm{H}-\mathrm{NMR}\left(400 \mathrm{MHz}, \mathrm{CDCl}_{3}\right): \delta 1.32\left(3 \mathrm{H}, \mathrm{s}, \mathrm{CH}_{3}\right), 1.51(3 \mathrm{H}, \mathrm{s}$, $\left.\mathrm{CH}_{3}\right), 2.74\left(3 \mathrm{H}, \mathrm{s}, \mathrm{NHSO}_{2} \mathrm{CH}_{3}\right), 3.05\left(3 \mathrm{H}, \mathrm{s}, \mathrm{SO}_{3} \mathrm{CH}_{3}\right), 3.29-3.30(2 \mathrm{H}, \mathrm{m}$, $\left.2 \times \mathrm{H}-1^{\prime}\right), 3.59\left(1 \mathrm{H}, \mathrm{dd}, J=10.4,2.4, \mathrm{H}-6_{a}\right), 3.71(1 \mathrm{H}, \mathrm{dd}, J=10.4,2.4$, $\left.\mathrm{H}-6_{b}\right), 4.10-4.16(1 \mathrm{H}, \mathrm{m}, \mathrm{H}-5), 4.31\left(1 \mathrm{H}, \mathrm{d}, \mathrm{J}=10.8, \mathrm{H}-1_{a}\right), 4.36(1 \mathrm{H}, \mathrm{J}=$ 10.8, H-1 $\left.{ }_{b}\right), 4.54\left(1 \mathrm{H}, \mathrm{d}, J=12.0, \mathrm{H}-7_{a}\right), 4.59\left(1 \mathrm{H}, \mathrm{d}, J=12.0, \mathrm{H}-7_{b}\right)$, $4.78(1 \mathrm{H}, \mathrm{d}, J=6.0, \mathrm{H}-3), 5.10(1 \mathrm{H}, \mathrm{t}, J=5.2, \mathrm{H}-4), 7.77(1 \mathrm{H}, \mathrm{dd}, J=8.0$, 4.4, NH), 7.28-7.36 (5H, m, $\left.5 \times \mathrm{H}_{\text {arom }}\right) .{ }^{13} \mathrm{C}-\mathrm{NMR}\left(100 \mathrm{MHz}, \mathrm{CDCl}_{3}\right): 25.2$ $\left(\mathrm{CH}_{3}\right), 27.0\left(\mathrm{CH}_{3}\right), 37.4\left(\mathrm{SO}_{3} \mathrm{CH}_{3}\right), 40.0\left(\mathrm{NHSO}_{2} \mathrm{CH}_{3}\right), 46.9\left(\mathrm{C}-1^{\prime}\right), 69.0$ (C-1), 69.6 (C-6), 73.7 (C-7), 81.6 (C-4), 83.4 (C-3), 84.4 (C-2), 84.5 (C-

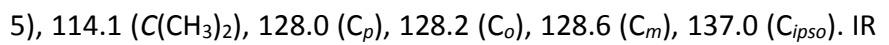
$\left(\mathrm{CHCl}_{3}, \mathrm{Cm}^{-1}\right): 3282(\mathrm{br}), 2936(\mathrm{~m}), 2359(\mathrm{w}), 1559(\mathrm{~m}), 1327(\mathrm{~m}), 1175$ (m), 1075 (s), 967 (m). HRMS required for $\mathrm{C}_{19} \mathrm{H}_{29} \mathrm{NO}_{9} \mathrm{~S}_{2} \mathrm{Na}^{+}$is 502.1181, found 502.1176 .

\section{6-O-Benzyl-2-deoxy-3,4-O-isopropylidene-1-O-tosyl-2- \\ tosylaminomethyl- $\beta$-D-psicofuranose $\mathbf{2 5 b}$}

Chromatography of the crude residue over silica gel (isohexane/ ethyl acetate 6/4) gave the pure sulfonyl amidoester $25 \mathrm{~b}$ (1.22 g, 62\% o.y.) as foamy gum. Data for $25 \mathrm{~b}$ : $[\alpha]_{\mathrm{D}}{ }^{20}=+3.9\left(\mathrm{c}=0.01, \mathrm{CHCl}_{3}\right) .{ }^{1} \mathrm{H}-$ $\operatorname{NMR}\left(400 \mathrm{MHz}, \mathrm{CDCl}_{3}\right): \delta 1.22\left(3 \mathrm{H}, \mathrm{s}, \mathrm{CH}_{3}\right), 1.32\left(3 \mathrm{H}, \mathrm{s}, \mathrm{CH}_{3}\right), 2.41(3 \mathrm{H}$, s, $\left.\mathrm{PhCH}_{3}\right), 2.42\left(3 \mathrm{H}, \mathrm{s}, \mathrm{PhCH}_{3}\right), 2.95\left(1 \mathrm{H}, \mathrm{dd}, J=12.4,2.8, \mathrm{H}^{-1}{ }_{a}^{\prime}\right), 2.98$ $\left(1 \mathrm{H}, \mathrm{dd}, J=12.6,10.0, \mathrm{H}-1^{\prime}{ }_{b}\right), 3.47\left(1 \mathrm{H}, \mathrm{dd}, J=10.4,2.0, \mathrm{H}-6_{a}\right), 3.59$ $\left(1 \mathrm{H}, \mathrm{dd}, J=10.4,2.0, \mathrm{H}-6_{b}\right), 3.86-3.89(1 \mathrm{H}, \mathrm{m}, \mathrm{H}-5), 4.01(1 \mathrm{H}, \mathrm{d}, J=$ 10.4, H-1 $\left.1_{a}\right), 4.10\left(1 \mathrm{H}, \mathrm{d}, J=10.4, \mathrm{H}-1_{b}\right), 4.56\left(1 \mathrm{H}, \mathrm{d}, J=12.4, \mathrm{H}-7_{a}\right)$, $4.62\left(1 \mathrm{H}, \mathrm{d}, J=12.4, \mathrm{H}-7_{b}\right), 4.70(1 \mathrm{H}, \mathrm{d}, J=6.0, \mathrm{H}-3), 4.86(1 \mathrm{H}, \mathrm{t}, J=$ 5.6, H-4), $6.01(1 \mathrm{H}, \mathrm{dd}, J=9.6,2.8, \mathrm{NH}) .7 .25\left(2 \mathrm{H}, \mathrm{d}, J=8.0,2 \times \mathrm{H}_{m} \mathrm{Tol}\right)$, $7.30\left(2 \mathrm{H}, \mathrm{d}, J=8.4,2 \times \mathrm{H}_{m}\right.$ Tol), $7.32-7.37\left(5 \mathrm{H}, \mathrm{m}, 5 \times \mathrm{H}_{\text {arom }} \mathrm{Ph}\right), 7.54(2 \mathrm{H}$, $\left.\mathrm{d}, J=8.0,2 \times \mathrm{H}_{o} \mathrm{Tol}\right), 7.54\left(2 \mathrm{H}, \mathrm{d}, J=8.4,2 \times \mathrm{H}_{o}\right.$ Tol $) .{ }^{13} \mathrm{C}-\mathrm{NMR}(100 \mathrm{MHz}$, $\left.\mathrm{CDCl}_{3}\right): 21.5\left(\mathrm{PhCH}_{3}\right), 21.7\left(\mathrm{PhCH}_{3}\right), 25.1\left(\mathrm{CH}_{3}\right), 26.9\left(\mathrm{CH}_{3}\right), 47.4\left(\mathrm{C}-1^{\prime}\right)$, 69.0 (C-6), 69.2 (C-1), 73.6 (C-7), 81.2 (C-4), 83.5 (C-3), 84.2 (C-5), 84.3

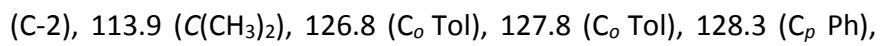
$128.6\left(C_{o} P h\right), 128.7\left(C_{m} P h\right), 129.8$ ( $C_{m}$ Tol), 132.4 ( $C_{\text {ipso }}$ Tol), 136.9 ( $\left.C_{\text {ipso }} \mathrm{Ph}\right), 143.4\left(\mathrm{C}_{p} \mathrm{Tol}\right), 145.0\left(\mathrm{C}_{p}\right.$ Tol). IR $\left(\mathrm{CHCl}_{3}, \mathrm{~cm}^{-1}\right)$ : $3270(\mathrm{br})$, 2926 (w), 2359 (w), 1189 (s), 1176 (s), 1120 (m), 988 (m). HRMS required for $\mathrm{C}_{31} \mathrm{H}_{37} \mathrm{NO}_{9} \mathrm{~S}_{2} \mathrm{Na}^{+}$is 654.1807 , found 654.1802 .

\section{6-O-Benzyl-2-deoxy-3,4-O-isopropylidene-1-O-nosyl-2- nosylaminomethyl- $\beta$-D-psicofuranose $25 \mathrm{c}$}

Chromatography of the crude residue over silica gel (isohexane/ ethyl acetate 6/4) gave the pure sulfonyl amidoester $25 \mathrm{c}$ (2.15 g, 97\% o.y.) as white solid. Data for $26 \mathrm{c}: \mathrm{Mp}=96-97{ }^{\circ} \mathrm{C}$. $[\alpha]_{\mathrm{D}}{ }^{25}=+2.1$ (c $\left.=0.01, \mathrm{CHCl}_{3}\right) .{ }^{1} \mathrm{H}-\mathrm{NMR}\left(400 \mathrm{MHz}, \mathrm{CDCl}_{3}\right): \delta 1.29\left(3 \mathrm{H}, \mathrm{s}, \mathrm{CH}_{3}\right), 1.43(3 \mathrm{H}$, $\left.\mathrm{s}, \mathrm{CH}_{3}\right), 3.52-3.61(2 \mathrm{H}, \mathrm{m} \mathrm{2} \times \mathrm{H}-6), 4.00\left(1 \mathrm{H}, \mathrm{d}, J=16.0, \mathrm{H}-1^{\prime}{ }_{a}\right), 4.11(1 \mathrm{H}$, $\left.\mathrm{d}, J=12.0, \mathrm{H}-1_{a}\right), 4.19\left(1 \mathrm{H}, \mathrm{d}, J=16.0, \mathrm{H}-1^{\prime}{ }_{b}\right), 3.20-4.22(1 \mathrm{H}, \mathrm{m}, \mathrm{H}-5)$, $4.35\left(1 \mathrm{H}, \mathrm{d}, J=10.5, \mathrm{H}-1_{b}\right), 4.51\left(1 \mathrm{H}, \mathrm{d}, J=11.6, \mathrm{H}-77_{a}\right), 4.55(1 \mathrm{H}, \mathrm{d}, J=$ $6.2, \mathrm{H}-3), 4.57\left(1 \mathrm{H}, \mathrm{d}, J=11.6, \mathrm{H}-7_{b}\right), 4.66(1 \mathrm{H}, \mathrm{dd}, J=6.8,4.1, \mathrm{H}-4)$, 7.26-7.35 (5H, m, $\left.5 \times \mathrm{H}_{\text {arom }} \mathrm{Ph}\right), 8.00\left(2 \mathrm{H}, \mathrm{d}, J=8.0,2 \times \mathrm{H}_{o} \mathrm{NHNs}\right), 8.26-$ $8.33\left(5 \mathrm{H}, \mathrm{m}, 4 \times \mathrm{H}_{\text {arom }} \mathrm{ONs}, \mathrm{NH}\right), 8.31\left(2 \mathrm{H}, \mathrm{d}, J=8.0,2 \times \mathrm{H}_{m} \mathrm{NHNs}\right) .{ }^{13} \mathrm{C}-$ $\operatorname{NMR}\left(100 \mathrm{MHz}, \mathrm{CDCl}_{3}\right): 24.6\left(\mathrm{CH}_{3}\right), 25.8\left(\mathrm{CH}_{3}\right), 53.3\left(\mathrm{C}-1^{\prime}\right), 69.3(\mathrm{C}-1)$, 70.3 (C-6), 73.6 (C-7), 82.0 (C-2), 82.6 (C-4), 82.9 (C-5), 84.4 (C-3),

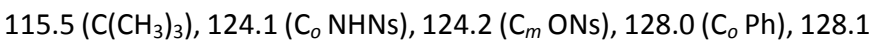
( $C_{o}$ ONs), $128.6\left(C_{p} \mathrm{Ph}\right), 129.5$ ( $\left.C_{o} \mathrm{NHNs}\right), 130.5$ ( $\left.\mathrm{C}_{m} \mathrm{Ph}\right), 137.4$ ( $\mathrm{C}_{\text {ipso }}$ $\mathrm{Ph}), 141.2$ ( $\left.\mathrm{C}_{\text {ipso }} \mathrm{NHNs}\right), 144.2$ ( $\left.\mathrm{C}_{\text {ispo }} \mathrm{ONs}\right), 150.7$ ( $\left.\mathrm{C}_{p} \mathrm{NHNs}\right), 150.9$ ( $\mathrm{C}_{p}$ ONs). IR ( $\left.\mathrm{CHCl}_{3}, \mathrm{~cm}^{-1}\right)$ : 3108 (w), 2357 (w), 1532 (s, N-O), 1350 (s, NO), $1172(\mathrm{~m}), 1082(\mathrm{~m}), 978(\mathrm{w})$. HRMS required for $\mathrm{C}_{23} \mathrm{H}_{27} \mathrm{~N}_{2} \mathrm{O}_{8} \mathrm{~S}^{+}$is 491.1488, found 491.1482 .

\section{General procedure for Sulfoazetidine Spirocyclization}

Sodium hydride ( $60 \%$ dispersion in mineral oil, 10 eq.) was placed in a three necked round bottom flask equipped with thermometer, stirrer bar and pressure equalising dropping funnel under a nitrogen atmosphere. It was then charged with anhydrous DMF (0.05M) at 0 ㄷ, maintaining an internal temperature less than $25^{\circ} \mathrm{C}$. A solution of suitable sulfonyl amidoester 25a-c in anhydrous DMF (0.05 M) was then added dropwise over $15 \mathrm{~min}$ and and stirred for a further 15 $\min$ at $\mathrm{O}^{\circ} \mathrm{C}$ with careful control of exotherm. The reaction was allowed to warm to room temperature and stirred until TLC analysis showed complete reaction (16-48 h). The excess of $\mathrm{NaH}$ was quenched by careful dropwise addition of methanol at $0{ }^{\circ} \mathrm{C}$ maintaining an internal temperature of less than $25{ }^{\circ} \mathrm{C}$. The suspension was then diluted with water and extracted with diethylether. The combined organic extracts were washed with saturated aq. $\mathrm{NH}_{4} \mathrm{Cl}$ solution, dried over $\mathrm{MgSO}_{4}$, filtered and concentrated to dryness under reduced pressure and purified by column chromatography.

\section{(6R,7S,8R)-2-Aza-6-benzyloxymethyl-7,8-}

(dimethylmethylenedioxy)-2- $\mathrm{N}$-mesyl-5 oxaspiro[3.4]-octane 26a ${ }^{16}$ Chromatography of the crude residue over silica gel (isohexane/ ethyl acetate 7/3) gave the pure mesyl spiroazetidine $\mathbf{2 6 a}$ (485 mg, $63 \%$ ) as colourless oil. Data for 26a: Oily. $[\alpha]_{D}{ }^{20}=-63.7(\mathrm{c}=0.01$, $\left.\mathrm{CHCl}_{3}\right) .{ }^{1} \mathrm{H}-\mathrm{NMR}\left(400 \mathrm{MHz}, \mathrm{CDCl}_{3}\right): \delta 1.36\left(3 \mathrm{H}, \mathrm{s}, \mathrm{CH}_{3}\right), 1.42(3 \mathrm{H}, \mathrm{s}$, $\left.\mathrm{CH}_{3}\right), 2.85\left(3 \mathrm{H}, \mathrm{s}, \mathrm{SO}_{2} \mathrm{CH}_{3}\right), 3.48(1 \mathrm{H}, \mathrm{dd}, J=10.0,2.5, \mathrm{H}-6 a), 3.52(1 \mathrm{H}$, $\left.\mathrm{dd}, J=10.0,2.5, \mathrm{H}-6_{b}\right), 3.57\left(1 \mathrm{H}, \mathrm{d}, J=8.8, \mathrm{H}-1^{\prime}{ }_{a}\right), 3.59(1 \mathrm{H}, \mathrm{dd}, J=$ $\left.10.0,2.5, \mathrm{H}-6_{b}\right), 3.67\left(1 \mathrm{H}, \mathrm{d}, J=8.8, \mathrm{H}-1^{\prime}{ }_{b}\right), 3.92\left(1 \mathrm{H}, \mathrm{d}, J=8.8, \mathrm{H}-1_{a}\right)$, 4-20-4.23 (1H, m. H-5), $4.21\left(1 \mathrm{H}, \mathrm{d}, J=8.8, \mathrm{H}-1_{b}\right), 4.40(1 \mathrm{H}, \mathrm{d}, J=12.0$, $\left.\mathrm{H}-7_{a}\right), 4.50\left(1 \mathrm{H}, \mathrm{d}, J=11.6, \mathrm{H}-7_{b}\right), 4.73(1 \mathrm{H}, \mathrm{d}, J=6.0, \mathrm{H}-3), 4.79(1 \mathrm{H}$, $\mathrm{d}, J=6.0, \mathrm{H}-4), 7.25-7.38\left(5 \mathrm{H}, \mathrm{m}, 5 \times \mathrm{H}_{\text {arom }}\right) .{ }^{13} \mathrm{C}-\mathrm{NMR}\left(100 \mathrm{MHz}, \mathrm{CDCl}_{3}\right)$ : $25.2\left(\mathrm{CH}_{3}\right), 27.0\left(\mathrm{CH}_{3}\right), 37.4\left(\mathrm{SO}_{3} \mathrm{CH}_{3}\right), 40.0\left(\mathrm{NHSO}_{2} \mathrm{CH}_{3}\right), 46.9\left(\mathrm{C}-1^{\prime}\right)$, 69.0 (C-1), 69.6 (C-6), 73.7 (C-7), 81.6 (C-4), 83.4 (C-3), 84.4 (C-2), 84.5

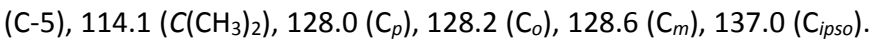


IR $\left(\mathrm{CHCl}_{3}, \mathrm{~cm}^{-1}\right)$ : 2935 (w), 2359 (w), $1336(\mathrm{~m}), 1130(\mathrm{~s}), 1070(\mathrm{~m}), 960$ (w). HRMS required for $\mathrm{C}_{18} \mathrm{H}_{25} \mathrm{NO}_{6} \mathrm{SNa}^{+}$is 406.1295 , found 406.1295 .

\section{(6R,7S,8R)-2-Aza-6-benzyloxymethyl-7,8-} (dimethylmethylenedioxy)-2- $\mathrm{N}$-tosyl-5 oxaspiro[3.4]-octane 26b Chromatography of the crude residue over silica gel (isohexane/ ethyl acetate 7/3) gave the pure tosyl spiroazetidine $\mathbf{2 6 b}$ (243 mg, $54 \%)$ as colourless oil. Data for 26b: Oily. $[\alpha]_{D}{ }^{20}=-70.4$ (c=0.01, $\left.\mathrm{CHCl}_{3}\right) .{ }^{1} \mathrm{H}-\mathrm{NMR}\left(400 \mathrm{MHz}, \mathrm{CDCl}_{3}\right): \delta 1.29\left(3 \mathrm{H}, \mathrm{s}, \mathrm{CH}_{3}\right), 1.36(3 \mathrm{H}, \mathrm{s}$, $\left.\mathrm{CH}_{3}\right), 2.45\left(3 \mathrm{H}, \mathrm{s}, \mathrm{PhCH}_{3}\right), 3.40(2 \mathrm{H}, \mathrm{s}, 2 \times \mathrm{H}-6), 3.54(1 \mathrm{H}, \mathrm{d}, J=9.6, \mathrm{H}-$ $\left.1^{\prime}{ }_{a}\right), 3.57\left(1 \mathrm{H}, \mathrm{d}, J=9.7, \mathrm{H}_{-1}{ }^{\prime}{ }_{b}\right), 3.67\left(1 \mathrm{H}, \mathrm{d}, J=8.8, \mathrm{H}-1_{a}\right), 4.10-4-14$ $\left(2 \mathrm{H}, \mathrm{m}, \mathrm{H}-5, \mathrm{H}-\mathrm{1}_{b}\right), 4.37\left(1 \mathrm{H}, \mathrm{d}, J=11.7, \mathrm{H}-7_{a}\right), 4.43(1 \mathrm{H}, \mathrm{d}, J=11.7, \mathrm{H}-$ $7 b), 4.49(1 \mathrm{H}, \mathrm{d}, J=5.9, \mathrm{H}-3), 4.70(1 \mathrm{H}, \mathrm{d}, J=5.9, \mathrm{H}-4), 7.22-7.26(2 \mathrm{H}$, $\mathrm{m}, 5 \times \mathrm{H}_{m}$ Tol), 7.32-7.39 $\left(5 \mathrm{H}, \mathrm{m}, 2 \times \mathrm{H}_{\text {arom }} \mathrm{Ph}\right), 7.68\left(2 \mathrm{H}, \mathrm{d}, J=7.9, \mathrm{H}_{o}\right.$ Tol). ${ }^{13} \mathrm{C}-\mathrm{NMR}(100 \mathrm{MHz}, \mathrm{CDCl}): 21.6\left(\mathrm{PhCH}_{3}\right), 25.0\left(\mathrm{CH}_{3}\right), 26.4\left(\mathrm{CH}_{3}\right)$, 57.3 (C-1), 64.0 (C-1'), 71.5 (C-6), 73.9 (C-7), 80.9 (C-2), 82.9 (C-4), 83.8 (C-5), $85.5(\mathrm{C}-3), 112.4\left(\mathrm{C}\left(\mathrm{CH}_{3}\right)_{2}\right), 128.1\left(\mathrm{C}_{p} \mathrm{Ph}\right), 128.2\left(\mathrm{C}_{o} \mathrm{Ph}\right)$, 128.4 ( $C_{o}$ Tol), 128.6 ( $C_{m}$ Tol), $129.7\left(C_{m} P h\right), 131.7$ ( $C_{p}$ Tol), 137.0 ( $C_{\text {ipso }}$ $\mathrm{Ph}), 143.9$ ( $\mathrm{C}_{\text {ipso }}$ Tol). ). IR ( $\left.\mathrm{CHCl}_{3}, \mathrm{~cm}^{-1}\right)$ : 2937 (w), 2359 (w), $1344(\mathrm{~m})$, 1127 (s), 1090 (m). HRMS required for $\mathrm{C}_{24} \mathrm{H}_{29} \mathrm{NO}_{6} \mathrm{SNa}^{+}$is 482.1613 , found 482.1608 .

\section{(6R,7S,8R)-2-Aza-6-benzyloxymethyl-7,8-} (dimethylmethylenedioxy)-2- $\mathrm{N}$-nosyl-5 oxaspiro[3.4]-octane 26c Chromatography of the crude residue over silica gel (isohexane/ ethyl acetate $7 / 3$ ) gave the pure nonyl spiroazetidine $26 \mathrm{c}(84 \mathrm{mg}$, $12 \%$ ) as colourless oil. Data for 26c: Oily. $[\alpha]_{D}{ }^{25}=-67.2$ ( $c=0.01, I=$ $0.025 \mathrm{dm}, \mathrm{CHCl}_{3}$ ). ${ }^{1} \mathrm{H}-\mathrm{NMR}\left(400 \mathrm{MHz}, \mathrm{CDCl}_{3}\right): \delta 1.28\left(3 \mathrm{H}, \mathrm{s}, \mathrm{CH}_{3}\right), 1.36$ $\left(3 \mathrm{H}, \mathrm{s}, \mathrm{CH}_{3}\right), 2.45\left(3 \mathrm{H}, \mathrm{s}, \mathrm{PhCH}_{3}\right), 3.41-3.47(2 \mathrm{H}, \mathrm{m}, 2 \times \mathrm{H}-6), 3.57(1 \mathrm{H}$, $\left.\mathrm{d}, J=9.3, \mathrm{H}-1^{\prime}{ }_{a}\right), 3.62\left(1 \mathrm{H}, \mathrm{d}, J=9.3, \mathrm{H}-1^{\prime}{ }_{b}\right), 3.75\left(1 \mathrm{H}, \mathrm{d}, J=9.1, \mathrm{H}-1_{a}\right)$, $4.12(1 \mathrm{H}, \mathrm{t}, J=2.1, \mathrm{H}-5), 4.20\left(1 \mathrm{H}, \mathrm{d}, J=9.1, \mathrm{H}-1_{b}\right), 4.38(1 \mathrm{H}, \mathrm{d}, J=$ 12.0, H-7 $\left.7_{a}\right), 4.42\left(1 \mathrm{H}, \mathrm{d}, J=12.0, \mathrm{H}-7_{b}\right), 4.43(1 \mathrm{H}, \mathrm{d}, J=5.9, \mathrm{H}-3), 4.70$ $(1 \mathrm{H}, \mathrm{d}, J=6.0, \mathrm{H}-4), 7.21-7.28\left(2 \mathrm{H}, \mathrm{m}, 2 \times \mathrm{H}_{0} \mathrm{Ph}\right), 7.35-7.42(3 \mathrm{H}, \mathrm{m}$, $\left.2 \times \mathrm{H}_{m}, \mathrm{H}_{p} \mathrm{Ph}\right), 7.94\left(2 \mathrm{H}, \mathrm{d}, J=7.9, \mathrm{H}_{o} \mathrm{Ns}\right), 8.37\left(2 \mathrm{H}, \mathrm{d}, J=7.9, \mathrm{H}_{o} \mathrm{Ns}\right)$. ${ }^{13} \mathrm{C}-\mathrm{NMR}\left(100 \mathrm{MHz}, \mathrm{CDCl}_{3}\right): 25.0\left(\mathrm{CH}_{3}\right), 26.4\left(\mathrm{CH}_{3}\right), 57.8(\mathrm{C}-1), 64.7$ (C$\left.1^{\prime}\right), 71.6$ (C-6), 74.0 (C-7), 81.2 (C-2), 83.1 (C-4), 83.8 (C-5), 85.5 (C-3),

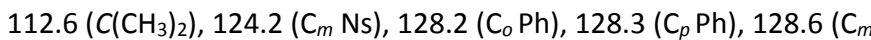
$\mathrm{Ph}), 129.4$ ( $\left.\mathrm{C}_{o} \mathrm{Ns}\right), 136.8$ ( $\left.\mathrm{C}_{\text {ipso }} \mathrm{Ph}\right), 141.2$ (Ci $\left.\mathrm{i}_{p s o} \mathrm{Ns}\right), 150.0$ ( $\left.\mathrm{C}_{p} \mathrm{Ns}\right)$. IR $\left(\mathrm{CHCl}_{3}, \mathrm{~cm}^{-1}\right): 2932$ (w), 2157 (w), 1550 (s, N-O), 1349 (s, N-O), 1163 (s), 737 (s). HRMS required for $\mathrm{C}_{23} \mathrm{H}_{27} \mathrm{~N}_{2} \mathrm{O}_{8} \mathrm{~S}^{+}$is 491.1488 , found 491.1482

\section{(6R,7S,8R)-2-Aza-6-benzyloxymethyl-7,8-}

\section{(dimethylmethylenedioxy)-5-oxa-2-azaspiro[3.4]-octane 28}

To a stirred suspension of $\mathrm{K}_{2} \mathrm{CO}_{3}(56 \mathrm{mg}, 0.41 \mathrm{mmol})$ in $\mathrm{CH}_{3} \mathrm{CN}(1 \mathrm{~mL})$ was added a solution of $\mathrm{N}$-nosyl spiroazetidine $26 \mathrm{c}(100 \mathrm{mg}, 0.20$ mmol) in $\mathrm{CH}_{3} \mathrm{CN}(1 \mathrm{~mL})$ under $\mathrm{N}_{2}$ atmosphere followed by thiophenol $(21 \mu \mathrm{L}, 0.61 \mathrm{mmol})$. The reaction mixture was stirred for $18 \mathrm{~h}$, diluted with ethyl acetate, washed with brine, dried over $\mathrm{MgSO}_{4}$, filtered and concentrated to dryness under reduced pressure. Purification was performed by mass directed prep HPLC using a XBridge $\mathrm{dC}_{18} 5 \mu$ OBD $30 \times 100 \mathrm{~mm}$ prep column. RP-HPLC was conducted with an elution gradient of $1-100 \%$ B over $11.40 \mathrm{~min}$, where $A$ is $\mathrm{H}_{2} \mathrm{O}$ in $10 \mathrm{mM}$ Ammonium Acetate and $\mathrm{B}$ is $\mathrm{CH}_{3} \mathrm{CN}$ and gave pure azetidine spironucleoside 27 (29 mg, 48\%). Data for 27: Oily. $[\alpha]_{D}{ }^{25}=-56.0$ (c= $\left.0.01, \mathrm{I}=0.025 \mathrm{dm}, \mathrm{CH}_{3} \mathrm{OH}\right) .{ }^{1} \mathrm{H}-\mathrm{NMR}\left(400 \mathrm{MHz}, \mathrm{CDCl}_{3}\right): \delta 1.35(3 \mathrm{H}, \mathrm{s}$, $\left.\mathrm{CH}_{3}\right), 1.41\left(3 \mathrm{H}, \mathrm{s}, \mathrm{CH}_{3}\right), 3.44\left(1 \mathrm{H}, \mathrm{dd}, J=10.2,3.0, \mathrm{H}-6_{a}\right), 3.48(1 \mathrm{H}, \mathrm{dd}$, $\left.J=10.2,3.0, \mathrm{H}-6_{b}\right), 3.59\left(1 \mathrm{H}, \mathrm{d}, J=10.1, \mathrm{H}-1_{a}^{\prime}\right), 3.76(1 \mathrm{H}, \mathrm{d}, J=10.3$, \left.\left.${\mathrm{H}-1^{\prime}}_{b}\right), 3.87\left(1 \mathrm{H}, \mathrm{d}, J=10.3, \mathrm{H}-1_{a}\right), 4.081 \mathrm{H}, \mathrm{d}, J=10.2, \mathrm{H}-1_{b}\right), 4.19(1 \mathrm{H}$, $\mathrm{t}, J=2.6, \mathrm{H}-5), 4.39\left(1 \mathrm{H}, \mathrm{d}, J=11.8, \mathrm{H}-7_{a}\right), 4.48\left(1 \mathrm{H}, \mathrm{d}, J=11.8, \mathrm{H}-7_{b}\right)$, $4.76(1 \mathrm{H}, \mathrm{d}, J=6.0, \mathrm{H}-3), 4.82(1 \mathrm{H}, \mathrm{d}, J=6.0, \mathrm{H}-4), 5.04(1 \mathrm{H}, \mathrm{br}, \mathrm{NH})$, 7.22-7.38 (5H, m, 5xHarom). ${ }^{13} \mathrm{C}-\mathrm{NMR}\left(100 \mathrm{MHz}, \mathrm{CDCl}_{3}\right): 25.1\left(\mathrm{CH}_{3}\right)$, $26.4\left(\mathrm{CH}_{3}\right), 52.6$ (C-1'), 59.2 (C-1), 71.5 (C-6), 73.9 (C-7), 83.1 (C-4),

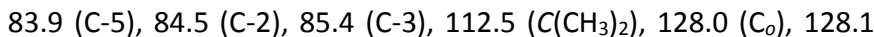
$\left(\mathrm{C}_{p}\right), 128.6\left(\mathrm{C}_{\mathrm{m}}\right), 137.0\left(\mathrm{C}_{\text {ipso }}\right) . \mathrm{IR}\left(\mathrm{CH}_{3} \mathrm{OH}, \mathrm{cm}^{-1}\right): 2936(\mathrm{~m}), 1556(\mathrm{~m})$, 1380 (s), 1280 (s), 1160 (s), 1051 (s), 871 (s). HRMS required for $\mathrm{C}_{7} \mathrm{H}_{14} \mathrm{NO}_{4}{ }^{+}$is 306.170 found 306.170 .

\section{General procedure for $\boldsymbol{O}$-deprotection}

Isopropylidene sulfoazetidine spironucleoside $\mathbf{2 6} \mathbf{a}-\mathbf{b}$ was dissolved in a solution of methanol/water 8/2 (0.025 M concentration). Dowex ${ }^{\circ}$ $50 \mathrm{WX} 8$ hydrogen form $(3.4 \mathrm{~g} / \mathrm{mol})$ was added in one portion and the resulting suspension was stirred vigorously at $50{ }^{\circ} \mathrm{C}$ until total consumption of the starting material (4-6 h), then the resin was filtered off and washed with methanol. The filtrate was evaporated under reduced pressure to afford crude benzyl ether spironucleoside crude as pale yellow oil. Residue was dissolved in methanol (0.1 M) and charged into hydrogenation vessel. Palladium on activated charcoal $10 w t . \%$, (10\% of weight with respect of $\mathbf{2 6 a - b}$ ) was added in one portion. The reactor was purged three times with $\mathrm{N}_{2}$ and the mixture was agitated for $5 \mathrm{~min}$. After purging with $\mathrm{H}_{2}$ a further three times, the reactor was pressurised to 4 bar and the resulting suspension was stirred vigorously until total consumption of the starting material (ca. $22 \mathrm{~h}$ ). The catalyst was filtered off, and the filtrate was evaporated to dryness.

\section{(6R,7S,8R)-2-Aza-7,8-dihydroxy-6-hydroxymethyl-2-N-mesyl-5- oxaspiro[3.4]octane 27 a}

Purification of the crude product by column chromatography (silica gel, dichloromethane/ methanol 94/6) gave the title compound 27a $\left(120 \mathrm{mg}, 94 \%\right.$ yield) as colourless oil. $[\alpha]_{D}{ }^{25}=-32.0$ ( $c=0.01, \mathrm{I}=0.025$ dm, $\mathrm{CH}_{3} \mathrm{OH}$ ). ${ }^{1} \mathrm{H}-\mathrm{NMR}\left(400 \mathrm{MHz}, \mathrm{CD}_{3} \mathrm{OD}\right): \delta 2.94\left(3 \mathrm{H}, \mathrm{s}, \mathrm{SO}_{2} \mathrm{CH}_{3}\right), 3.54$ $\left(1 \mathrm{H}, \mathrm{dd}, J=12.0,4.0, \mathrm{H}-6_{a}\right), 3.67\left(1 \mathrm{H}, \mathrm{dd}, J=12.0,3.5, \mathrm{H}-6_{b}\right), 3.80(1 \mathrm{H}$, $\left.\mathrm{dd}, J=9.0,1.0, \mathrm{H}-1_{a}\right), 3.85-3.88(1 \mathrm{H}, \mathrm{m}, \mathrm{H}-5), 3.90(1 \mathrm{H}, \mathrm{dt}, J=9.0,1.0$, $\left.\mathrm{H}-1_{a}^{\prime}\right), 3.96\left(1 \mathrm{H}, \mathrm{dd}, J=9.0,0.8, \mathrm{H}-1^{\prime}{ }_{b}\right), 3.98-4.06(2 \mathrm{H}, \mathrm{m}, \mathrm{H}-3, \mathrm{H}-4)$, $4.31\left(1 \mathrm{H}, \mathrm{dd}, J=9.0,1.0, \mathrm{H}-1_{b}\right) .{ }^{13} \mathrm{C}-\mathrm{NMR}\left(125 \mathrm{MHz}, \mathrm{CD}_{3} \mathrm{OD}\right): 34.3$ $\left(\mathrm{SO}_{2} \mathrm{CH}_{3}\right), 59.2$ (C-1), 61.6 (C-1'), 62.9 (C-6), 72.4 (C-3), 75.7 (C-4), 80.1 (C-2), 85.6 (C-5). IR ( $\left.\mathrm{CH}_{3} \mathrm{OH}, \mathrm{cm}^{-1}\right)$ : 3422 (br), 2963 (w), 1397 (w), 1262 (s), 1092 (s), 1024 (s), 801 (s).

\section{(6R,7S,8R)-2-Aza-7,8-dihydroxy-6-hydroxymethyl-2- $N$-mesyl-5- oxaspiro[3.4]octane 27b.}

Purification of the crude product by column chromatography (silica gel, dichloromethane/ methanol 95/5) gave the title compound 27b ( $215 \mathrm{mg}, 52 \%$ yield) as amorphous solid. White needle crystals were obtained after recrystallisation with ethyl acetate. $\mathrm{Mp}=96-97{ }^{\circ} \mathrm{C}$. $[\alpha]_{D}{ }^{25}=-40.0\left(\mathrm{c}=0.01, \mathrm{I}=0.025 \mathrm{dm}, \mathrm{CH}_{3} \mathrm{OH}\right) .{ }^{1} \mathrm{H}-\mathrm{NMR}(400 \mathrm{MHz}$, $\mathrm{CD}_{3} \mathrm{OD}$ ): ${ }^{1} \mathrm{H}-\mathrm{NMR}\left(400 \mathrm{MHz}, \mathrm{CDCl}_{3}\right): \delta 2.46\left(3 \mathrm{H}, \mathrm{s}, \mathrm{PhCH}_{3}\right), 3.44(1 \mathrm{H}$, 
$\left.\mathrm{dd}, J=12.2,4.1, \mathrm{H}-6_{a}\right), 3.53\left(1 \mathrm{H}, \mathrm{d}, J=8.6, \mathrm{H}-1_{a}\right), 3.57(1 \mathrm{H}, \mathrm{dd}, J=$ $\left.12.2,3.1, \mathrm{H}-6_{b}\right), 3.67\left(1 \mathrm{H}, \mathrm{d}, J=8.8, \mathrm{H}-1^{\prime}{ }_{a}\right), 3.71\left(1 \mathrm{H}, \mathrm{d}, J=8.8, \mathrm{H}-1^{\prime}{ }_{b}\right)$, 3.73-3.77 (1H, m, H-5), $3.87(1 \mathrm{H}, \mathrm{d}, J=4.7, \mathrm{H}-3), 3.94(1 \mathrm{H}, \mathrm{dd}, J=5.7$, 4.7, H-4), $4.17\left(1 \mathrm{H}, \mathrm{d}, J=8.6, \mathrm{H}-1_{b}\right), 7.46\left(2 \mathrm{H}, \mathrm{d}, J=8.0,2 \times \mathrm{H}_{m}\right), 7.72$ $\left(2 \mathrm{H}, \mathrm{d}, J=8.3,2 \times \mathrm{H}_{0}\right) \cdot{ }^{13} \mathrm{C}-\mathrm{NMR}\left(100 \mathrm{MHz}, \mathrm{CD}_{3} \mathrm{OD}\right): 22.1\left(\mathrm{PhCH}_{3}\right), 60.0$ (C-1), 62.7 (C-1'), 63.2 (C-6), 72.6 (C-4), 76.3 (C-3), 80.2 (C-2), 85.6 (C5), $130.2\left(\mathrm{C}_{o}\right), 131.5\left(\mathrm{C}_{m}\right), 132.8\left(\mathrm{C}_{p}\right), 146.3\left(\mathrm{C}_{\text {ipso }}\right) . \mathrm{IR}\left(\mathrm{CH}_{3} \mathrm{OH}, \mathrm{cm}^{-1}\right)$ : 3347 (br), 2928 (w), 1332 (w), 1157 (m), 1090 (s), 1017 (s), 814 (m). HRMS required for $\mathrm{C}_{14} \mathrm{H}_{20} \mathrm{NO}_{6} \mathrm{~S}^{+}$is 330.101 found 330.100 .

\section{Crystallography}

Crystal structures at $150 \mathrm{~K}$ for $\mathbf{1 7 a}$ and $\mathbf{2 7 b}$ were obtained using an Oxford Diffraction Gemini single-crystal diffractometer equipped with an Oxford Instruments Cryojet cooling device. Whilst a satisfactory solution and refinement of the structure of 17a was achieved, and the structure of $\mathbf{2 7 b}$ easily solved, refinement of the latter did not progress to a satisfactory conclusion. Diffraction data for 27b were therefore recollected at 150K at the EPSRC UK National Crystallography Service at the University of Southampton and the structure then refined satisfactorily as a 4-component twin. Both crystal structures have been deposited with the CCDC as reference numbers 1840501 (17a) and 1840502 (27b).

\section{Viruses and cells.}

The A59 strain of Mouse hepatitis virus was used in all experiments. $17 \mathrm{Cl}-1$ mouse lung fibroblast cells were grown in complete growth medium consisting of Dulbecco's modified Eagle medium (DMEM; Invitrogen) supplemented with $10 \%$ heat-inactivated foetal bovine serum (FBS; Invitrogen), penicillin and streptomycin (Invitrogen), and nonessential amino acids (NEAA; Invitrogen).

\section{MTT Toxicity assay.}

MTT [3-(4,5-dimethylthiazol-2-yl)-2,5-diphenyltetrazolium bromide] assays were used to measure cell viability of experimentally treated cells. $17 \mathrm{Cl}-1$ cells in complete growth medium were treated with specified concentrations of test substance in a total volume of $2 \mathrm{ml}$ and plated in 96-well plates at a density of about $50 \%$ confluence. After $72 \mathrm{~h}$ of treatment, $5-\mathrm{mg} / \mathrm{ml}$ MTT (Sigma) was added to each well in a six-well plate. Cells were then incubated at $37^{\circ} \mathrm{C}$ for $1 \mathrm{~h}$, when blue coloration appeared in the majority of untreated control cells indicating that the MTT had been reduced to the insoluble compound formazan. Assays were protected from light during MTT treatment. The medium was then aspirated and replaced with $1 \mathrm{ml}$ of dimethyl sulfoxide to solubilize the cells. Absorbance at $540 \mathrm{~nm}$ was read in a Molecular Devices plate reader and analysed by the SOFTmax program.

\section{Virus growth inhibition assay.}

$17 \mathrm{Cl}-1$ cells were seeded at a density of $2 \times 10^{5}$ cells per well of a 12 well tissue culture plate and allowed to adhere overnight at $37^{\circ} \mathrm{C}$ and $5 \% \mathrm{CO}_{2}$. Cells were pre-treated for $3 \mathrm{~h}$ with $2 \mathrm{ml}$ of complete medium containing $100 \mu \mathrm{l}$ of test compounds dissolved in a vehicle of $90 \%$ water and $10 \%$ dimethyl sulfoxide or vehicle alone. After the pretreatment, cells were inoculated at a multiplicity of about $10 \mathrm{PFU} /$ cell with MHV-A59. After $1 \mathrm{~h}$ cells were rinsed three times with warm phosphate-buffered saline to remove any unbound virus, then culture medium containing the same treatment as before was reapplied. 14h after inoculation, cell culture medium was collected and stored for virus quantification.

\section{Virus quantification by plaque assay.}

$17 \mathrm{Cl}-1$ cells were seeded in 12 -well tissue culture plates at $2 \times 10^{5}$ cells per well and allowed to adhere overnight at $37^{\circ} \mathrm{C}, 5 \% \mathrm{CO}_{2}$. Culture medium was removed and replaced with $0.5 \mathrm{ml}$ of serial dilutions of inoculum in culture medium, then incubated at $37^{\circ} \mathrm{C}$ for $1 \mathrm{~h}$. Inocula were left in place, and cells were overlaid with $0.7 \%$ agarose (Doc Frugal) in DMEM supplemented with $2 \%$ serum (final concentration) and incubated at $37^{\circ} \mathrm{C}$ with $5 \% \mathrm{CO}_{2}$ for 2 days. Cells were fixed with $25 \%$ formaldehyde in phosphate-buffered saline; agarose plugs were removed, and cells were stained with $0.1 \%$ crystal violet to visualize viral plaques.

\section{Syncytium inhibition assay.}

$17 \mathrm{Cl}-1$ cells were seeded in $25-\mathrm{cm}^{2}$ flasks, pre-treated, and inoculated as before. Infection was allowed to proceed for $24 \mathrm{~h}$ before medium was removed, and cells were fixed and stained as before. Multinucleate cells, including virus-induced syncytia, were observed and photographed as described above. Multinucleate cells falling within a 4- $\mathrm{mm}^{2}$ window were counted manually for each flask. Statistical significance of differences between syncytium formation after control or experimental treatment was tested by using a twosample $t$ test in Instat 3.0 (Graphpad).

\section{Conflicts of Interest}

There are no conflicts to declare

\section{Acknowledgements}

We would like to thank the following for funding : University of Reading and Syngenta (to ADI), the Iraqi Ministry of Higher Education and Scientific Research, Al-Mustansiriya University and the University of Baghdad (to BOA and HMNA), the Society for General Microbiology (to WE), the Royal Society of Biology (to AWDB). Some of the viral work was supported by the German Center for Infection Research (DZIF), partner site Giessen, Germany (TTU Emerging Infections), for which we are grateful. We also thank the EPSRC UK National Crystallography Service at the University of Southampton for the collection of the crystallographic data from crystals of $\mathbf{2 7} \mathbf{b}$, and in particular Dr. James Orton for resolving the space group ambiguity for this material.

\section{Notes and references}

1 J. T. Witkowski, R. K. Robins, R. W. Sidwell, L. N. Simon, J. Med. Chem. 1972, 15, 1150.

2 E. De Clercq, Nature Reviews Drug Discovery, 2007, 6, 1001.

3 R. G. Gish, J. Antimicrob. Chemother., 2006, 57, 8.

4 M. S., Sulkowski, Clin. Infect. Dis., 2003; 37, Suppl 4, S315. 
5 L. De Franceschi, G. Fattovich, F. Turrini, K. Ayi, C. Brugnara, F. Manzato, F. Noventa, A. M. Stanzial, P. Solero, R. Corrocher Hepatology, 2000; 31, 997.

6 C. Lamberth, Heterocycles, 2005, 65, 667.

7 L. A. Paquette, D. R. Owen, R. T. Bibart, C. K. Seekamp, C., Org. Lett., 2001, 3, 4043.

8 L. A. Paquette, A. L. Kahane, C. K. Seekamp, J. Org. Chem., 2004, 69, 5555.

9 For useful reviews, see : a) M. A. Campbell, J. Wengel, Chem. Soc. Rev., 2011, 40, 5680. b) H. Kaur, B. R. Babu, S. Maiti, Chem. Rev., 2007, 107, 4672. c) V. E. Marquez, V. M. Siddiqui, A. Ezzitouni, P. Russ, J. Wang, R. W. Wagner, M. D. Matteucci, J. Med. Chem., 1996, 39, 3739.

10 R. S. Perali, S. Mandava, R. Bandi, Tetrahedron, 2011, 67, 4031.

11 H. Sano, S. Mio, J. Kitagawa, S. Sugai, Tetrahedron: Asymmetry, 1994, 5, 2233.

12 K. Sonogashira, Y. Tohda, N. Hagihara, Tetrahedron Lett. 1975, 16, 4467.

13 R. Li, D. Jansen, A. Datta, Org. Biomol. Chem., 2009, 7, 1921.

14 A. Dell'Isola, M. M. W. McLachlan, B. W. Neuman, H. M. N. Al-Mullah, A. W. D. Binks, W. Elvidge, K. Shankland, A. J. A. Cobb, Chem. Eur. J., 2014, 20, 11685.

15 For useful reviews, see: (a) U. Pradere, E. C. GarnierAmblard, S. J. Coats, F. Amblard, R. F. Schinazi, Chem. Rev. 2014, 114, 9154. (b) F. Pertusati, M. Serpi, C. McGuigan, Antivir. Chem. Chemother., 2011, 22, 181.

16 F. J., Sayago, M. Ángeles Pradera, C. Gasch, J. Fuentes, Tetrahedron, 2006, 62, 915.

17 A. R. Weiss, J. L. Leibowitz, Adv. Virus. Res. 2011, 81, 85.

18 B. W. Neuman, P. Chamberlain, F. Bowden, J. Joseph, Virus Res. 2014, 194, 49.

19 A. Azzi, S. X. Lin, Proteins Struct. Funct. Bioinf. 2004, 57, 12.

20 G. A. Levy, G. Adamson, M. J. Phillips, L. A. Scrocchi, L. Fung, P. Biessels, N. F. Ng, A. Ghanekar, A. Rowe, M. X. Ma, A. Levy, C. Koscik, W. He, R. Gorczynski, S. Brookes, C. Woods, I. D. McGilvray, D. Bell Hepatology 2006, 43, 581.

21 G. Di Stefano, F. P. Colonna, A. Bongini, C. Busi, A, Mattioli, L. Fiume Biochem. Pharmacol. 1997, 54, 357.

22 Q. Ning, D. Brown, J. Parodo, M. Cattral, R. Gorczynski, E. Cole, L. Fung, J. W. Ding, M. F. Liu, O. Rotstein, M. J. Phillips, G. Levy J. Immunol. 1998, 160, 3487.

23 B. W. Neuman, D. A. Stein, A. D. Kroeker, M. J. Churchill, A. M. Kim, P. Kuhn, P. Dawson, H. M. Moulton, R. K. Bestwick, P. L. Iversen, M. J. Buchmeier, J. Virol. 2005, 79, 9665. 